\title{
Family Planning Programs for the 21st Century: Rationale and Design
}

John Bongaarts

Population Council

John C. Cleland

John Townsend

Population Council

Jane T. Bertrand

Monica Das Gupta

Follow this and additional works at: https://knowledgecommons.popcouncil.org/departments_sbsr-rh

Part of the Demography, Population, and Ecology Commons, Family, Life Course, and Society

Commons, International Public Health Commons, Maternal and Child Health Commons, Medicine and Health Commons, and the Women's Health Commons How does access to this work benefit you? Let us know!

\section{Recommended Citation}

Bongaarts, John, John C. Cleland, John Townsend, Jane T. Bertrand, and Monica Das Gupta. 2012.

"Family Planning Programs for the 21st Century: Rationale and Design." New York: Population Council. 


\section{FAMILY PLANNING PROGRAMS FOR \\ THE 21ST CENTURY \\ RATIONALE AND DESIGN}

JOHN BONGAARTS

JOHN CLELAND

JOHN W. TOWNSEND

JANE T. BERTRAND

MONICA DAS GUPTA

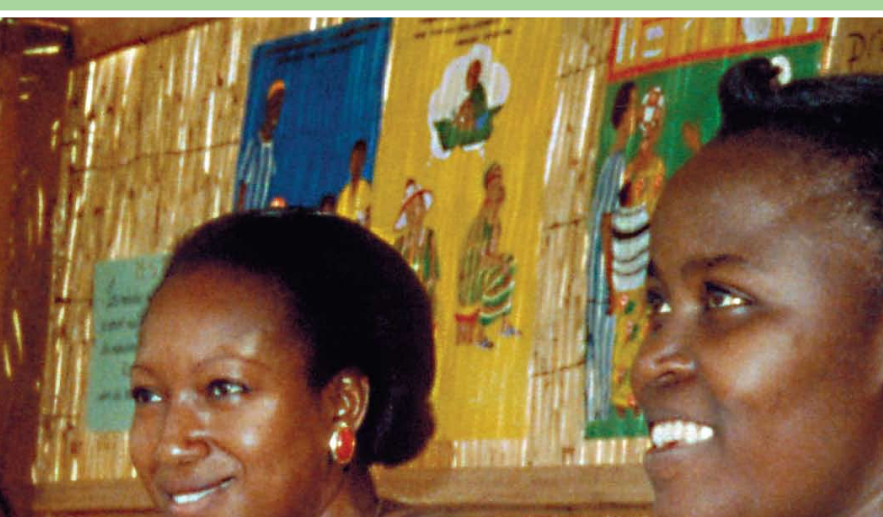

$\frac{4}{4}$

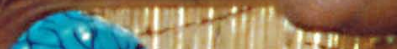

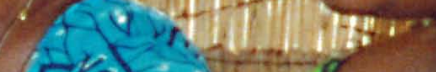

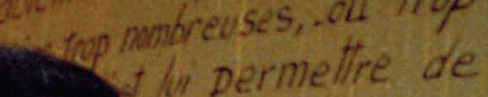

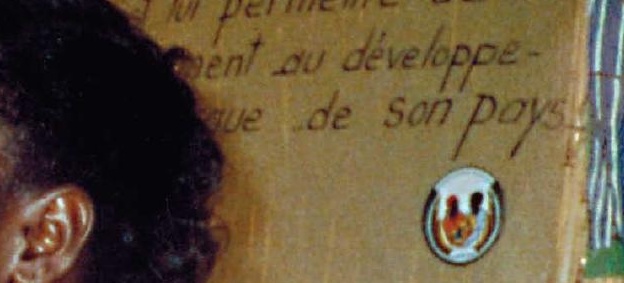

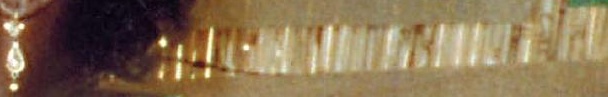

(andin

$(5,25)-90,14$

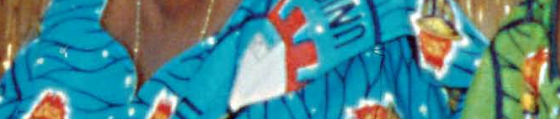
1. is $=y m$ in

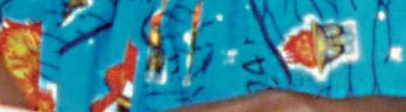
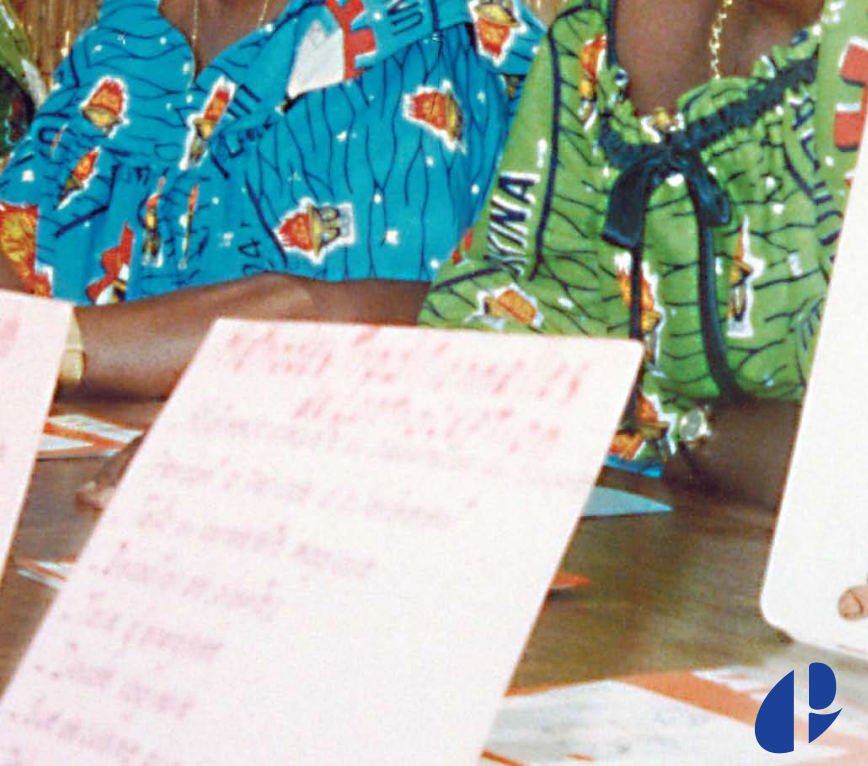

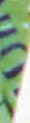
seriss

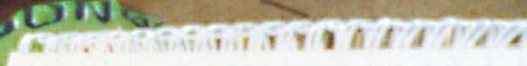

Population Council 


\section{FAMILY PLANNING \\ PROGRAMS FOR \\ THE 21ST CENTURY \\ RATIONALE AND DESIGN}

JOHN BONGAARTS

JOHN CLELAND

JOHN W. TOWNSEND

JANE T. BERTRAND

MONICA DAS GUPTA 


\section{(1) Population Council}

The Population Council confronts critical health and development issues-from stopping the spread of HIV to improving reproductive health and ensuring that young people lead full and productive lives. Through biomedical, social science, and public health research in 50 countries, we work with our partners to deliver solutions that lead to more effective policies, programs, and technologies that improve lives around the world. Established in 1952 and headquartered in New York, the Council is a nongovernmental, nonprofit organization governed by an international board of trustees.

(c) 2012 The Population Council, Inc.

Population Council

One Dag Hammarskjold Plaza

New York, NY 10017 USA

http://www.popcouncil.org

\section{Population Council Library Cataloging-in-Publication Data}

Family planning programs for the 21st century : Rationale and design / John Bongaarts, et al. New York : The Population Council, 2012. ix, 94 p. ; $28 \mathrm{~cm}$.

1. Birth control-Developing countries. 2. Fertility, Human-Developing countries.

3. Communication in birth control-Developing countries. 4. Birth control programs-Developing countries. I. Bongaarts, John. II. Cleland, John. III. Townsend, John W. IV. Bertrand, Jane T. V. Das Gupta, Monica. VI. Population Council.

ISBN: 978-0-87834-127-6

HQ 763.5 .D44 F355 2012 


\section{CONTENTS}

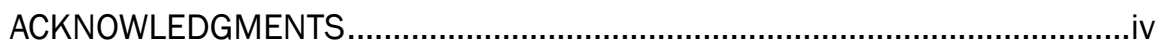

EXECUTIVE SUMMARY .................................................................... v

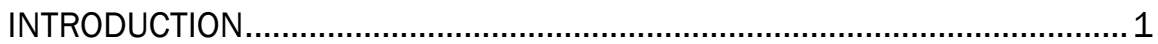

CHAPTER 1: EXPLAINING THE NEGLECT OF FAMILY PLANNING PROGRAMS SINCE THE MID-1990s......................................... 3

CHAPTER 2: THE IMPACT OF VOLUNTARY FAMILY PLANNING PROGRAMS ON FERTILITY...................................................21

CHAPTER 3: FAMILY PLANNING SERVICES AND THE STRENGTHENING OF HEALTH SYSTEMS ...................................45

CHAPTER 4: FAMILY PLANNING COMMUNICATION PROGRAMS .................59

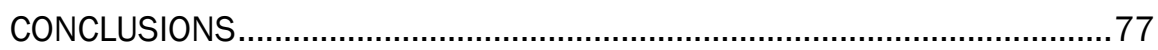

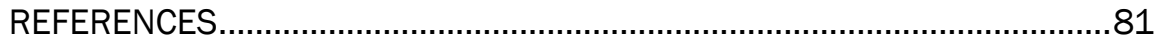

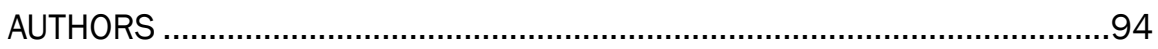




\section{ACKNOWLEDGMENTS}

This book was commissioned and funded by the World Bank. We thank the Hewlett Foundation for grant support through Trust Fund TF070424 given to the World Bank. These are the authors' personal views and should not be attributed to the World Bank or any affiliated organization or member country. The authors thank Ian Askew, Population Council Director of Reproductive Health Services and Research, for his valuable comments, and Robert Heidel for his careful editing. 


\section{EXECUTIVE SUMMARY}

he evidence is clear: Family planning improves health, reduces poverty, and empowers women. Yet, today, more than 200 million women in the developing world want to avoid pregnancy but are not using a modern method of contraception. They face many obstacles, including lack of access to information and health care services, opposition from their husbands and communities, misperceptions about side effects, and cost. If these obstacles could be overcome and the demand for family planning met, 54 million unintended pregnancies, more than 79,000 maternal deaths, and more than a million infant deaths could be averted each year. Families could save more and begin to break the grip of poverty. And communities could make greater investments in education, health care, and infrastructure.

Voluntary family planning programs are highly cost-effective and have demonstrable poverty-reducing effects. They also help women achieve their human rights to health, autonomy, and personal decisionmaking about family size. But for more than a decade-from 1995 to 2007—funding from donors and policymakers did not keep pace with the growing need. During that time, international support for family planning fell by more than half, before beginning a turnaround in more recent years.

The task ahead is to convert this incremental turnaround into a groundswell of support for effective programs where they are needed most. In many countries around the world, high fertility and rapid population growth continue to jeopardize social and economic development.

This publication is a comprehensive resource for policymakers and donors. The first half of the book makes the case for why increased funding and support for voluntary family planning programs are needed:

- Chapter One-Explaining the neglect of family planning programs since the mid1990s-argues for a reinvestment in publicly funded family planning programs and presents new evidence on fertility decline and its economic and health benefits. 
- Chapter Two-The impact of voluntary family planning programs on fertilityprovides proof that voluntary family planning programs reduce fertility and can lower the trajectory of future population growth.

The second half explains how reinvigorated voluntary family planning programs can be structured to operate more effectively:

- Chapter Three-Family planning services and the strengthening of health systems-illustrates how family planning can be integrated into national health systems and proposes innovative strategies for reaching the most vulnerable individuals; and

- Chapter Four-Family planning communication programs-discusses the importance of behavior change communication campaigns to educate the general population and motivate potential users to adopt family planning.

\section{Chapter One: Explaining the neglect of family planning programs since the mid-1990s}

From the 1970 s to the mid-1990s, support for international family planning grew dramatically around the world. In the 1970s and 1980s, governments in developing countries in Asia and Latin America began prioritizing support for voluntary family planning programs. And by 1996, 115 countries around the world had official policies to support family planning.

But shortly thereafter, this strong support began to wane as a result of several factors:

- Thanks in part to highly successful voluntary family planning programs, fertility rates had dropped-leading to a sense that the "population problem" was largely solved;

- There appeared to be little empirical evidence proving that rapid population growth and high fertility were serious impediments to economic progress;

- Observers were alarmed about coercive elements in some Asian programs; and

- New health priorities, especially HIV and AIDS, had emerged.

Today, interest in family planning is increasing. Recent research has shown that high-quality voluntary family planning programs advance economies and improve health. International family planning conferences in 2009 in Kampala 
and in 2011 in Dakar drew unexpectedly large audiences. And major donors such as the Bill \& Melinda Gates Foundation, the World Bank, and the UK Department for International Development have recently prioritized family planning. However, this revival has not yet resulted in widespread change in government policies or programs in countries with the highest fertility and fastest population growth.

\section{Chapter Two: The impact of voluntary family planning programs on fertility}

Evidence of family planning program effectiveness can be seen around the world in both controlled and "natural" experiments. One of the most compelling controlled experiments demonstrating the benefits of family planning is the landmark project undertaken in the Matlab district of Bangladesh. The Matlab population of 173,000 people was divided into two areas: a control area, which received the standard set of health care services that were available countrywide; and an experimental area, where access to services was greatly expanded to include home visits, a wide array of contraceptive choices, and follow-up care. The impact in the experimental area was large and immediate: contraceptive use increased markedly, fertility declined rapidly, and women's health, household earnings, and use of preventive health care improved. The program was so successful that it was expanded nationwide, contributing to a rapid fertility decline in Bangladesh.

Natural experiments, which compare two countries with similar social, economic, cultural, and religious characteristics_-but with differing approaches to family planning programs-also demonstrate the powerful impact of voluntary family planning. Jordan and Iran share many cultural and social characteristics, and their development indicators are nearly identical. Both countries have made major investments in health, and rates of infant and child mortality have dropped steeply over recent decades. But family planning has not been a government priority in Jordan, and the same was true in Iran until the late 1980s. In 1989 the Iranian government abruptly reversed course and became a strong supporter of family planning. Free contraceptive services were provided throughout the country by an extensive network of village health workers, and a vigorous communications campaign publicized the benefits of small families. The response was immediate and large. Fertility declined from more than 5 births per woman in the late 1980s to around 2 in 2000. No other country with a population over one million experienced a decline of such magnitude during the 1990s. 


\section{Chapter Three: Family planning services and the strengthening of health systems}

Family planning services in developing countries have evolved significantly since the first programs were launched in the 1950s, when contraceptive products were limited to barrier methods. Since then, family planning has been identified as a critical element of reproductive health. Services have been broadened to offer a wider array of methods and to include education and counseling, contraception for sexually active young people, safe abortion where it is legal, and postabortion care.

Greater public acceptance of family planning has led to an increased variety of mechanisms for providing modern contraception. Beyond hospitals, public clinics, and private physicians, other avenues include community-based distribution, social marketing, social franchises, and reproductive health vouchers. Setting an affordable price and ensuring a local source of contraceptives are key strategies for enhancing access and use.

The most difficult challenge ahead is to reduce inequities in access and use, such as those related to poverty, gender, age, or marital status. For example, sexually active adolescents, whether married or not, face barriers related to access, quality, and cost of contraceptive services. And the ability of family planning to reduce maternal deaths can only be realized if the poorest individuals and those with unmet need are reached on a wide scale.

\section{Chapter Four: Family planning communication programs}

A vital part of the success of voluntary family planning programs is promoting the benefits of contraception to women, their partners, and communities. Behavior change communication (BCC) programs-disseminated via mass media, community-level events, interpersonal communication/counseling, and electronic media-increase awareness and acceptance of contraception by encouraging individuals to look to a better future and promoting family planning as one means to that end. They provide factual information on types of contraceptive methods, safety, sources of supply, and management of side effects. Communication programs dispel myths and misconceptions in an effort to overcome barriers to use. Finally, BCC programs aim to motivate individuals to action: to discuss family planning with their spouse or partner, visit a clinic or community worker, and initiate use of a contraceptive method when pregnancy is not desired. 
The most effective programs employ the principles of strategic communication. They use multiple channels with mutually reinforcing messages tailored to specific segments of the audience. Formative research, monitoring, and evaluation guide the process and offer indications of potential mid-course corrections needed, and provide evidence of effectiveness.

Studies have shown that these campaigns can increase:

- demand for services at clinics,

- knowledge of modern family planning methods,

- partner communication about family planning,

- approval of family planning, and

- use of modern contraceptive methods.

Today, programs are employing new strategies and technologies to stay relevant. For example, many programs are combining family planning communication with other critical health services, such as HIV prevention or adolescent health programs. Programs are also using cell phone and internet technology to reach their target audience.

\section{In sum}

Family planning is one of the most successful development interventions of the past 50 years. It is unique in its range of potential benefits, encompassing economic development, maternal and child health, educational advances, and women's empowerment. Research shows that with high-quality voluntary family planning programs, governments are able to reduce fertility and produce largescale improvements in health, wealth, human rights, and education.

But in countries where contraceptive use is still uncommon and attitudes can range from ambivalent to hostile, strong political commitment will be essential to achieve rapid gains in contraceptive prevalence. Substantial investments in promoting voluntary family planning programs and increasing access for all women should be a top priority. The tide is starting to turn, with large and influential donors renewing their commitments to achieving family planning equity. We must capitalize upon this growing momentum to firmly establish voluntary family planning programs as accepted, expected, and routine elements of national health care systems. 



\section{INTRODUCTION}

W ith the human population exceeding 7 billion and food and energy prices rising, the longstanding question of the adverse consequences of expanding populations in the developing world and rising consumption everywhere is commanding the attention of growing numbers of scientists and policymakers. In addition to the depletion of environmental resources and the impact of global climate change, other potential adverse effects of rapid population growth and high fertility include poor health among women and children, slow economic growth and widespread poverty, and political instability in countries with large numbers of unemployed young people.

Since the 1960s, alongside efforts to increase levels of education and improve health conditions, the main policy response to rapid population growth has been the implementation of voluntary family planning programs that provide information about, and access to, contraception. This policy has permitted women and men to control their reproductive lives and avoid unwanted childbearing. The choice of voluntary family planning programs as the principal policy to reduce fertility has been based largely on the documentation of a substantial level of unwanted childbearing and an unsatisfied demand for contraception. Family planning programs provide a win-win solution. The welfare of individual women and children is improved, and the national economy and the local and global environment benefit. The international consensus on this issue is reflected in the UN Millennium Development Goals, specifically the goals of providing universal access to reproductive health by 2015 and reducing the unmet need for family planning.

Despite this longstanding and widely accepted rationale for voluntary family planning programs, interest in and funding for these programs declined after the mid-1990s. A number of reasons can be cited, including the claim that such programs are ineffective; new priorities among donors; persistent opposition from conservative governments and institutions; and the need for resources to address other pressing problems, such as the AIDS epidemic. This neglect is now being reconsidered in the face of mounting evidence that continuing high levels of fertility in sub-Saharan Africa and South Asia contribute to poor health, im- 
pose constraints on social and economic development, and harm the natural environment. For example, the US administration proposed a substantial increase in fiscal-year 2010 funding for international family planning activities (USAID 2010), and the World Bank announced a major new Reproductive Health Action Plan (World Bank 2010). Substantial additional resources have become available in 2012 with the renewed commitment to family planning from DfID and the Bill \& Melinda Gates Foundation. These two donors have organized an International Family Planning Summit in London in July 2012 aimed at catalyzing international political and financial support for family planning. This new infusion of resources partially reverses the earlier decline in international support for family planning programs.

This report reviews the rationale for family planning programs and the lessons from past programs. The four chapters discuss (1) Reasons for neglect of family planning since the mid-1990s and reasons for renewed interest (including the economic, environmental, and health benefits of reduced fertility); (2) How family planning programs reduce fertility: reducing unmet need for contraception and unplanned childbearing, and altering the demand for children; (3) Organization and management of family planning services: public- versus private-sector, clinic-based versus community outreach, and efforts to ensure high-quality services; and (4) Organization and management of family planning communication programs: IEC (information, education, and communication) and BCC (behavioral change communication) programs. 


\section{CHAPTER 1}

EXPLAINING THE NEGLECT OF FAMILY PLANNING PROGRAMS SINCE THE MID-1990s

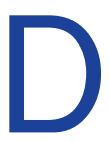

uring the 1970s and 1980s, government promotion of modern contraception in developing countries in Asia and to a lesser extent Latin America was a high-priority and well-funded activity. Between 1960 and 1996, the number of countries with official policies to support family planning rose from two to 115 (UN 2004), and international funding increased in real dollars from US\$168 million in 1971 to $\$ 512$ million by 1985 (UN Population Fund 1988). The rationale for this form of development assistance was largely economic. Persistently high fertility, typically in the range of five to seven births per woman, together with rapidly declining death rates, resulted in rapid population growth and high dependency ratios, which in turn reduced the ratio of capital to labor and reduced savings and investment in the modernization of agriculture and industry (Coale and Hoover 1958).

This economic argument was buttressed by more portentous concerns, in this era before the Green Revolution, that food production would not keep pace with population growth, that non-renewable resources would soon be exhausted, and that environmental limits to growth in human numbers and affluence might be imminent (Ehrlich 1968; Meadows et al. 1972). As president of the World Bank from 1968 to 1981, Robert McNamara had become convinced that rapid population growth acted as a major brake on development and that the promotion of family planning could accelerate a return to population stabilization. These views were shared by many developing-country leaders, notably Prime Minister Indira Gandhi of India and President Ziaur Rahman of Bangladesh. With the creation of the United Nations Fund for Population Activities in 1969, the stage was set for a proliferation of family planning programs.

Since the mid-1990s, this strong international support for family planning has waned. As shown in Figure 1.1, donor support for family planning between 1995 and 2007 fell from US\$980 million to \$340 million in constant 2007 dollars, while support for other forms of reproductive health rose and support 


\section{FIGURE 1.1}

Trends in international assistance for population activities, 1995-2007

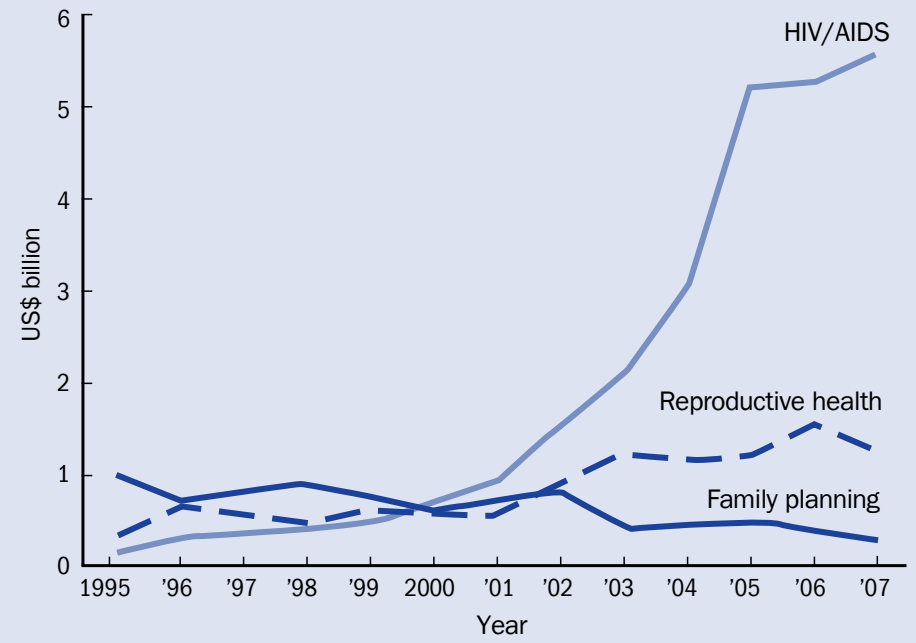

SOURCE: United Nations Commission on Population and Development (2009). The numbers in this report have been adjusted for inflation.

for HIV/AIDS increased sharply (UN 2009). Major US foundations, such as Ford and Rockefeller, withdrew from the field. Population issues were entirely absent from the Millennium Development Goals (MDGs) and from most of the World Bank's Poverty Reduction Strategy Papers, even in countries with continuing high fertility and rapid population growth. World Bank projects on family planning and population virtually disappeared after 1997 (World Bank 2009). The term "family planning" (or contraception) was largely replaced in international development discourse by the much broader term "reproductive health and rights." Individuals and agencies involved in international efforts to increase access to family planning clearly came to believe that the movement had lost urgency and visibility (Blanc and Tsui 2005).

No single factor can fully account for this abrupt shift in priorities. Rather, a confluence of factors are implicated: the sense that the "population problem" was largely solved; the weak empirical evidence that rapid population growth and high fertility were serious impediments to economic progress; strong criticisms of coercive elements in some large Asian family planning programs; the emergence of compelling new priorities, especially HIV/AIDS; and the recommendations of the 1994 International Conference on Population and Development. We discuss each of these factors below. 
By 1990-95, the rate of increase in the world's population had slowed from its peak of 2 percent per year in the 1960s to 1.5 percent, and fertility in Asia and Latin America had dropped from over five births per woman to about three. Even in sub-Saharan Africa, fertility decline was well established in a few countries such as Kenya, South Africa, and Zimbabwe. Over the same period, the level of childbearing in developed countries had also fallen steeply from over 2.5 births to 1.7 births, raising new concerns about long-term population decline and aging. As early as 1979 a few demographers were proclaiming that rapid population growth was coming to an end (Bogue and Tsui 1979); by 1990, that view was more widespread, despite the persistence of high fertility in most of the world's poorest countries, concentrated in Africa. In the words of Stan Bernstein, "The race against population growth was, in effect, declared over before everyone crossed the finish line" (Bernstein 2005: 129).

Concurrent with the widespread fertility declines of the 1970s and 1980s, the Coale-Hoover thesis that rapid population growth had a large negative effect on economic progress came under critical scrutiny from economists. Whereas key reports from the early 1970s had strongly endorsed the economic imperative of curbing population growth, the 1986 US National Academy of Sciences report came to more balanced conclusions (National Academy of Sciences 1971; UN 1973; National Research Council 1986). Allen Kelley's subsequent review of that report suggested several reasons for this change (Kelley 2001). First, development theories since Coale and Hoover minimized the contribution of physical capital accumulation to economic growth and instead emphasized the importance of human capital, technological change, and institutions and policies. Second, empirical research had found little evidence that rapid population growth resulted in reduced savings, nor was any correlation apparent between slower population growth and increases in per capita income. Third, economists had a much greater influence on the 1986 report than on the earlier reports. As a result, the economic rationale for investment in family planning programs was greatly weakened.

The sense that rapid population growth was coming to an end, together with the weakening of the economic case for halting such growth, might have been sufficient for a gradual shift from family planning to other priorities. But the shift was abrupt and the key reason was a concerted attack on government family planning programs by some women's groups promoting reproductive health and rights. The essence of the argument was that high-pressure programs, with their aggregate demographic targets, ignored women's broader reproductive health and rights. According to these critics, an emphasis on long-acting con- 
traceptive methods, particularly sterilization, restricted freedom of choice and made women dependent on providers. The use of financial incentives for individuals undergoing sterilization (and for those who "recruited" them), a common feature of Asian programs but absent in other regions, posed a further threat to informed choice, represented an invitation to corruption, and ran the risk that the poorest women would sacrifice future childbearing for a one-time monetary payment. By implication, all programs with demographic targets were tarnished with elements of coercion.

Most of the objections to traditional programs did not deny the desirability of population stabilization, but proposed a radically different approach to achieving this aim (Dixon-Mueller 1993; Sen, Germain, and Chen 1994). Women's education and empowerment, along with ready access to contraceptives and other reproductive health services, would reduce birth rates to sustainable levels. The concept of unmet need for contraception (the proportion of women wishing to stop or postpone childbearing but not using a method to achieve this goal) provided common ground between this feminist approach and the more orthodox family planning community (Hodgson and Watkins 1997). Fertility-reduction targets could be met by addressing unmet need (Sinding, Ross, and Rosenfield 1994).

This coalition bore fruit at the 1994 International Conference on Population and Development in Cairo. Concerns about population growth and the need for family planning were replaced by an agenda of women's rights and empowerment, and contraception was demoted to one of many ingredients of women's reproductive health. Although the Cairo agenda was ambitious, it lacked clear yardsticks by which to measure subsequent progress. Now that the economic case for it had been largely abandoned, it seemed inevitable that family planning would lose its pre-eminence.

This loss of pre-eminence was accelerated by new concerns and priorities that attracted the attention and funding of donors. The 1990s brought justified alarm that HIV/AIDS would evolve into a worldwide pandemic with consequences as serious as those being documented in the generalized epidemics of East and Southern Africa. The misconception arose that any remaining potential for population growth would be largely eliminated by rapidly rising death rates. Peter Piot, formerly head of UNAIDS, characterized HIV/AIDS as a threat to economic progress and stability, as well as a health and humanitarian disaster, and was thus able to engage the support of development agencies such as the World Bank. Extremely large sums of money were mobilized to address the threat. No doubt family planning programs suffered as funds, staff, and political energy were diverted to combat this new disease, particularly in Africa (Mayhew and Adjei 2004). 


\section{A revival of interest in family planning}

After many years of benign neglect, there is recent evidence of a revival of interest in family planning, perhaps best illustrated by the unexpectedly large attendance at international conferences on the topic held in Kampala in late 2009, the first of its kind for at least 15 years, and, two years later, in Dakar. The long battle to include the key Cairo Conference demand for "universal access to reproductive health," including family planning, as one of the MDG targets was won in 2008. This revival is starting to be reflected in changes in government policies or programs in some countries where high fertility and rapid population growth still prevail. In this section, we review the case for reasserting the importance of government-sponsored family planning programs.

\section{New economic evidence}

Paradoxically, just when the international community was abandoning the economic rationale for investment in family planning at the Cairo conference, the evidence from economic modeling and empirical analysis tilted decisively toward the conclusion that demographic factors exert important influences on countries' living standards. A longer time-series of data and better methods were partly responsible for this change, but perhaps the key factor was a more comprehensive representation of demographic transition in place of a narrow focus on the rate of population increase or the level of fertility.

Demographic transition describes the changes that occur as countries evolve from a state of high mortality balanced by high fertility to a state of low mortality and low fertility. The first change is inevitably a decline in mortality, which has its greatest effect on child survival and increases the proportion of children in the population. At this early stage, about half the population is below age 20. Population size and density increase. After a lag, fertility declines and the youth dependency burden falls, but, as a legacy of past high fertility, the working-age population continues to grow. The ratio of workers to less-productive age groups - the young and the old-rises steeply. Birth rates and population growth, however, remain high for several decades because of the disproportionately large number of people in the reproductive ages, a feature termed demographic momentum. In the final stage of transition, population growth (in the absence of in-migration) ceases or even becomes negative, as in the case of contemporary Europe, while the population ages, the old-age dependency burden rises, and the proportion of working-age adults falls.

Most of the new insights into the relationships between demography and the economy have come from separate analyses of these components of demo- 
graphic transition: population size and density, mortality, fertility, and, most crucially, age structure (Kelley and Schmidt 1995). The results of this research can be summarized briefly. Increases in population size and density have mild positive effects on per capita output; mortality and fertility decline have considerably larger positive effects; and the period of mid-transition when dependency burdens are at their lowest offers a unique but transitory opportunity for rapid economic progress, which has become known as the demographic dividend. It is not surprising that a rise in the ratio of working-age to total population offers a potential economic boost, but the effects in East Asian countries are estimated to have been far larger than those attributable to simple demographic accountancy. The reason lies in the enhanced opportunity for savings and investment, both in higher-quality education, thereby raising human capital, and in physical capital, thereby facilitating agricultural intensification and industrialization. This analysis suggests that about 30 percent of the rapid economic growth of the East Asian tigers is attributable to changes associated with the demographic transition (Bloom, Canning, and Malaney 2000).

These findings do not amount to demographic determinism, nor have they gone unchallenged. As specified in Barro's model of economic growth, for example, many other factors determine such growth, including terms of trade, the rule of law, secure property rights, and institutions that encourage public- and private-sector investment (Barro 1997). These facilitating conditions were met in East Asia but were absent in much of Latin America, where similar demographic changes occurred but economic growth was weaker and less widespread.

A strong correlation between poverty and the number of children in a household has been observed for decades. Children with many siblings tend to be less well educated and less well nourished. Causal interpretation, however, has been problematic. Do the poor choose to have larger families than betteroff families because of perceived advantages of future labor contributions or as a form of security in old age? Or is their poverty in part a consequence of high fertility? Studies of twins, which minimize problems of causality, suggest that large family sizes do negatively affect the education and health of children (Rosenzweig and Wolpin 1980; Rosenzweig and Zhang 2009). Other social scientists, including demographers, tend to emphasize lack of choice and are more likely than economists to interpret high fertility as a barrier to the escape from poverty. The large body of survey evidence on unwanted childbearing supports the latter view. As shown in Figure 1.2, unwanted childbearing is invariably more common among the poor than the rich. Sound reasons can account for this relationship. The poor have less information about contraception, greater misgivings about its use, and restricted access to services. 


\section{FIGURE 1.2}

Unwanted fertility by wealth quintile, average for 41 countries

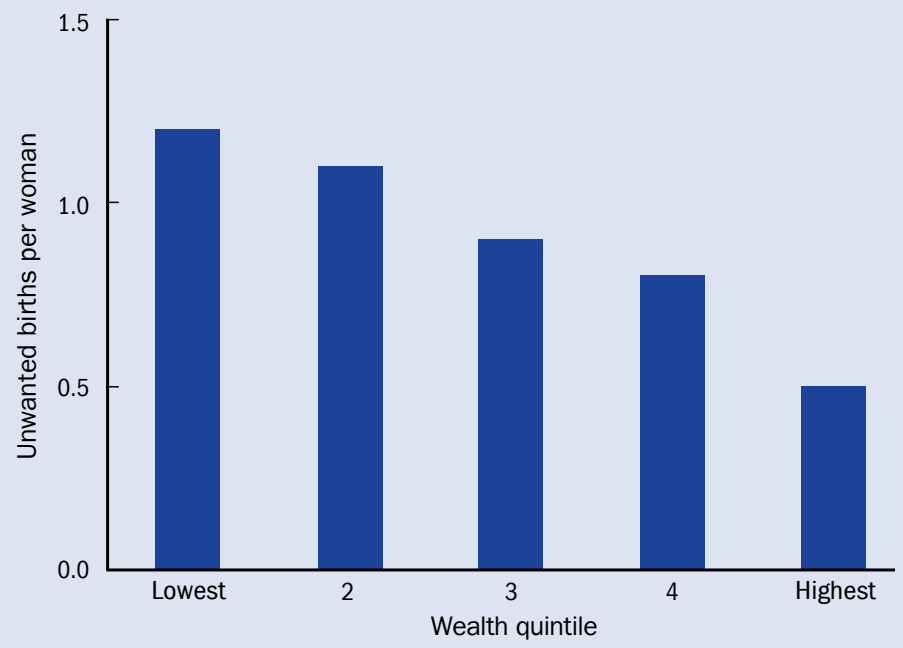

SOURCE: Gillespie et al. (2007).

Convincing evidence that the poor benefit from smaller family size comes from the quasi-experiment in Matlab, a poor district in Bangladesh. Starting in 1977, half the area received high-quality intensive family planning services in addition to other services, while the other half continued to receive routine government services. Fertility fell faster and earlier in the experimental area than in the control area, although by 1996 the gap had closed. Among the long-term consequences of this difference was higher education of children, greater asset accumulation, and greater use of preventive health services in the experimental area (Joshi and Schulz 2007).

A further contribution of demographic change to economic growth is the increased employment of women. When fertility levels are high, women's lives are dominated by a repeated sequence of pregnancy, breastfeeding, and nurture of young children. This preoccupation may not preclude women's contributions to the household economy, such as work on a family farm, but it is clearly not conducive to paid employment outside the home. When fertility falls to two children, for instance, this period of intensive motherhood is compressed to less than a decade, thus raising the feasibility of non-domestic activities, including employment. The relationship between women's labor force participation, defined broadly, and national GDP per head is U-shaped (see Figure 1.3). The relatively high participation rate in the poorest countries, particularly in Africa, is 


\section{FIGURE 1.3}

Schematic relationship between women's work and fertility, according to level of GDP per capita

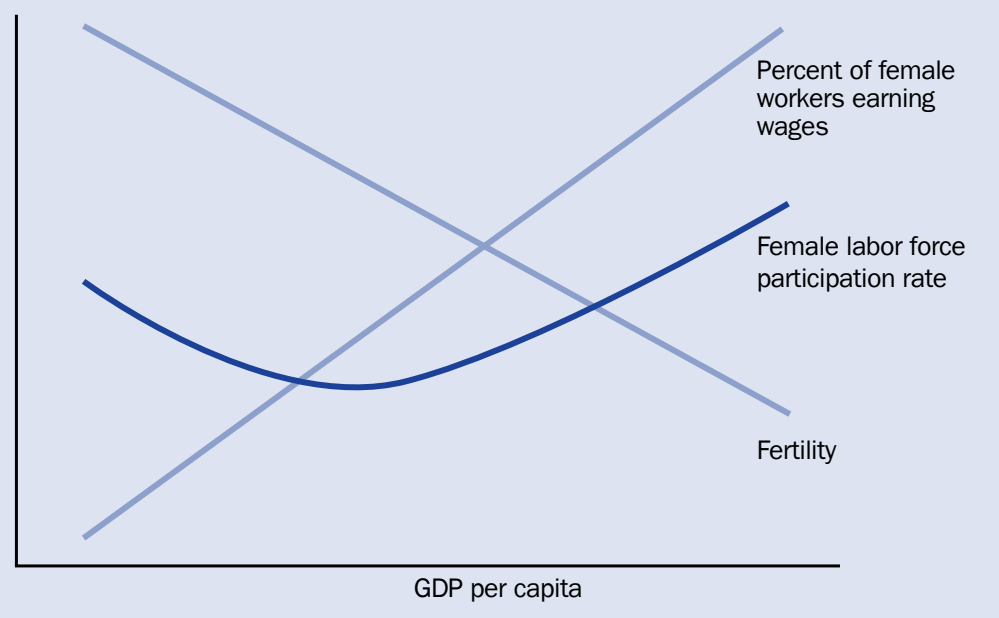

SOURCE: Adapted from Mammen and Paxton (2000).

largely attributable to unpaid work on family enterprises. After an initial dip, participation rises steeply with increased GDP and fertility decline, and represents an appreciable contribution to economic growth (Mammen and Paxton 2000).

Most of the positive effects of fertility decline and associated population change on economic development unfold over decades. For this reason, investments in family planning programs and policies may be unattractive to political leaders with short time horizons. Analyses by the Futures Group address this concern by demonstrating that family planning can also bring short-term gains (Moreland and Talbird 2006). For 16 African countries investigators estimated 1) the costs of meeting unmet need for family planning; 2) the number of unintended pregnancies and births averted by family planning; and 3) the savings represented by these averted births in meeting Millennium Development Goals by 2015 . The average estimated benefit/cost ratio for the 16 countries was an impressive 3.7. The largest savings were in primary schooling (with an obvious lag of five years) and in obstetric care, with additional savings in immunization, provision of bednets for malaria control, and improvements in water supply and sanitation (Figure 1.4). These considerations related to schooling are particularly important in sub-Saharan Africa, where the number of children aged 5-15 years will rise by an average of 21 percent between 2010 and 2020. In the highestfertility countries, such as Uganda, the increase is about 35 percent. In this re- 


\section{FIGURE 1.4}

Benefit/cost ratio of investments in family planning by sector, average for 16 countries in sub-Saharan Africa

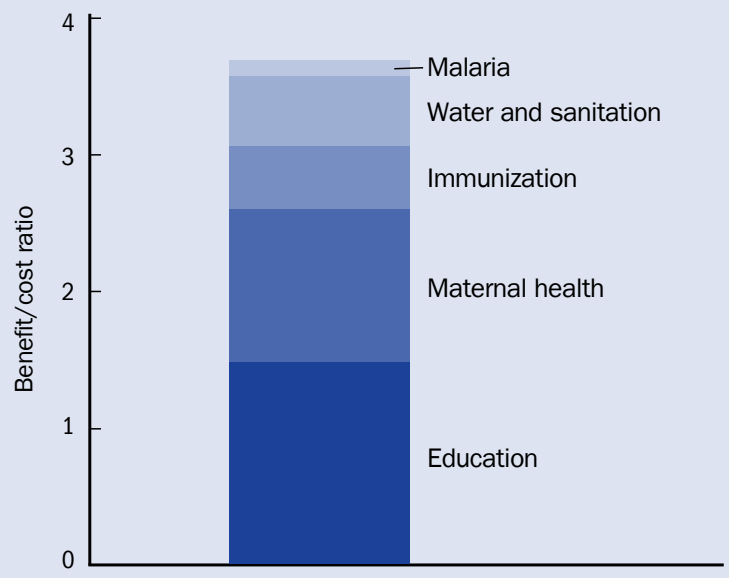

SOURCE: Moreland and Talbird (2006).

gion, either education budgets will need to rise steeply to maintain the existing quality of schooling, or quality will decline further, with negative implications for the human capital of the future labor force. Taking into account both reductions in deaths and likely increases in per capita income attributable to investment in family planning and associated fertility decline, the long-term benefit/ cost ratios will be much larger than the short-term benefits documented by Moreland and Talbird (Kohler 2012: 59).

\section{Growing concerns about population, food production, and the environment}

One of the most significant changes that have occurred since the Cairo conference is growing concern that human numbers and activity are destabilizing the planet's environment. The most acute global threat comes from increased use of fossil fuels and the associated rise in $\mathrm{CO}_{2}$ emissions, resulting in global warming, rising sea levels, and a higher incidence of extreme weather events. $\mathrm{CO}_{2}$ emissions are strongly correlated with living standards. Rising incomes and energy use, rather than population growth per se, have been the main drivers of global climate change and will continue to be so in the coming decades.

Nevertheless, the contribution of population growth to climate change is by no means trivial. For instance, the increase in total $\mathrm{CO}_{2}$ emissions attributable to expected population growth between 2000 and 2050 in poorer countries, even 
assuming no change in emissions per head in these countries, would entirely offset the effect of a decline in emissions of 40 percent per head in developed countries over this period (Dyson 2005). Moreover, some poor people eventually become richer. Marked increases in $\mathrm{CO}_{2}$ emissions per head have occurred in countries such as Brazil, China, and India in step with their rapid economic growth, and these countries are still experiencing population increases. Clearly, the development of alternative energy sources to replace fossil fuels and the means to finance their application in both rich and poorer countries are a top priority, but reductions in expected population growth can make a major contribution. Indeed, it has been argued that the prevention of unwanted births is likely to be one of the most cost-effective ways to preserve the planet's environment in the long term (Birdsall 1994).

The urgency of addressing climate change for development agencies, such as the World Bank, stems from the broad consensus that poor agrarian countries, particularly in sub-Saharan Africa, will be the most vulnerable to the consequences of such change. Continued temperature rises will affect crop production most severely in the tropics and sub-tropics (IPCC 2007). One-sixth of the world's population lives in arid and semi-arid regions, and 250 million people are already directly affected by desertification (World Bank 1999). Nearly threequarters of Africa's farmers rely on rain-fed agriculture (Pinstrup-Andersen 2002). $\mathrm{CO}_{2}$-related declines in rainfall and/or increased irregularity of precipitation could result in widespread disruptions in food supply.

Population growth is more directly implicated in the environmental consequences of the need for increased food production. Between the end of the last century and 2030, demand for food in developing countries is expected to grow by 2.0 percent per year compared with population growth of 1.3 percent (FAO 2003). Despite the reduction in rates of population growth, this factor remains the major cause of increased food demand. Among the consequences are changes in land use, including loss of natural habitats and deforestation; loss of biodiversity; unsustainable depletion of water resources; and degradation of fragile ecosystems resulting from over-cropping and over-grazing. Future challenges will be most severe in sub-Saharan Africa, the only region that will experience continued growth of both rural and urban populations. Thus in many parts of Africa, poorquality and fragile soils must support increasing population density. In the absence of technological advances or effective local conservation efforts, encroachment onto marginal land and widespread environmental degradation are likely.

These environmental concerns in Africa are accompanied by classic Malthusian alarms that population increase will outstrip food production. In contrast to 
all other regions, agricultural yields per hectare in Africa have remained unchanged in recent decades (World Bank 2008). As a result, food production has not kept pace with population increase. In 2000, Africa was importing US $\$ 20$ billion worth of food per year, mostly from the commercial market, equivalent to total overseas development aid at that time (Commission for Africa 2005). Because nearly twothirds of employment in Africa is in agriculture, it is widely recognized that greatly improved productivity in this sector is the key to reducing poverty and malnutrition (World Bank 2008). Reductions in fertility and population growth undeniably make an important contribution to lowering rates of poverty and hunger.

\section{Reaffirming the health benefits of family planning}

The health benefits to mothers and their children stemming from the ability to choose the number and timing of births have been well documented for decades and have always been one of the rationales for government investment in family planning services. For reasons that we outline below, however, these benefits have been under-appreciated in much of the research on maternal and child health and in the establishment of international health priorities.

\section{Maternal health}

The key Millennium Development Goal for maternal health is a 75 percent reduction in the maternal mortality ratio, the number of pregnancy-related deaths per 100,000 live births. Effective contraceptive use can contribute to this target in two ways. First, it can virtually eliminate the estimated 13 percent of maternal deaths due to unsafe abortion, nearly all of which occur in developing countries. Second, it can reduce the proportion of pregnancies that pose an above-average risk to women's survival. The risk of death has a $U$-shaped relationship to maternal age and parity. It is high in the early teenage years and for first births, falls at intermediate ages and parities, and rises again at ages 35 and above and for parities five or higher.

The advent of widespread contraceptive practice, and in its wake lower fertility, invariably means a decline in higher-parity births and usually reduces childbearing at older ages. The likely effect of contraceptive use on high-risk teenage pregnancies is more context-specific. In South Asia, marriage nearly always precedes sexual initiation and pregnancy, and use of contraception to delay the first marital birth is rare. Hence age at marriage rather than contraception is the major determinant of teenage pregnancies. In Latin America and sub-Saharan Africa, sex and pregnancy risk before marriage are more common, thus contraception has a greater potential impact. Quantifying the potential ef- 
fect of desirable changes in the age and parity composition of pregnancies on the maternal mortality ratio is difficult because of the scarcity of data. Estimates range from a 10 percent reduction to over 20 percent (Trussell and Pebley 1984; Winikoff and Sullivan 1987). Two recent estimates suggest substantial beneficial effects of increased contraceptive use on the maternal mortality ratio (Jain 2011; Cleland et al. in press). Obviously this contribution to reducing mortality will be greatest in countries where fertility remains high.

The maternal mortality ratio is not the only way of measuring the risk of maternal health and has the disadvantage of circumventing the fact that women who avoid pregnancy run no risk. From a public health perspective, the preferred measures are the maternal mortality rate (the number of deaths per 1000 women of childbearing age) and the lifetime risk of maternal death. The contribution of contraception and fertility declines to reductions in both measures are direct and substantial, but have been overshadowed by the choice of the maternal mortality ratio as the MDG target. It is estimated that, in 2008, use of modern contraception in developing countries was responsible for averting 230,000 maternal deaths, equivalent to a 43 percent reduction (Singh et al. 2009). Much larger numbers of abortions and miscarriages were also averted (see Table 1.1). This major contribution was due entirely to avoidance of unintended pregnancies. An additional 150,000 maternal deaths, representing a further reduction of 28 percent, could be prevented by satisfying the unmet need for contraception.

Because fertility and unmet need for contraception remain much higher in sub-Saharan Africa than in other regions, the prevalence of maternal deaths is increasingly concentrated in this region. Between 1980 and 2008, the proportion of all maternal deaths that occurred in Africa rose from 23 percent to 52

\section{TABLE 1.1}

Number of unintended pregnancies and maternal deaths averted (in thousands) by using modern contraception and meeting unmet need for contraception among women in developing countries who want to avoid pregnancy, 2008

\begin{tabular}{lrrr} 
Measure & $\begin{array}{r}\text { Current use of } \\
\text { modern methods }\end{array}$ & $\begin{array}{c}\text { Meeting unmet need } \\
\text { for modern methods }\end{array}$ & Total \\
\hline Unintended pregnancies averted & 187,800 & 53,460 & 241,260 \\
Unplanned births & 53,550 & 21,820 & 75,370 \\
Abortions & 112,310 & 24,800 & 137,100 \\
Miscarriages & 21,940 & 6,840 & 28,780 \\
Maternal deaths averted & 230 & 150 & 380 \\
Number of contraceptive users & 603,090 & 214,450 & 817,540 \\
\hline
\end{tabular}

NOTE: Numbers may not add up to totals because of rounding. SOURCE: Singh et al. (2009). 
percent, and 15 of the 21 countries with the largest number of deaths are in this region (Hogan et al. 2010). Even if the maternal mortality ratio remains unchanged, fertility decline in Africa will greatly reduce the rate and lifetime risk of death in pregnancy or childbirth. To illustrate, holding the maternal mortality ratio constant at 600 deaths per 100,000 live births, a reduction in fertility from six to four births per woman would reduce the lifetime risk from 1:28 to 1:42, and a further fall to two births would reduce it to 1:84.

Greater use of contraception has an additional benefit that will be most pronounced in Africa, where many maternal deaths are linked to HIV infection (Hogan et al. 2010). Provision of family planning methods to HIV-positive women who wish to avoid pregnancy should thus be a top priority and carries the additional advantage of reducing mother-to-child transmission of the virus. The use of condoms for pregnancy prevention among sexually active unmarried women has increased markedly and is now the most prevalent method in this segment of the population in both sub-Saharan Africa and Latin America. Together with changes in sexual behavior, increased condom use is responsible for the declines in HIV incidence among young people in many African countries. Condom use is much lower among married couples, although it is also increasing in Southern Africa.

\section{Child health}

The interval between a birth and the next conception may influence the health and survival of the mother, although the evidence is not robust. However, interval length has a demonstrable effect on the health and survival of children. Most of the evidence on this relationship comes from retrospective birth histories collected initially by the World Fertility Survey and, since 1985, by the Demographic and Health Surveys (DHS). The most comprehensive DHS study performed a pooled analysis on data from 52 countries that undertook a survey between 2000 and 2005 (Rutstein 2008). Half of these countries were in sub-Saharan Africa. For infant mortality, children conceived within 24 months of an older sibling's birth (equivalent to an inter-birth interval of less than 33 months) were at excess risk of dying even after adjustment for a large number of potentially confounding factors. The shorter the interval, the greater the risk. These results are consistent with findings from studies in the United States, prospective data from Matlab, Bangladesh, and a meta-analysis that show associations between birth interval length and adverse perinatal outcomes, such as fetal death, prematurity, and low birth weight (Zhu 2005; DaVanzo et al. 2008; Conde-Agudelo, Rosas-Bermudez, and Kafury-Goeta 2006). The causal mechanism is probably related to maternal nutritional depletion (Smits and Essel 2001). 
Rutstein's results for early childhood mortality are even more remarkable. Unlike infant mortality, there is no threshold in the effect of interval length. The longer the interval, the smaller the risk of dying (Figure 1.5). Although the mechanisms are poorly understood, competition for maternal and familial resources and cross-infection from older siblings may both be implicated. The significant effects of interval length on stunting of surviving children, also found in the DHS pooled analysis, are consistent with either mechanism. Children are also vulnerable to short following intervals. Cross-national studies showed that the birth of a younger sibling within two years was associated with a doubling of mortality between ages one and two years and a smaller adverse effect in later childhood (Hobcraft, McDonald, and Rutstein 1985).

Birth-to-conception intervals that pose a risk to the health and survival of children are commonplace. In the 52 countries in Rutstein's study, 54 percent of second and higher-parity children were born following intervals of less than 24 months and an additional 21 percent after intervals of 24-35 months. Rutstein's analysis implies that elimination of intervals of less than 24 months would reduce mortality under age five by 13 percent, and this figure rises to 25 percent with the elimination of intervals of less than 36 months. It may seem unrealistic

\section{FIGURE 1.5}

Adjusted relative risk of under-five and child mortality ${ }^{a}$ by interval from birth to conception, 52 DHS surveys

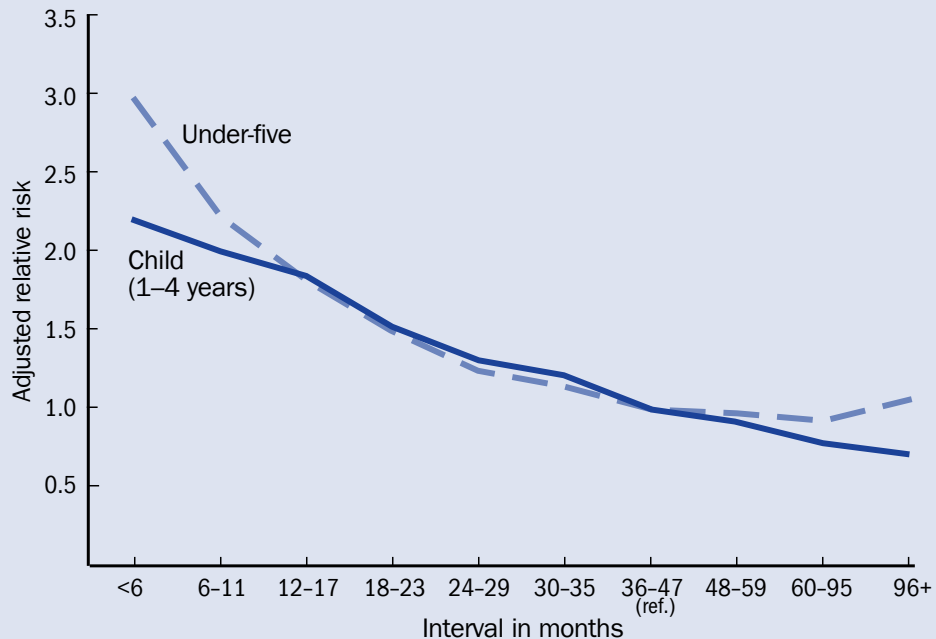

ander-five mortality = death at 0 to 59 months after birth; child mortality = death at 12 to 59 months after birth. Under-five mortality based on $1,049,196$ births; child mortality based on 903,417 children. SOURCE: Rutstein (2008). 
to expect couples to space children nearly four years apart, as implied by avoidance of intervals of less than 36 months, but an analysis showed that in 14 out of 20 African countries the preferred birth interval length exceeded three years and that if women were able to implement their preferences infant mortality would fall by 6 percent (Rafalimanana and Westoff 2000). This appreciable potential contribution to child survival of wider spacing of births by use of contraception is usually overlooked in the setting of health care priorities.

These results are particularly relevant to high-fertility countries in sub-Saharan Africa for three reasons. First, African couples place a high value on child spacing, but the traditional ways of achieving this through prolonged intensive breastfeeding and postpartum sexual abstinence are waning. Thus contraception as an alternative should have special appeal. Second, mortality between ages one and five years accounts for a higher fraction of all under-five deaths in Africa than in other regions. Third, in high-fertility countries a greater proportion of all children are second or higher-parity births and thus, unlike first births, are vulnerable to inadequate spacing; they are also less likely to be last-born children and are therefore susceptible to short preceding and following intervals.

\section{The stalling fertility decline}

Extensive changes in reproductive behavior have occurred in large parts of the developing world over the past half century. The average number of births per woman has been halved: from six in the early 1960s to just below three in the early 2000s (UN 2009). Reductions in fertility have been largest in Asia (58 percent) and Latin America (62 percent) (Figure 1.6). As we argue in Chapter 2 , family planning programs can take much of the credit for the rapid fertility declines that have occurred even in the poorest countries, such as Bangladesh and Nepal.

Significant exceptions remain where birth rates are still high (e.g., Afghanistan and Pakistan), and high levels of unintended childbearing among the poor, as we illustrated in Figure 1.2, remain a more widespread problem because they make the escape from poverty more difficult. However, fertility on average in Asia and Latin America is now about 2.3 births per woman and is expected to fall further. Between 2010 and 2050, population size in the two regions is projected to increase by about 30 percent, largely because of population momentum, but by mid-century the era of population growth will be over. A large body of evidence, discussed above, shows that this fertility transition in Asia and Latin America has brought widespread benefits in health and welfare, particularly to women and children. 


\section{FIGURE 1.6}

Trends in fertility by region, 1960s-2000s

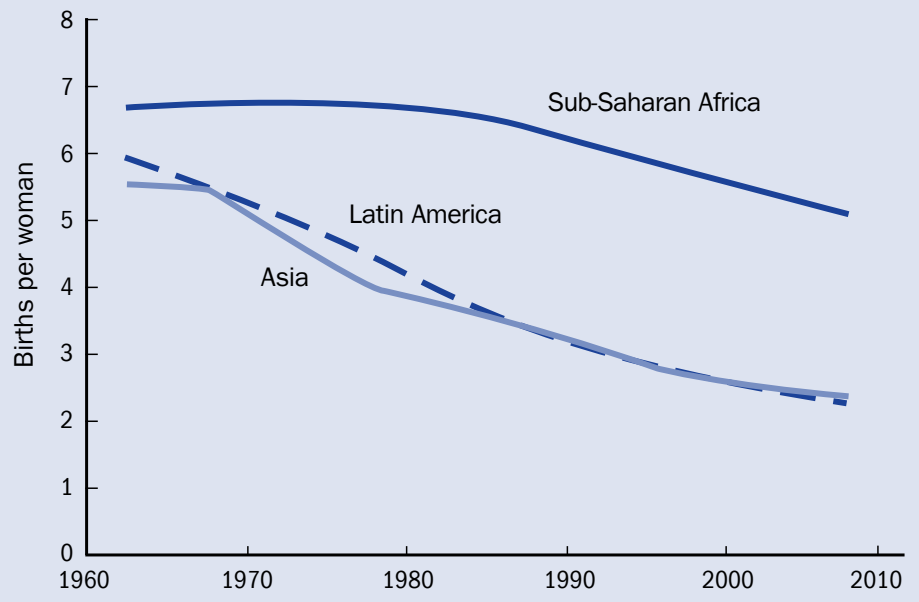

SOURCE: UN (2011)

The demography of sub-Saharan Africa stands in stark contrast to that of other poor regions. By the time many African governments accepted the need for population stabilization, the promotion of family planning was no longer an international development priority. Funding had fallen and political energy had shifted to other concerns. Partly as a result, the fertility decline in most of Africa has been slow, faltering, or non-existent with the exception of a few middleincome countries in Southern Africa. Of the 45 countries with total fertility rates of four or more births per woman, 36 are in sub-Saharan Africa and these 36 contain over 90 percent of the region's population (Table 1.2). Fertility in this region as a whole is now about five births per woman.

Recent analyses have concluded that the slow pace of decline in fertility has become even slower in the past decade and may have stalled entirely in some countries (Bongaarts 2008; Ezeh, Mberu, and Emina 2009). The situation is of particular concern in West Africa. Between 1991 and 2004, use of effective contraception among married or cohabiting women rose from an average of 7 percent to 15 percent, despite evidence of much higher levels of unmet need than elsewhere. In 2004 only 29 percent of women in West Africa were aware of the two main methods of contraception (pills and injectables) and a source of supplies, a vivid illustration of the neglect of family planning (Cleland, Ndugwa, and Zulu 2011). Typically an increase in contraceptive use of $15-17$ percentage points is required 


\section{TABLE 1.2}

Total fertility rate $2005-2010$ in countries with a total fertility rate of 4 or higher

\begin{tabular}{|c|c|c|c|}
\hline Region/country & $\begin{array}{l}\text { TFR (births } \\
\text { per woman) }\end{array}$ & Region/country & $\begin{array}{l}\text { irths } \\
\text { nan) }\end{array}$ \\
\hline \multicolumn{4}{|l|}{ Africa } \\
\hline Niger & 7.2 & Madagascar & 4.8 \\
\hline Mali & 6.5 & Kenya & 4.8 \\
\hline Somalia & 6.4 & Mauritania & 4.7 \\
\hline Uganda & 6.4 & Eritrea & 4.7 \\
\hline Zambia & 6.2 & Cameroon & 4.7 \\
\hline Chad & 6.2 & Burundi & 4.7 \\
\hline Congo (D.R.) & 6.1 & Ivory Coast & 4.7 \\
\hline Malawi & 6.0 & Congo & 4.6 \\
\hline Burkina Faso & 6.0 & Sudan & 4.6 \\
\hline Angola & 5.8 & Ethiopia & 4.6 \\
\hline Nigeria & 5.6 & Ghana & 4.3 \\
\hline Tanzania & 5.6 & Togo & 4.3 \\
\hline Benin & 5.5 & & \\
\hline Guinea & 5.5 & Asia & \\
\hline Rwanda & 5.4 & Afghanistan & 6.6 \\
\hline Liberia & 5.4 & Timor-Leste & 6.5 \\
\hline Equatorial Guinea & 5.4 & Yemen & 5.5 \\
\hline Guinea-Bissau & 5.4 & Iraq & 4.9 \\
\hline $\begin{array}{l}\text { Guinea-BISSau } \\
\text { Sierra Leone }\end{array}$ & 5.3 & Occupied Palestinian Territory & 4.7 \\
\hline $\begin{array}{l}\text { Slerra Leone } \\
\text { Mozambiaue }\end{array}$ & 5.2 & Solomon Islands & 4.4 \\
\hline $\begin{array}{l}\text { IIOzambique } \\
\text { Gambia }\end{array}$ & $\begin{array}{l}5.1 \\
51\end{array}$ & Papua New Guinea & 4.1 \\
\hline Comoros & $\begin{array}{l}5.1 \\
5.1\end{array}$ & Tonga & 4.0 \\
\hline Senegal & 5.0 & Latin America and the Caribbean & \\
\hline Central African Republic & 4.9 & Guatemala & 4.2 \\
\hline
\end{tabular}

SOURCE: UN (2011).

to reduce fertility by one birth per woman. If the pace of change in contraceptive use observed between 1991 and 2004 is maintained, it will take 25 years for fertility in West Africa to fall from its 2000-05 level of 5.6 births to 4.6 births. Increased resort to induced abortion might partially compensate for lack of contraception, but abortion is illegal in most West African countries and often unsafe. West Africa already has the highest risk of abortion-related mortality of any region, with an estimated 140 abortion deaths per 100,000 live births (Shah and Ahman 2009).

Evidence that fertility transition in sub-Saharan Africa is faltering has resulted in an upward revision of projections of fertility and population size. In the United Nations 2008 medium variant projections, the total fertility rate and total population size were envisaged to be 2.5 and 1.75 billion, respectively, by mid-century. These two figures were raised to 3.0 and 1.96 billion in the 2010 
projections. By 2050 the population of sub-Saharan Africa is likely to account for about 20 percent of the world total.

Continued high fertility, high dependency ratios, and rapid population growth in Africa will make achievement of most of the Millennium Development Goals nearly impossible. The reasons for this verdict are specified above. But failure to achieve these goals does not adequately capture the gravity of the demographic situation for some countries that confront the possibility of deepening poverty and widespread hunger. The countries of the Sahel are particularly vulnerable to future massive increases in population. In Niger, for example, population size is projected to increase from 17 million to 50 million in the next 40 years, even under the UN's optimistic assumption that fertility will halve from 7 to 3.5 births over this period. Niger has already lost half its arable land to encroachments by the Sahara, and the country experienced an acute food shortage in 2005. Population pressure on the fragile ecosystem is likely to result in further environmental degradation, thereby exacerbating problems of food security. Even if steep declines in fertility in Niger and similar countries can be achieved, future prospects for health and welfare appear bleak. 


\section{CHAPTER 2}

THE IMPACT OF VOLUNTARY FAMILY PLANNING PROGRAMS ON FERTILITY

$\mathrm{T}$

he remarkable recent trends in reproductive behavior in the developing world have been well documented and the empirical record is not in dispute. The causes of these trends, however, are the subject of continuing debate and there is at present no generally accepted theory of fertility. Instead, over time a number of theories and their variants have been developed, each with important new insights that are crucial to a full understanding of reproductive change.

\section{Why has fertility declined?}

\section{Conventional theories}

The oldest and best-known demographic theory was formulated to explain the fertility decline that occurred in the West from the late nineteenth century through the 1930s (Davis 1945; Notestein 1945, 1953). In traditional rural, agricultural societies, fertility was seen as necessarily high to offset high mortality and ensure population survival. As a society modernizes, economic and social changes such as industrialization, urbanization, new occupational structure, and increased education first lead to a decline in mortality, and subsequently also to a decline in fertility. The rising costs of children (e.g., for education) and their declining economic value (e.g., for labor and old-age security) were the central forces believed to be driving the decline in desired family size. This in turn led to a rise in the demand for and adoption of birth control. The chain of causation linking socioeconomic change to fertility is summarized in the upper part of Figure 2.1. This conventional framework, still regarded as largely valid, has been the basis for various elaborations by economists, sociologists, and demographers.

Contributions by economists to fertility theories focused on the micro-economics of reproductive decisionmaking (Becker 1960, 1981; Lee and Bulatao 1983; Schultz 1976, 1981; Willis 1974). Parents are considered to be rational actors who aim to maximize the utility derived from various choices they make in the face of time and other resource constraints. These include choices related to 


\section{FIGURE 2.1}

Analytic framework for the determinants of fertility

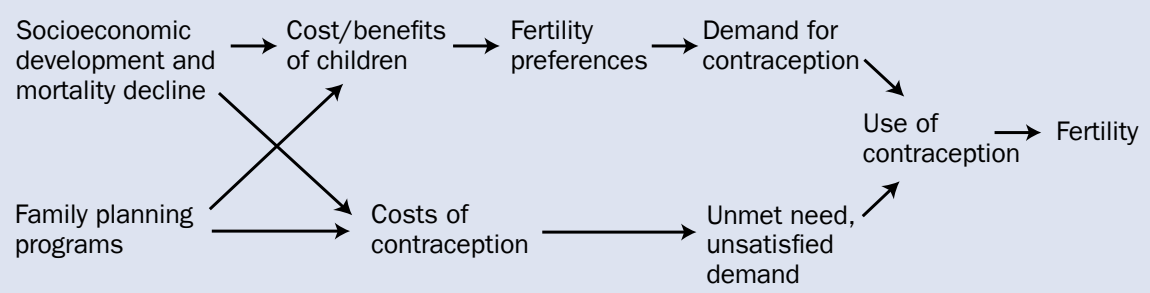

conventional goods and services as well as to children. In choosing a family size, parents have preferences not only for the number of children but also for their "quality" (i.e., their health and education). As countries develop, parents want higher-quality children. Providing the means to raise such children increases their cost, thus leading parents to want smaller families. This school of thought is usually referred to as "demand theory."

Empirical evidence is broadly consistent with demand theories: countries' fertility levels are inversely related to socioeconomic indicators such GDP per capita, life expectancy, child survival, literacy, school enrollment, and urbanization (Bryant 2007). There is little doubt that, as countries develop, fertility behavior changes more or less along the lines demand theories propose. This is the course taken by the now-developed world, where fertility declines began in the late nineteenth century. These historical reductions in birth rates were accompanied by slow declines in mortality, hence population growth remained modest throughout the demographic transition. In contrast, in contemporary developing countries, public health programs (often implemented with external assistance and funding) have produced large declines in child mortality at an early stage in the development process while fertility remained high. The result has been very rapid population growth that is likely to continue if development takes its natural course of steady but slow fertility declines.

There are notable exceptions to this generalization. In particular, fertility has declined rapidly in a few countries with unfavorable development conditions (e.g., in Bangladesh, Indonesia, Nepal, and Sri Lanka). These are traditional, poor, rural, and agricultural societies, yet fertility has declined to low levels. The explanations for these unexpected trends are the priority given by governments to social development (e.g., schooling and women's empowerment) and the implementation of family planning and health programs. No fertility decline has 
been observed in a poor and largely illiterate country in the absence of a strong family planning program.

\section{Revisionist theories}

A crucial assumption of demand theories is that the cost of contraception is sufficiently low to be ignored. This assumption became questionable in the late 1960s and early 1970s when surveys from the developing world showed that many women were not using contraception even though they did not want to become pregnant (Freedman and Berelson 1976). In addition, the frequent resort to induced abortion in both developed and developing countries demonstrated that unintended pregnancies were common (Rochat et al. 1980; Tietze 1981).

These findings contributed to an influential revision of the economic theory of fertility by Richard Easterlin (Easterlin 1975, 1978; Easterlin and Crimmins 1985). His framework for the determinants of fertility added two critical elements to demand theories. First, it acknowledged the role of biology in childbearing outcomes. Specifically, without efforts to control conception, women who are sexually active will bear large numbers of children, because a pregnancy takes only nine months and the reproductive years last decades. To avoid having "excess" children, parents must practice birth control. This fact makes the "acquisition" of children fundamentally different from the purchase of durable goods. Second, Easterlin recognized that the cost of birth control could be substantial, thus leading to significant numbers of unplanned pregnancies. These costs are broadly defined to include economic, health, psychological, and social obstacles.

A more fundamental challenge to demand theories came in the 1980s when empirical tests of these theories were conducted using historical and contemporary data. The massive study of province-level data from European countries for the period 1870-1960 (Coale and Watkins 1986; Knodel and van de Walle 1979; Watkins 1986,1987) yielded two surprising conclusions: 1) socioeconomic conditions were only weakly predictive of fertility declines, and transitions started at widely varying levels of development; 2 ) once a region in a country had begun a decline, neighboring regions sharing the same language or culture followed after short delays, even when they were less developed. Similarly, results from numerous fertility surveys of women in 41 developing countries in the 1970s and early 1980s failed to find the expected dominant influence of economic characteristics on fertility (Cleland 1985; Cleland and Wilson 1987). Moreover, levels and trends in fertility in the developing world since the 1950s deviated widely from expectations (Bongaarts and Watkins 1996). For example, Hong Kong and Singapore started their fertility transitions when they had much higher levels of 
income, literacy, and urbanization than Bangladesh, where fertility decline began when the country was still largely rural and agricultural. In sum, these empirical studies failed to find the tight link between development indicators and fertility expected from conventional theories. Although most traditional societies do have high fertility when compared to modern industrial societies, the transition itself is poorly predicted by customary quantitative measures of development.

These unexpected findings required a revision of thinking about the fertility transition and led to the introduction of theories of the "diffusion" of innovations. Diffusion refers to the process by which new technologies, ideas, behaviors, and attitudes spread within a population through a variety of mechanisms (e.g., social networks, opinion leaders, media). This spread is most rapid within linguistically and culturally homogeneous populations and is often largely independent of social and economic changes. In particular, the diffusion of information about methods of birth control is now considered an important mechanism of fertility change. In addition, new ideas about the costs and benefits of children that may lead to a smaller desired family size are also subject to diffusion processes (e.g., Cleland 2001; Cleland and Wilson 1987; Casterline 2001a, 2001b; Hornik and McAnany 2001; Knodel and van de Walle 1979; Kohler 2001; Montgomery and Casterline 1993, 1996; Retherford and Palmore 1983; Rogers 1973, 1983; Watkins 1987).

Conventional demographic and economic theories emphasize the demanddriven nature of reproductive change, thus leaving little or no role for family planning programs (Pritchett 1994). In contrast, the now widely accepted revisions and elaborations of these theories assign crucial roles to the cost of birth control and to diffusion mechanisms. As a result, these revisions provide a strong rationale for policy intervention. Family planning programs can accelerate fertility transitions by reducing the various costs of contraception and by providing information that can alter parents' evaluation of the costs and benefits of children (see bottom part of Figure 2.1). We now examine these issues in greater detail.

\section{Obstacles to the use of contraception}

A wide range of social, health, and economic factors pose barriers to women (and men) who wish to practice contraception (Asturias de Barrios et al. 1998; Bongaarts and Bruce 1995; Cleland et al. 2006; Casterline and Sinding 2000; Casterline, Perez, and Biddlecom 1997; Casterline, Sathar, and Haque 2001; El-Zanaty et al. 1999; Mishra et al. 1999; Stash 1999; Viswanathan, Godfrey, and Yinger 1998; Westoff and Bankole 1995). Following are the main obstacles identified by this research. 


\section{Lack of knowledge}

Ignorance about modern contraception is by definition an absolute barrier to adoption of these methods. In order to use a modern method, women must be aware of its existence and they must know how to use the method and where to obtain supplies. Knowledge of at least one modern method is widespread in Asia and Latin America, but less so in sub-Saharan Africa (Westoff and Bankole 1995). Knowledge of multiple methods is often limited and incomplete, and erroneous information about where to obtain methods and how to use them is common (Robey, Ross, and Bhushan 1996).

\section{Availability of family planning methods}

A couple must have access to a contraceptive method in order to adopt it. For traditional methods such as abstinence and withdrawal no source is required; and for permanent methods such as sterilization, one-time access suffices. But for widely used modern methods such as injectables and the pill, a dependable source within a reasonable distance is needed. Supply chains have been built in many countries that may include hospitals, health and family planning centers, work-based clinics, mobile medical and paramedical units, communitybased distribution, and commercial outlets (subsidized or not). The density of these access points varies widely between and within countries. Access is most difficult in rural communities in countries where family planning programs are absent or weak and is particularly problematic when purdah restricts women's mobility. The most effective programs have minimized access obstacles by training female outreach workers who visit women in their homes.

While physical proximity is important, services must be of adequate quality and reasonably priced. The direct cost of commodities (e.g., pills, condoms, IUDs), transportation, and provider fees for contraceptives and health care services can be substantial. As a result, poor women are often unable to afford modern methods without the subsidies provided by family planning programs.

\section{Health concerns and side effects}

Health concerns and fear of side effects are two of the most commonly expressed reasons for non-use and for discontinued use of contraception. Choosing a method often involves weighing a variety of drawbacks to find the method that is least objectionable. The most serious health effects are cardiovascular complications of the pill; pelvic inflammatory disease, uterine perforation, and anemia for the IUD; and various infections associated with sterilization and other methods. These complications are rare if users are well informed and service 
providers are well trained and have access to appropriate equipment and drugs. In addition, significant physiological effects of contraceptive methods (e.g., nausea, headache, weight gain, menstrual changes) can influence women's choices.

Still other drawbacks play potentially significant roles in the decision to adopt a method. For example, manipulation of genitals or interruption of intercourse is required for the use of the condom, diaphragm, cap, sponge, and spermicides. Many women dislike the physical exams (often performed by male providers) required for IUD insertions and for fitting the diaphragm and caps. Others fear the surgical procedures associated with sterilization and implants. Loss of potency is a concern for some men who might otherwise consider a vasectomy. Moreover, many health concerns are based on misinformation. For example, a major fear in Africa is that the use of a hormonal method will permanently impair future fertility.

\section{Objections from husbands or other family members}

For many married women, objections to family planning from their husbands or partners is a sufficient reason not to practice contraception despite their desire to do so. Other family members (e.g., parents or parents-in-law) or neighbors may also discourage the practice of contraception. Reasons for these objections may include the desire for more children than the women herself wants, costs of contraceptive supply and associated health care, concerns about side effects, and moral or religious beliefs. In traditional societies, family limitation and negotiation over sexual matters may not be considered respectable subjects, and it is not uncommon for husbands and wives to avoid discussion of contraception or sexual matters. As a result, women's perceptions of husbands' views may be incorrect and wives may report husbands' objections that the men do not confirm when interviewed separately.

\section{Concerns about moral and social acceptability}

In nearly every society the introduction of the idea of birth control and the methods used to achieve it meet resistance from political, church, and medical leaders on a number of grounds: usurping the divine will, encouragement of promiscuity leading to a breakdown of family life, and a threat to individual health and national vitality (Cleland 2001). Such forms of resistance were common in Europe in the late nineteenth century, and resistance is also common in many contemporary developing countries. Sometimes the opposition is embodied in formal religious doctrine (e.g., the Roman Catholic ban on artificial methods and the Islamic opposition to sterilization). More often, hostility or 
ambivalence is less formalized but may be no less deeply felt. Too close an identification of the family planning program with foreign donors can lead to accusations of intended genocide.

\section{Estimates of unsatisfied demand for contraception}

These obstacles to contraceptive use lead some women to forgo use despite their intention not to become pregnant. Estimates of the demand for contraception and the degree to which it is satisfied can be derived from responses to questions about fertility preferences and the use of contraception in the Demographic and Health Surveys (Westoff and Ochoa 1991; Westoff and Bankole 1995). The proportion of married women who are fecund and do not wish to become pregnant soon are assumed to have a "demand" for contraception. Some of these women are practicing contraception and some are not. The former are current users whose need for a method of contraception is considered to have been met (even though they may not be satisfied with their current method); the latter are considered to have an unmet need for contraception: demand = current use + unmet need. Estimates of demand, current use, and unmet need include both women who state that they want no children in the near term ("spacers") and women who have reached their desired family size ("limiters").

Estimates for these measures are available from the most recent DHS survey for 34 countries in sub-Saharan Africa, 13 countries in Asia/Middle East/North Africa, and ten countries in Latin America. Regional averages (unweighted) of these country-specific estimates are provided in Figure 2.2. Sub-Saharan Africa has the lowest demand and the lowest contraceptive use while having the highest unmet need (26 percent). In fact, the unmet need in this region exceeds contraceptive use and, as a result, the proportion of demand that is satisfied is only 45 percent. In contrast, on average more than 70 percent of women in the other regions want to avoid pregnancy, and three-quarters of them are using some method of contraception. The average unmet need is 17 percent in Asian/ Middle Eastern/North African countries and 18 percent in Latin America.

Further insight into the variation among countries can be gained by plotting demand and use according to desired family size (see Figure 2.3). Desired family size ranges from 8.9 children in Chad to 2.2 in Colombia, and the corresponding levels of demand and use are 24 and 3 percent for Chad and 86 and 78 percent for Colombia. As expected, demand rises as desired family size declines, and this relationship is approximately linear. However, the relationship between desired family size and use is non-linear. As a result, the gap between demand and use (i.e., unmet 


\section{FIGURE 2.2}

Demand for and current use of contraception by region, 57 countries

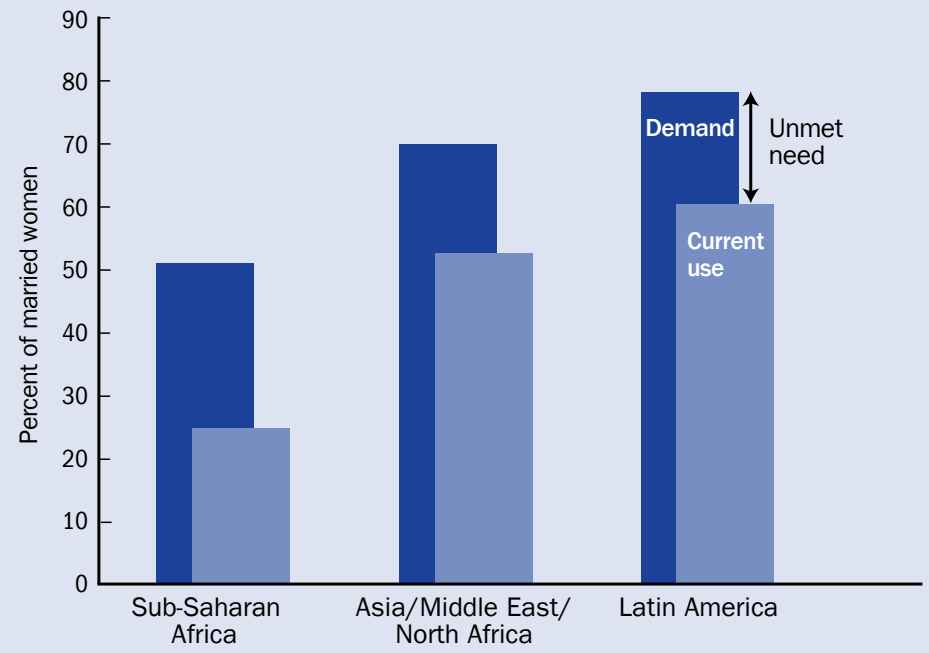

SOURCE: DHS country reports.

\section{FIGURE 2.3}

Demand for and current use of contraception, 57 countries

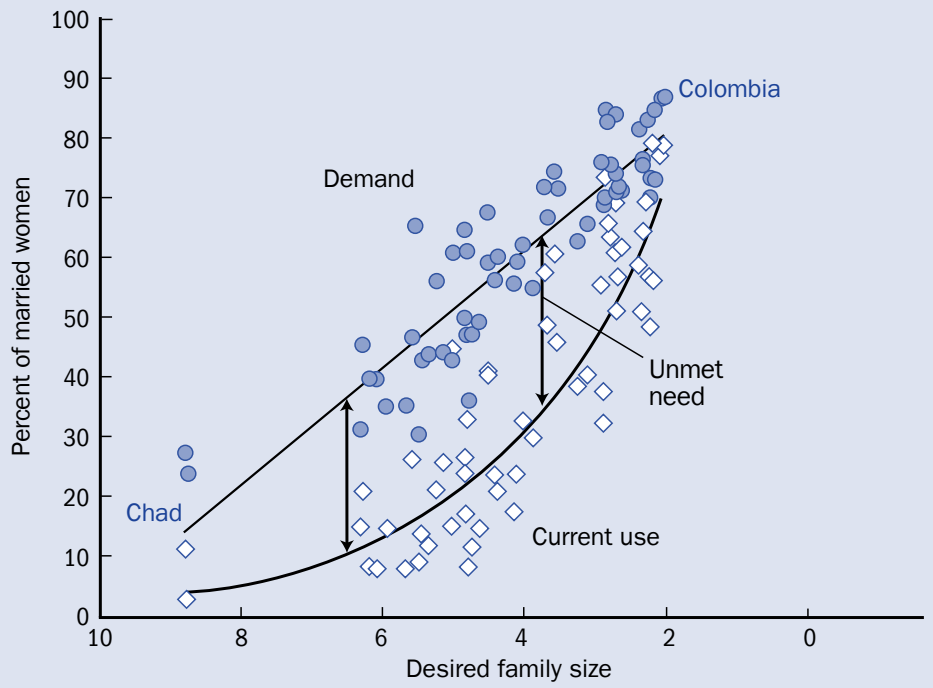

SOURCE: DHS country reports. 
need) is smallest at the highest and lowest levels of desired family size and largest in between. The explanation for this pattern is as follows. In countries with very high desired family size, demand for contraception is low. Even if only a small proportion of this low demand is satisfied, the resulting unmet need is low in absolute terms. At intermediate levels of desired family size, countries often experience rising demand, but use has not kept pace with this demand (because barriers remain substantial). This results in a high level of unmet need. Finally, more-developed countries tend to have low desired family size and high demand, and obstacles to family planning have declined, thus yielding relatively low unmet need.

Most countries have similar patterns of use, demand, and unmet need over time: unmet need can rise early in the fertility transition but it generally declines as countries reach the end of the transition. These trends imply that, in countries with intermediate or high demand, contraceptive use tends to rise faster over time than demand as the satisfaction of demand increases (Feyisetan and Casterline 2000).

Differences in satisfaction of demand for contraception are also found among socioeconomic groups within countries. To illustrate, Figure 2.4 plots the percent of demand in a given region that is satisfied according to house-

\section{FIGURE 2.4}

Percent of contraceptive demand that is satisfied, by wealth quintile

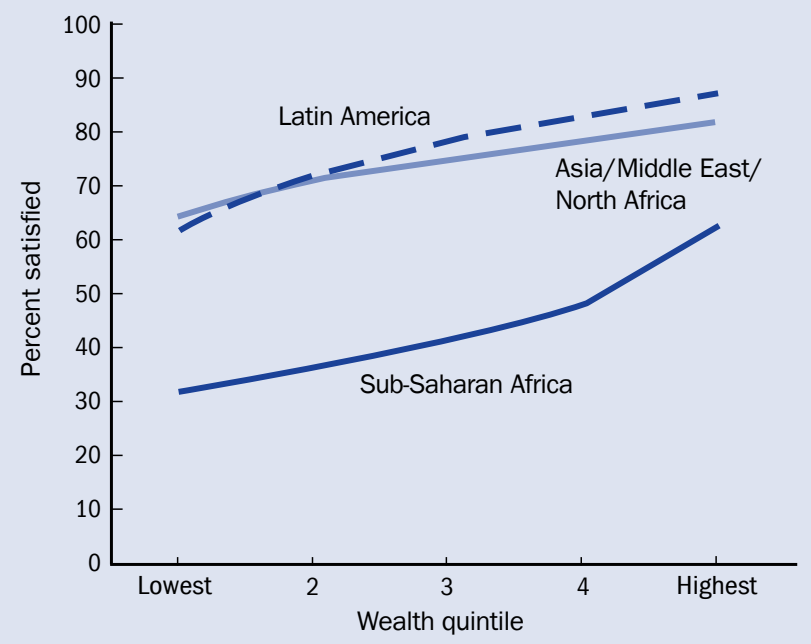


hold wealth quintile (regional estimates are unweighted averages of country estimates). Within each region the percent satisfied rises with increased wealth. Sub-Saharan Africa has much lower levels of satisfaction of demand than Latin America and Asia/Middle East/North Africa in all wealth quintiles.

\section{Unwanted fertility}

An unmet need for contraception inevitably results in unintended pregnancies. An estimated 40 percent of all pregnancies in the developing world are unintended (Singh et al. 2009). These unintended pregnancies lead to three distinct outcomes (ignoring a small number of miscarriages): induced abortion, mistimed births among women who have not yet reached their desired family size, and unwanted births among women who want no more children. Here we limit our discussion to unwanted childbearing.

In DHS surveys estimates of the wanted status of births are obtained by dividing observed births into those that occur before and after women's desired family size is reached; the former are considered wanted (even though some may be mistimed), the latter unwanted. Estimates of wanted and unwanted fertility are available from DHS surveys in 63 countries. These results are sum-

\section{FIGURE 2.5}

Wanted and unwanted components of total fertility

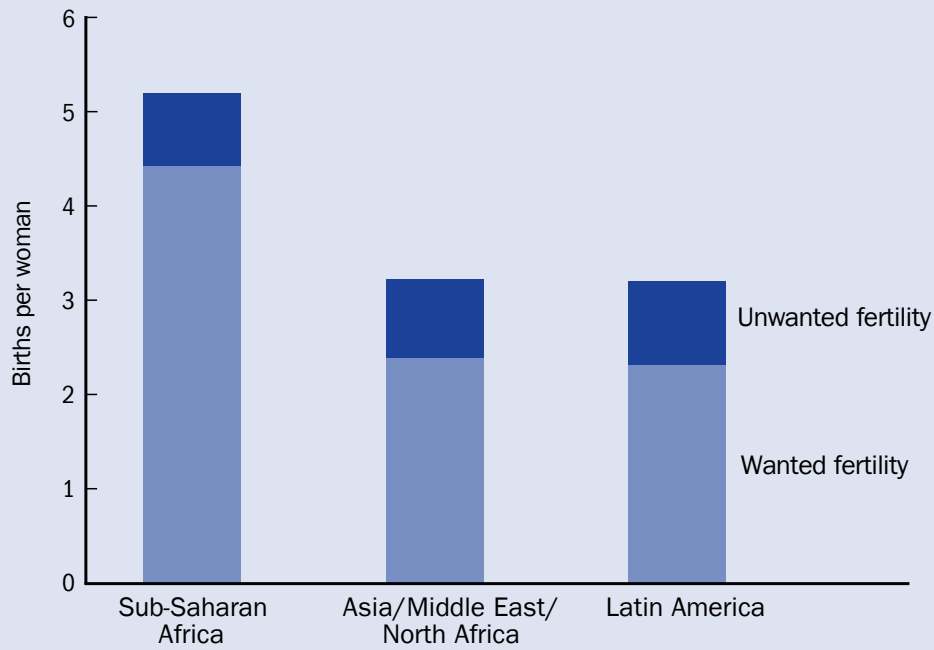

SOURCE: DHS country reports. 
marized in Figure 2.5, which presents (unweighted) regional averages. Average wanted fertility ranges from 4.4 in sub-Saharan Africa to 2.4 in Asia/Middle East/North Africa and 2.3 in Latin America. Average unwanted fertility varies little by region: 0.8 in sub-Saharan Africa and in Asia/Middle East/North Africa and 0.9 in Latin America.

Insight into the factors determining levels and trends in unwanted fertility is provided in Figure 2.6, which plots total fertility and its wanted and unwanted components by desired family size for individual countries. As expected, the total fertility rate declines as desired family size declines. The reason for this trend is clear: women use contraception to bring their actual childbearing in line with their preferences. The approximate number of births averted by contraception can be estimated as the difference between potential fertility (around 7-8 births per woman) and observed fertility. In countries with high desired fertility, actual fertility is also high and very few births are averted by contraception. In contrast, when desired family size is low, many births are averted by contraception. In fact, women in these societies use contraception during most of their reproductive lives because they can achieve their desired family size in a few years.

\section{FIGURE 2.6}

Total fertility and its wanted and unwanted components, according to desired family size

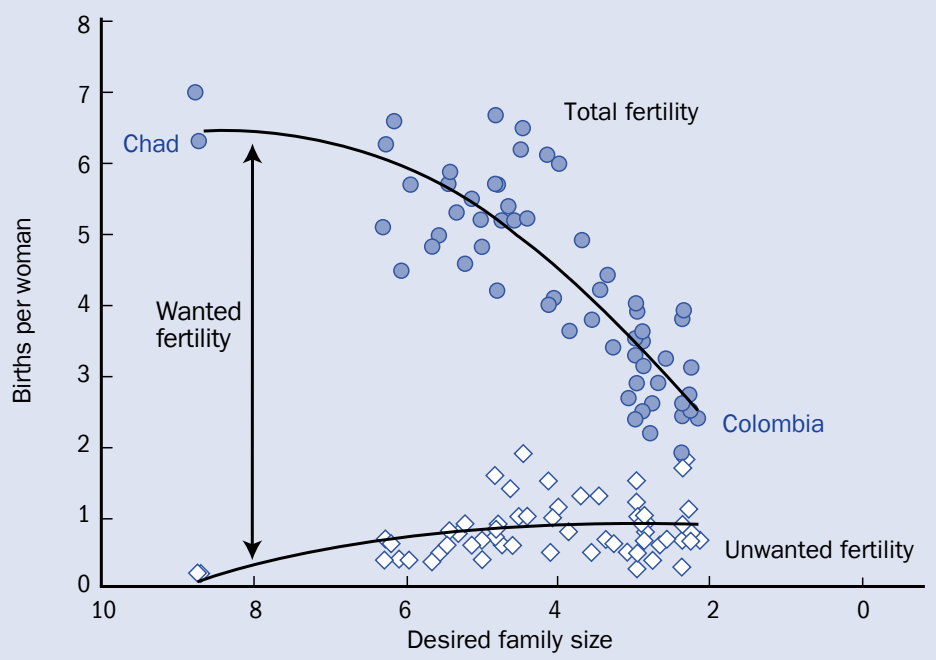

SOURCE: DHS country reports. 
As shown Figure 2.6, unwanted fertility is very low in countries with high desired family size, while at intermediate levels of desired family size unwanted fertility approaches two births per women in countries such as Uganda where family planning programs are ineffective. In the last stages of the fertility transition, unwanted fertility tends to decline again. This inverted $U$-shaped pattern of unwanted fertility, evident in the cross-sectional data in Figure 2.6, is also often found in trends over time in unwanted fertility in individual countries.

These findings lead to a paradox. At the onset of the fertility transition, the practice of birth control aimed at reducing unwanted pregnancies rises rapidly, while simultaneously unwanted childbearing in many countries increases as well. The cause of this initial increase in unwanted fertility is a decline in desired family size over time that leads to a rise in the proportion of women who are at risk of having unwanted pregnancies. In pre-transitional societies, relatively few women are exposed to this risk because they want large numbers of children and few attempt to stop childbearing. Nearly all of the fecund childbearing years are needed to achieve the large families desired, and little reproductive time is left to bear unwanted children. As societies develop, however, desired family size declines, resulting in a corresponding rise in the proportion of women who wish to stop childbearing. Women complete their desired childbearing at increasingly earlier ages, thus leaving rising proportions of the potential childbearing years during which unwanted pregnancies can occur. At the end of the transition, desired family size is typically near two children. Therefore, except for the few years required to have two children, sexually active women are at risk of unwanted childbearing for a large portion of their reproductive lives. If women in such societies do not practice effective birth control, they can have several unwanted births over their lifetimes.

Unwanted fertility also varies among socioeconomic groups within countries. Unwanted childbearing is more common among poor, rural, and uneducated women than among their well-off, urban, and educated counterparts. An analysis of unwanted fertility by household wealth in 41 developing countries by Gillespie et al. (2007) found that unwanted fertility was more than two times higher in the poorest quintile than in the richest quintile (1.2 vs. 0.5 births per woman; see Figure 2.7). This disparity is much smaller in countries with strong family planning programs. For example, in Indonesia, where the family planning program has been strong for many decades, unwanted fertility is very low ( 0.4 on average) and the difference between the highest and lowest quintiles is just 0.1 births per woman. In contrast in the Philippines, with a weak program, unwanted fertility averages 1.0 birth per woman and the wealth differentials between the poorest and richest quintiles are much larger (2.2 vs. 0.3$)$. 


\section{FIGURE 2.7}

Unwanted fertility by wealth quintile

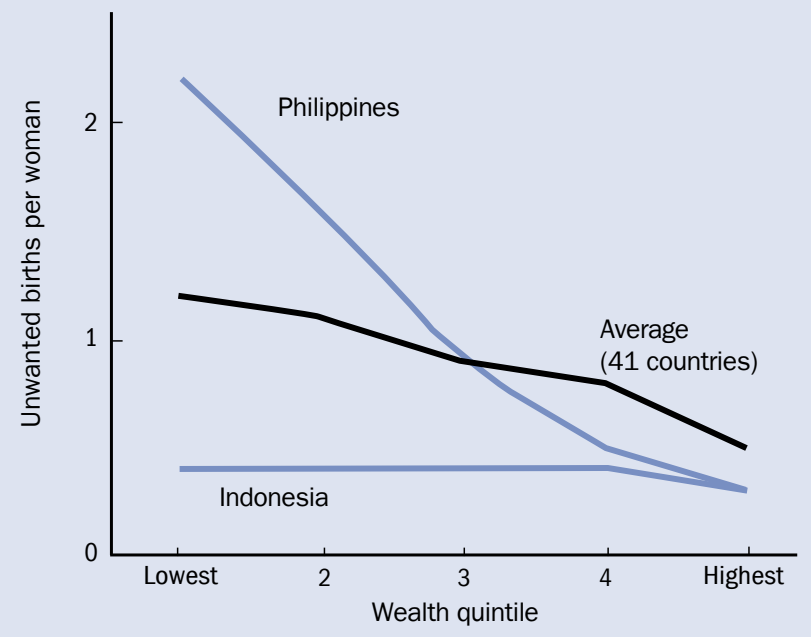

SOURCE: Gillespie et al. (2007).

\section{The impact of family planning programs on desired family size}

As a country develops, the cost of children rises and their benefits to parents decline, leading parents to want fewer children. It is therefore not surprising that desired family size is inversely related to standard socioeconomic indicators. Figure 2.8, which plots desired family size by GDP per capita for 62 countries, shows a clear inverse relationship. Countries in sub-Saharan Africa are plotted separately from those in other continents. The comparison indicates that desired family sizes in Africa are higher than elsewhere in the developing world after controlling for GDP per capita (similar results hold for other development indicators). This result is expected from earlier research which demonstrated that African societies are particularly pronatalist as a consequence of certain cultural conditions on this continent (Caldwell and Caldwell 1988).

While these associations between desired family size and development indicators are expected, there is much unexplained variance. In particular, countries can undergo declines in fertility preferences that are largely unrelated to development (Robinson and Cleland 1992). For example, Kenya's desired family size dropped from 7.1 to 4.4 in just over a decade between 1978 and 1989. Kenya's trajectory, plotted separately in Figure 2.8, is much more rapid than expected 


\section{FIGURE 2.8}

Desired family size by GDP per capita

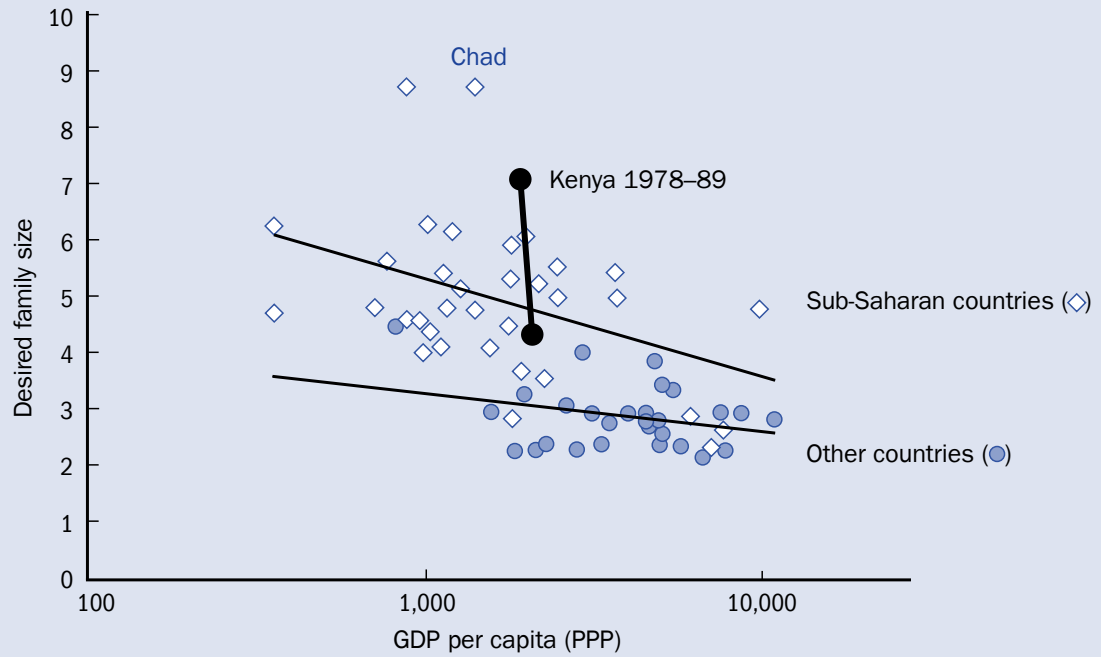

SOURCE: DHS country reports.

from the rise in GDP per capita (similar results hold for other development indicators). A more plausible explanation for this decline is Kenya's family planning program, which was well funded and organized in the late 1970s and 1980s.

Several mechanisms can potentially explain a change in desired family size independent of socioeconomic conditions:

1) Diffusion of ideas about the benefits of smaller families. As noted above, the rapid adoption of birth control in traditional societies is likely explained in part by diffusion mechanisms. But the diffusion of ideas can apply to many behaviors, attitudes, or values, including desired family size. Once the means of birth control become socially acceptable, it is natural to consider a wider range of options regarding family size. Discussion of the cost and benefits of children among family members, neighbors, and in social networks can lead to a reevaluation of desired family size.

2) Media messages through newspapers, radio, and television bring information about modern lifestyles and values from developed countries to the homes of rural and isolated societies. This knowledge about how others live and about the availability of consumer goods and lifestyles can lead to a reassessment of fertility preferences. Several studies of the impact of mass media 
have examined this link (Faria and Potter 1999; Hornik and McAnany 2001; Westoff 1999; Westoff and Bankole 1997; Westoff and Rodriguez 1995).

3) Information, education, and communication (IEC) campaigns by family planning programs are generally aimed at providing women with information about birth control methods and where and how to obtain them. This information increases the social acceptability of birth control and dispels unfounded rumors or negative perceptions of methods. IEC messages often also discuss the advantages of small families. Such messages, especially on radio and television, appear to have an effect on fertility preferences (Bongaarts 2011; Cleland et al. 2006; Hornik and McAnany 2001; Westoff 1999; Westoff and Bankole 1997; Westoff and Rodriguez 1995). We discuss these effects and their impact in detail in Chapter 4.

\section{Critiques of family planning programs}

Critics have argued that investments in family planning programs are not effective (e.g., Pritchett 1994). The evidence presented above sheds light on the critics' main objections:

1) "If improved family planning programs were driving fertility declines, they should be accompanied by a reduction in excess fertility. This is not the case" (Pritchett 1994: 34). This argument ignores the rise in the exposure to the risk of unwanted pregnancies that occurs as desired family size declines (Bongaarts 1994, 1997a,b). In the absence of contraception, a decline in desired family size would be accompanied by a roughly equivalent rise in unwanted/excess births. In reality, such huge increases in unwanted fertility are not observed because women practice contraception, but unwanted births nevertheless occur because of the many obstacles to the use of contraception and because of contraceptive failure. Family planning programs reduce but do not eliminate these obstacles. As a result, a substantial impact of family planning programs is consistent with a non-declining or even a rising level of unwanted fertility in the early phases of the fertility transition.

2) 'The level of 'unmet need' and other measures of contraceptive access are not empirically important determinants of fertility" (Pritchett 1994: 30) and "fertility is inelastic with respect to contraceptive costs because contraceptive costs are so small in comparison to the costs of children" (ibid.: 3). This view ignores the abundant evidence for the substantial costs of practicing contraception reviewed above and the existence of large numbers of unintended pregnancies. The total number of unintended pregnancies in the developing world is estimated at 75 million per year, of which 35 million end in induced abortion (Singh et al. 2009). 
It is unfortunate that the critics' arguments have encouraged some governments, donors, and international development organizations to assign low priority to family planning programs.

\section{The fertility impact of family planning programs}

The preceding discussion focused on the mechanisms through which family planning programs can reduce fertility. Estimates of the size of their fertility effect require the estimation of an unobservable quantity: the level of fertility that would have been observed in a population in the absence of a family planning program. Subtracting observed fertility from this estimate yields the impact. The literature on this topic provides two general approaches to obtain such estimates.

\section{Controlled experiments}

This is the gold standard for evaluating interventions, but very few large-scale controlled experiments have been conducted to assess family planning programs because they are expensive and take a long time to complete. The largest and most influential of these experiments - the Family Planning and Health Services Project (FPHSP)—started in the late 1970s in Matlab, Bangladesh. At that time Bangladesh was one of the poorest and most highly agricultural countries in the world, and there was widespread skepticism that family planning would be accepted in such a traditional society.

The FPHSP divided the Matlab district (population of 173,000 in 1977) into experimental and control areas of approximately equal size. The control area received the same services as the rest of the country, while in the experimental area comprehensive high-quality family planning services were provided aimed at reducing the costs (monetary, social, psychological, and health) of adopting contraception. The experimental area provided free services and supplies of a range of methods (pills, condoms, injectables, IUD, and sterilization), home visits by well-educated female family planning workers, regular follow-up to address health concerns, comprehensive multimedia communication, and menstrual regulation services. Outreach to husbands, bari leaders, and religious leaders addressed potential social and familial objections from men (Cleland et al. 1994).

The impact of these intensive services on reproductive behavior is summarized in Figures 2.9 and 2.10. Within a year from the start of the program, the proportion of women using contraception in the experimental area rose from 


\section{FIGURE 2.9}

Impact on contraceptive use of the family planning experiment in Matlab, Bangladesh

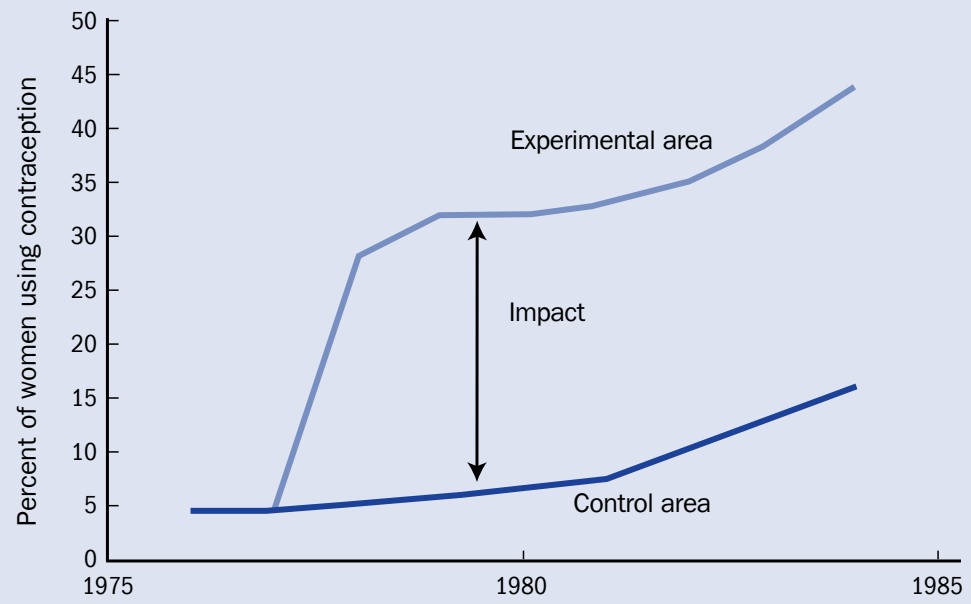

SOURCE: Cleland et al. (1994).

\section{FIGURE 2.10}

Impact on fertility of the family planning experiment in Matlab, Bangladesh

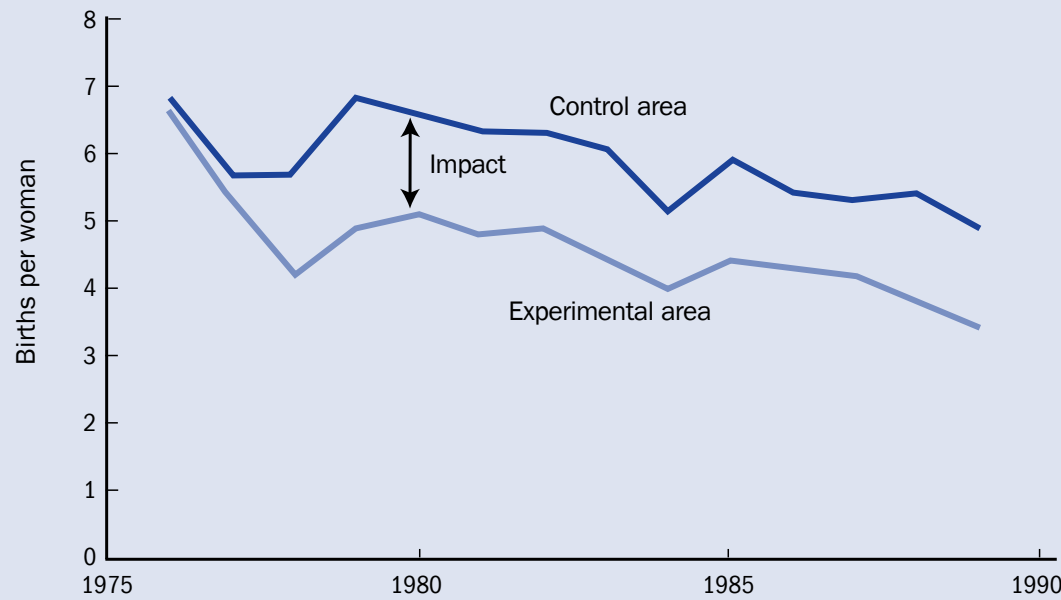


less than 5 percent to 28 percent. In contrast, very little change occurred in the control area or in the rest of Bangladesh during the first few years. The rise in contraceptive prevalence in the experimental area led to a decline in fertility to about 1.5 births per woman below that in the control area (see Figure 2.10). While the impact of the FPHSP on fertility and contraceptive use is clear-cut, the experimental and control areas saw similar declines in fertility preferences (Freedman 1997; Koenig et al. 1987). The likely explanation for this finding is that the IEC messages broadcast by the national family planning program reached and affected the control and experimental areas equally.

The Matlab experiment demonstrated that family planning programs can succeed even in traditional societies. The success of this program led the government of Bangladesh to adopt the Matlab model as its national family planning strategy.

\section{Natural experiments}

Consider two countries with similar social, economic, cultural, and religious characteristics and suppose that one of these countries has implemented a family planning program and the other has not. In this natural experiment we can observe the difference in fertility trends between the two countries and attribute any difference largely to the existence of the family planning program in the "experimental" country. Unfortunately, it is not possible to rule out a role for unobserved confounding factors, so the results from such natural experiments are not as robust as those from controlled experiments. Nevertheless these comparisons are instructive, and we present three such examples.

Bangladesh and Pakistan. Bangladesh and Pakistan were united as one country from 1947 until Bangladesh was established after a civil war in 1971. As a result, these two populations still have much in common and levels of development are broadly similar, even though Pakistan scores slightly higher on a number of development indicators. Figure 2.11 plots the countries' trends in fertility from 1975 to 2005 . In $1975-80$ the two countries had nearly the same high fertility of 6.8 births per woman, but trends diverged in subsequent decades. By the late 1990s Bangladesh's fertility had declined to 3.3 births per woman while in Pakistan fertility still stood at 5.0, a difference of 1.7 births per woman. After 2000 declines continued, with Bangladesh reaching near replacement fertility of 2.3 births per woman in 2011, a remarkably low level for such a poor country (National Institute of Population Research and Training et al. 2012). In contrast, Pakistan's fertility remained higher at 4.1 births per woman in 2006-07 (National Institute of Population Studies 2008). 


\section{FIGURE 2.11}

Trends in fertility in Pakistan and Bangladesh, 1975-2005

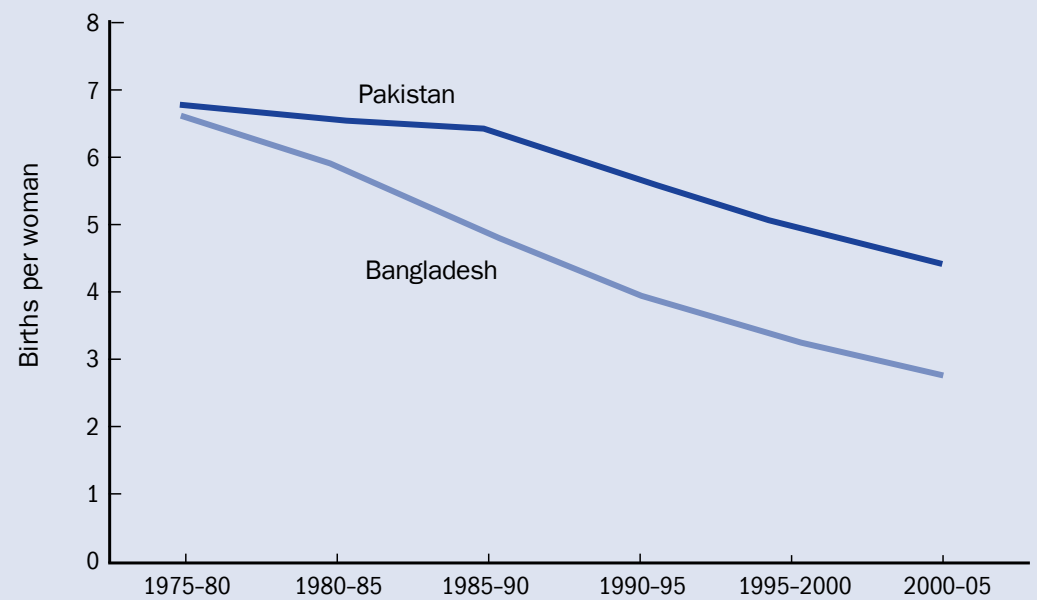

SOURCE: UN (2009)

The contrasting fertility trends in these two countries can plausibly be attributed to differences in their family planning programs. Pakistan's program has been weak and ineffective, lacking government funds and commitment. In contrast, Bangladesh has implemented one of the world's most effective voluntary family planning programs, using the experience and lessons from the Matlab experiment. A unique feature of the program is its staff of literate female workers who advise women and distribute supplies at their doorstep, thus overcoming the barriers posed by purdah (Simmons et al. 1988). In addition, the government implemented a nationwide IEC program. For example, Radio Bangladesh, heard throughout the country, has devoted more than an hour each day to population and family planning issues since the 1980s (Khuda et al. 1999). As a result of these contrasting family planning efforts, levels of unmet need and unwanted fertility are substantially higher in Pakistan than in Bangladesh.

Kenya and Uganda. These neighboring countries in East Africa share a colonial history that has left an imprint on numerous institutions. Levels of development are similar for the two countries. Figure 2.12 plots fertility trends for these two countries from 1975 to 2005. Uganda's fertility remained constant at about 7 births per woman throughout the period. In contrast, Kenya's fertility declined from 7.5 to 5 before stalling in the late 1990s. The difference between the countries reached 1.9 births per woman in the late 1990s. 


\section{FIGURE 2.12}

Trends in fertility in Uganda and Kenya, 1975-2005

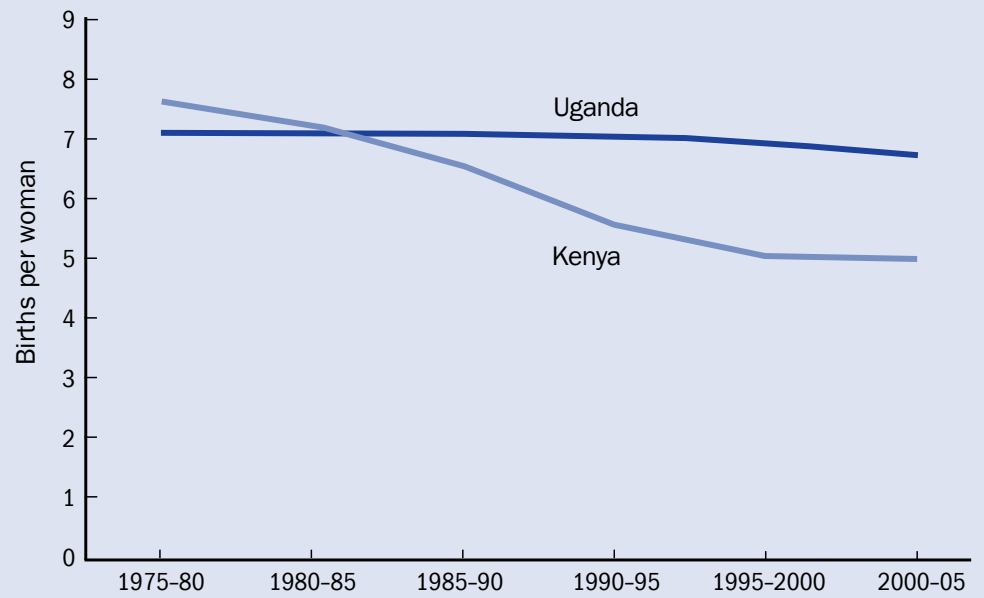

SOURCE: UN (2009)

Uganda's government has made very little investment in family planning (a decision partly based on the fear of high AIDS mortality when the epidemic spread in the 1980s). In contrast, Kenya in the 1960s was one of the first countries in Africa to develop a population policy and establish a family planning program. Although the program was initially weak, government support increased over time and Kenya received substantial funding and technical support from bilateral and multilateral donors. The program included large-scale communitybased distribution, which provided access to low-cost contraceptive services to rural clients; and it implemented nationwide IEC campaigns advocating small families and the use of contraception. After the mid-1990s, however, Kenya's family planning program lost its priority, and the commitment of the government and international donors declined substantially. This neglect is one of the main reasons for the stalling of fertility near 5 births per woman in recent years (Askew et al. 2009).

Jordan and Iran. These two West Asian populations share many cultural and social characteristics, and their development indicators are nearly identical. The countries also had similar fertility levels in the 1980s, but fertility trends diverged sharply in the 1990s; by the end of the 1990s Jordan's fertility was 1.8 births per woman higher than Iran's (see Figure 2.13). Both countries have made major investments in health, and rates of infant and child mortality have dropped 


\section{FIGURE 2.13}

Trends in fertility in Jordan and Iran, 1975-2005

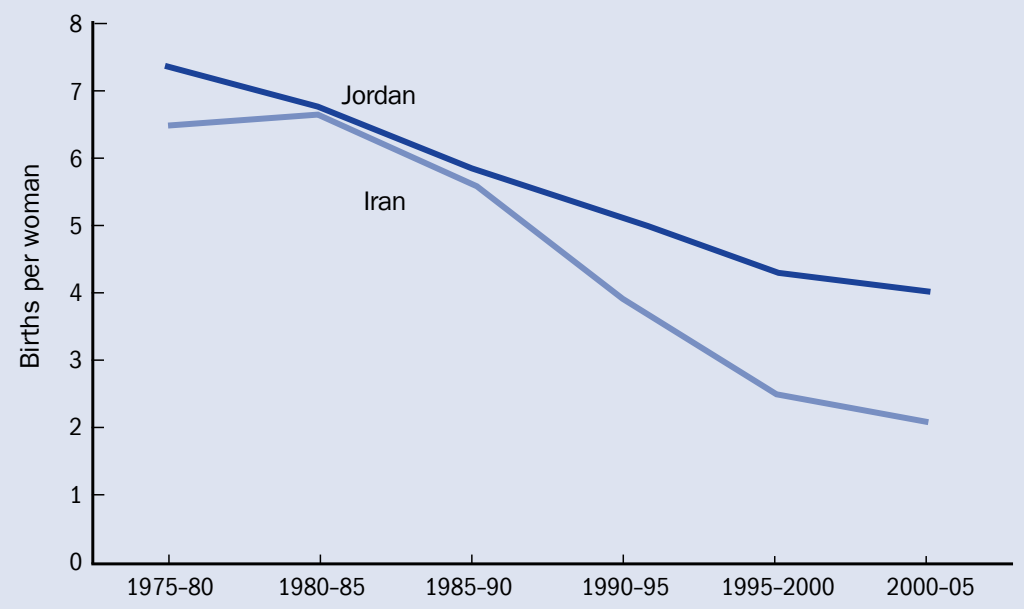

SOURCE: UN (2009).

steeply over recent decades. Family planning has never been a government priority in Jordan, and the same was true in Iran until the late 1980s. In 1989 the Iranian government abruptly reversed course and become a strong supporter of family planning (Roudi-Fahimi 2002). Free contraceptive services were provided throughout the country by an extensive network of village health workers, and a vigorous IEC campaign communicated the benefits of small families. The response was immediate and large. Fertility declined from more than 5 births per woman in the late 1980s to around 2 in 2000. No other country with a population over one million experienced a decline of such magnitude during the 1990s. While it is likely that some fertility change would have occurred in Iran without these new services, the unprecedented pace of the fertility decline argues for a substantial impact of the program.

The findings from these controlled and natural experiments are broadly in agreement: a well-organized family planning program with a substantial IEC component can reduce fertility by approximately 1.5 to 1.9 births per woman. This calculation may slightly underestimate the true impact because family planning services were not entirely absent in the "control" populations examined above. The aggregate impact of past investments in these programs has been substantial, with an estimated 43 percent of the fertility decline in the developing world before 1990 attributable to family planning programs (Bongaarts 1997b). 
Very recent evidence from a few poor African countries confirms that a commitment to family planning in such settings can be successful. Rwanda, the most densely populated country in Africa, is a good example. Rwanda's fertility was one of Africa's highest in the twentieth century, remaining above 6 births per woman until 2005 (DHS). But in the early 2000s the government renewed its lagging commitment to family planning and, with strong support from international donors, sharply increased access to contraceptive methods throughout the country. In addition, the president and other government officials spoke out about the need to reduce fertility, and a country-wide IEC program was implemented. Large changes in reproductive behavior resulted: the use of modern methods of contraception rose from 10 percent in 2005 to 45 percent in 2011 and fertility dropped to 4.6 births per woman (National Institute of Statistics of Rwanda 2012). Rapid change with a renewed investment in family planning programs has also occurred in Ethiopia and Malawi.

\section{Impact on population size}

Any program-induced fertility decline will of course change the future trajectory of population growth. To illustrate the population impact of a change in fertility trends, we compare the high and low variants of the UN population projections for sub-Saharan Africa (UN 2009). The only difference between these two projection variants is the fertility level assumed in the future: the high variant exceeds the low variant by 1 birth per woman. According to the high variant, the population of sub-Saharan Africa is expected to more than double in size from 0.86 billion in 2010 to 1.98 billion in 2050 (see Figure 2.14) (this projection takes into account the large impact of the AIDS epidemic). This trajectory could well become reality if no significant investments in family planning are made, especially because stalling of fertility decline seems to have become increasingly prevalent in this continent (Bongaarts 2008). The UN's low variant projection estimates a population of 1.54 billion in 2050. With substantial new investments in family planning, the low variant could probably be achieved. If so, the population of sub-Saharan Africa in 2050 would be nearly half a billion lower than projected in the UN's high variant.

It is important to note that any delay in fertility decline will result in substantial additional future population growth. For example, Pakistan's decision not to promote family planning in the 1970s and 1980s led to much more rapid population growth than in Bangladesh. In 1980, Pakistan's population was 8 million smaller than Bangladesh's, but by 2050 its population is projected to be 50 percent larger than Bangladesh's (335 vs. 222 million) (UN 2009). When popula- 


\section{FIGURE 2.14}

UN high and low variant population projections for sub-Saharan Africa

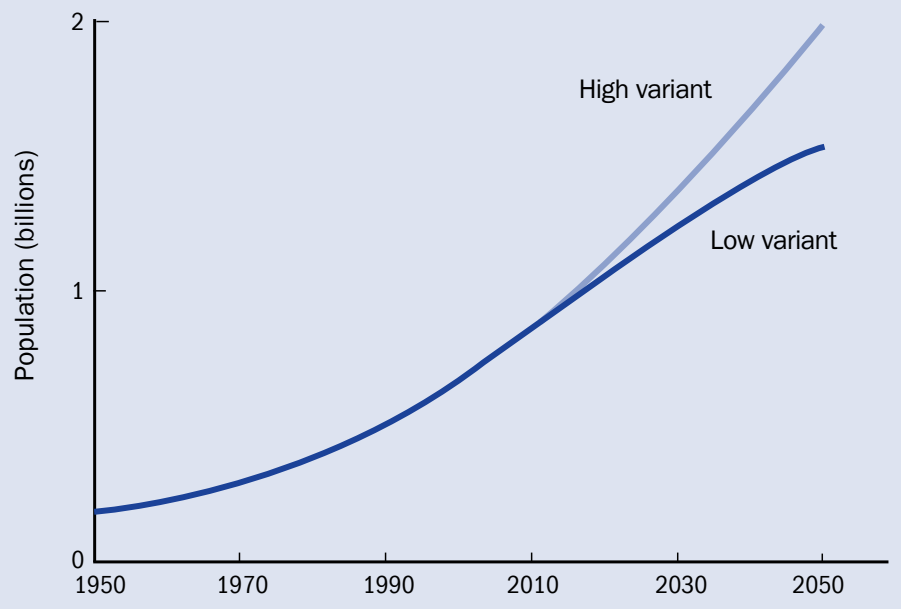

SOURCE: UN (2009)

tions are growing rapidly, delays in the implementation of family planning programs and in the fertility decline associated with them have major implications for future demographic trends.

\section{Conclusion}

The choice of voluntary family planning programs as the principal policy instrument for reducing fertility is based largely on the documentation of a considerable unsatisfied demand for contraception. When questioned in surveys, large proportions of married women in the developing world report that they do not want to become pregnant soon. A substantial proportion of these women (more than half in some countries) are not protected from the risk of pregnancy by practicing effective contraception and, as a result, unintended pregnancies are common. Family planning programs aim to reduce the various social, economic, and health obstacles to the use of contraception, thus reducing unwanted fertility. In addition, IEC messages can contribute to declines in desired family size. The evidence for these conclusions has been persuasive to many governments that have successfully conducted these programs. 



\section{CHAPTER 3}

FAMILY PLANNING SERVICES AND THE STRENGTHENING OF HEALTH SYSTEMS

amily planning services in developing countries have undergone a substantial evolution since the first programs, building on the pioneering work of Marie Stopes in the United Kingdom and Margaret Sanger in the United States, were launched in the 1950s. This evolution has included changes in approaches to meeting the reproductive needs of women and diverse responses to the issues of rights, responsibilities, and the distribution of programmatic benefits.

A fundamental part of this evolution has been the changing content of services. In the early 1950s, the contraceptive products available were limited to condoms and barrier methods such as the diaphragm. In many countries the legal system restricted both the distribution of these methods and the content of informational materials available to women and men. Since that time the World Health Organization has identified family planning as a critical element of reproductive health and defined reproductive health as the state of physical, mental, and social well-being related to the reproductive system in all stages of life. This definition has been refined to include the health of women and men in the context of a safe and satisfying sex life and as related to pregnancy, abortion, childbirth, and child survival.

With this broad conceptualization has come a host of specific issues that family planning programs have been asked to address. These include the need for education, counseling, and contraception for sexually active young people, family planning for women and men with disabilities, treatment for infertility, safe abortion where it is legal and postabortion care wherever abortion is conducted, reproductive health needs of peri-menopausal women and those requiring hysterectomies, and advocacy related to eliminating practices such as female genital mutilation (FGM) and gender-based and sexual violence. This vast range of issues emerges in part from the country settings in which services are provided (e.g., FGM is practiced in specific cultural contexts) and from the specific needs of the clients whom programs seek to serve (e.g., unmarried youth, who were excluded from early family planning programs). While most of the servic- 
es are targeted to women, men are increasingly included as clients, partners, and opinion leaders. New services have been the slowest to emerge in the area of sexuality and sex education, reflecting the difficulty of speaking frankly about sex and family planning.

The content and development of services have also been an outcome of the prevailing paradigm about how population and family planning should be conceptualized. During the 1970s, when international family planning support was growing rapidly, the prevailing view among policymakers was that family planning leads to lower fertility, slower population growth, and economic development. Following the UN-sponsored International Conference on Population in Mexico City in 1984, a consensus emerged that couples and individuals have the right to decide on the number, timing, and spacing of children and on the means to achieve their reproductive goals-particularly, contraceptive use to space or limit pregnancies, abstinence, and induced abortion where legal.

In 1994 the International Conference on Population and Development in Cairo placed women and reproductive health at the center of policy attention, and the key family planning issues were identified as individual benefits, rights, and choice, and responses to unmet need. In the past decade the health benefits of family planning for mothers and children have been emphasized and extensively documented. In addition, we now have a better understanding of the favorable development and poverty-reducing effects of slower population growth and reduced fertility.

The demand for family planning and other reproductive health services will increase sharply in coming decades as population size and the number of women and men at risk of unwanted pregnancies continue to rise. The need for more effective and less expensive contraceptive methods will also increase as women spend more of their reproductive lives using contraception, and much of the future increase in demand will occur among the poorest segments of the population in most countries. The benefits of family planning for maternal health and economic well-being will remain limited unless services are better focused on the most marginalized populations, who are in need of subsidized services and are unlikely to be served by purely private-sector outlets.

\section{Family planning programs and the health care system}

In the past 50 years, policymakers and program managers have learned a great deal about how to provide family planning services. The overarching strategy 
for family planning services is to offer clients easy access to a wide range of affordable contraceptive methods through multiple service delivery channels in a good-quality, reliable fashion. This strategy has been accompanied by an increased appreciation of the need to strengthen public-sector health systems and health systems operating in partnership with the public sector. Policymakers now have a much better understanding of the infrastructure requirements of programs and the needs of providers and clients to ensure access for all, an acceptable level of quality, and good governance.

The provision of primary health care in most developing countries is highly fragmented both by design and by clients' preferences. For example, in markets as diverse as Cambodia, China, Egypt, India, and Kenya, more than half of individuals' health expenditures are in the private sector, and in no case do health expenditures in the public sector reach 40 percent of the total. The private sector may include medical practitioners, nursing services, pharmacies, and even unqualified health practitioners. Individuals often prefer one sector over another for reasons of convenience, cost, or perceived quality.

Family planning providers, whether public, private commercial, NGO, or donor-financed social marketing, are integrated within one "market," segmented by clients' ability and willingness to pay. Policymakers should expand this market and increase its efficiency through better targeting of public, private, and NGO/social marketing subsidies to the poor and by allowing the commercial sector to develop products and services for people who have a greater ability or willingness to pay full cost. In practice this means that public programs would be evaluated on how they benefit the poorest economic groups, while individuals with the ability to pay would have access to a range of privatesector services. For example, a review of program policies and subsidies in Indonesia found that many women with the ability to pay were enjoying heavily subsidized services in urban areas, while the poorest women and those living in remote areas had limited access. In response, the government changed its subsidy strategy and encouraged a private market for family planning services. One result was that family planning services were not adversely affected by the banking crisis during 1997-99, which affected government spending for procurement and services but had a smaller impact on the choices families made about the content of care, specifically family planning services (Gardner and Amaliah 1999).

Family planning services are best understood as an integral part of health systems. Improving their performance should rely on the framework for ac- 
tion proposed by WHO to strengthen health systems (WHO 2010). WHO's framework has six building blocks: leadership and governance, service delivery, human resources, health information, medicines and technologies, and health financing. These blocks are clearly relevant to family planning programs either as stand-alone services or as integrated into more comprehensive health care services.

\section{Leadership and governance}

This building block involves fostering a policy framework for family planning provision, including a commitment to reproductive rights, respect for the decisions of clients about the timing and use of contraception, and ensuring fully informed consent for any procedure clients seek. Leadership may also include a commitment to serve particular segments of the population, such as the poor or marginalized groups, and a willingness and ability to defend policy positions in public forums and to oppose those who seek to limit any of these rights. Governance in this case refers to the commitment to oversee technical, human resource, financial, and ethical issues, including legal requirements by governments and donors. Good governance also requires feedback to community constituents and other stakeholders about the direction and distributive benefits of policy alternatives.

Accountability to ensure universal access to reproductive health information and services has become an increasingly important issue for governments and service delivery systems alike. The engagement of civil society and access to information about priorities are critical for ensuring that accountability initiatives are effective. Examples of efforts to promote accountability include DfID's focus on "value for money" of the United Kingdom's development assistance (DfID 2010), the French development agency's (AFD 2009) call "to hold them to account" for its international investments, and the role of UN treaty monitoring bodies in human rights compliance at the country level. In addition, new accountability strategies include legal cases against governments that violate their own laws on the rights of women to reproductive health services (e.g., see www. reproductiverights.org), and the monitoring of investments in maternal and child health by developing-country governments (e.g., International Budget Partnership 2012). The issue of accountability will become more critical as spending priorities become more explicit, the shortfalls in health financing grow more acute, and information about policy implementation becomes more readily accessible to civil society. 


\section{Service delivery}

This is the heart of family planning programs. Health systems should aim to deliver effective, safe, and high-quality care to those most in need, in a way that is acceptable to the individuals and communities served while also efficient in their use of resources. A key recent trend is the move away from static clinics, particularly in the poorest locations, to a greater array of service delivery options including social marketing, social franchising, pharmacies, community-based distribution of products and services, and even provision at clients' doorstep. Increasingly, private-sector elements are included in service delivery designs, in part because of the need to promote financial sustainability. Because privateand public-sector outlets often compete for the same clientele, health system strengthening should encourage synergy between these sectors.

Another critical issue is equity. Some clients are able to pay for services and therefore have access to a variety of sources, while those who are unable to pay are likely to be poorly served. Well-designed programs can address equity issues, as we illustrate in Figure 3.1. The lines highlight differences in contraceptive use by wealth quintile over time in Bangladesh and Kenya. Bangladesh began family planning with doorstep delivery, ensuring that all couples had

\section{FIGURE 3.1}

Contrast in equity in contraceptive prevalence over time: Bangladesh and Kenya

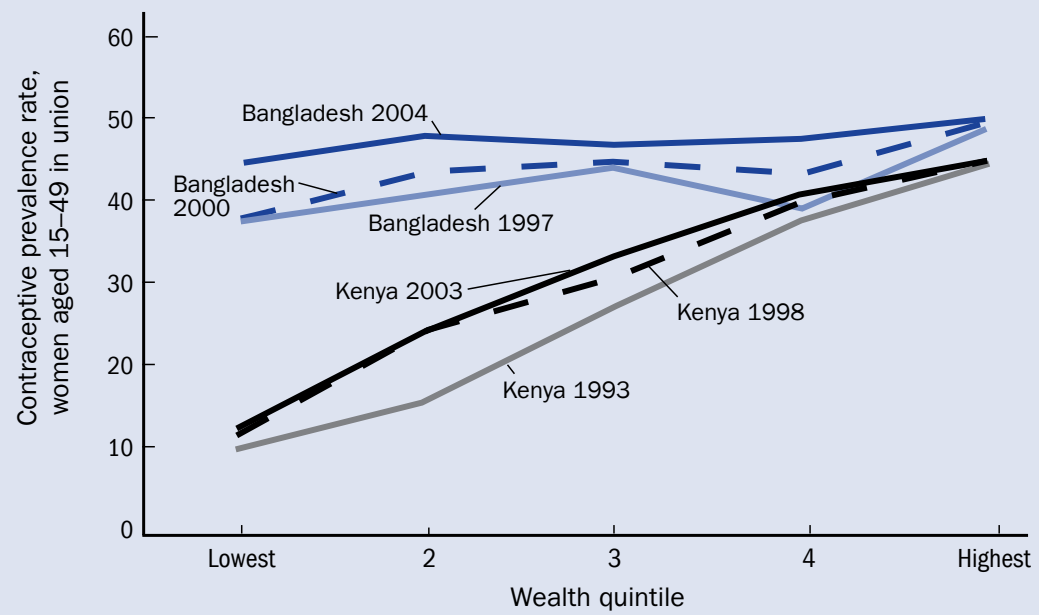

SOURCE: Gwatkin et al. (2007). 
access to family planning services. As a result, the difference in contraceptive use between the highest and lowest quintiles is remarkably small and has decreased further over time. This service strategy has diversified over time to include greater use of social franchising and commercial outlets, without compromising the needs of the poor. In Kenya, on the other hand, differences in contraceptive use between the program's wealthiest and poorest clients have remained large. This gap is attributable to several factors, including an emphasis on clinic-based services and the use of pharmacies, problems with publicsector procurement, and the low priority given to providing information about family planning. Health system strengthening thus requires explicit strategies for reducing inequity in service use.

\section{Human resources}

Human resources should be deployed to achieve the best health outcomes within the given context. The static clinic staffed with physicians is not a feasible model for many of the poorest developing countries, where the ratio of trained physicians to the general population, most of whom are concentrated in urban areas, is often an order of magnitude lower than in industrialized countries. Moreover, few qualified medical practitioners are available for or interested in preventive care, much less in family planning or public health obstetrics. Because these circumstances are common in much of sub-Saharan Africa and rural areas of South Asia, health care tasks are being systematically reviewed with the goal of either task-sharing (e.g., insertion of IUDs by both physicians and nurses) or task-shifting (moving a task from one professional cadre to another). For example, counseling clients about family planning methods is now rarely done by physicians or even primary care nurses, and in high-volume settings it is now often a responsibility of non-medical staff.

In pilot training programs, procedures such as female sterilization and cesarean sections are increasingly becoming the responsibility of non-physician surgical technicians. Given the high turnover of skilled staff within larger institutions and the combination of labor migration of health providers and the difficulty of filling government positions, there is often not enough staff to provide preventive services such as family planning. As a result, task-sharing and task-shifting are now inevitable. Similar changes are occurring in the private sector, where pharmacies are often unregulated and clerks serve more as drug vendors than as qualified counselors. Fortunately, the safety of most contraceptive products sold over the counter is well documented. 


\section{Health information}

Disseminating health information involves producing, analyzing, and communicating evidence on the status of services, performance of service delivery sites and providers, and the relation between demographic trends and the use of health care services. Increasingly, sponsors, funders, and program planners require timely information on the use of services for planning and reporting. Health information within family planning programs may include the results of surveys such as the DHS on contraceptive prevalence and unmet need by population segments, location and distribution of service delivery points, client records, procurement and supply information, volume of services and products provided, and information on the location, skills, and training needs of providers.

In the past decade, paper records have been largely replaced by electronic records or at least electronic consolidated records by site or geographic area. Handheld devices are being used for supervision and logistics management. With the declining cost of information technology, improvements in health information systems are becoming more affordable. Critical needs for the future include data collection strategies for monitoring the effectiveness of health systems that produce desirable results for clients; systems for archiving information in a safe and confidential retrieval system; and ensuring the appropriate use of this information in monitoring and evaluation. Providers spend substantial time on recordkeeping, so reducing the time and increasing the usefulness of this information will have major benefits for service delivery programs.

\section{Medicines and technologies}

Health system strengthening in this area should focus on ensuring equitable access to and availability of acceptable, high-quality contraceptives and related reproductive health products. WHO's Essential Drug List facilitates decisions about what products are appropriate for a given setting and skill level of providers. The most critical issue, beyond that of drug quality, to emerge in the context of countries no longer receiving substantial development assistance is contraceptive security, which combines efficient procurement strategies with efforts to make contraceptives accessible and affordable. Given the large role traditionally played by international donors in procurement, the low levels of funding for contraceptives in the budgets of countries with the greatest unmet need, and the emergence of private health delivery systems, the need to ensure a consistent supply of safe, effective, and affordable products in both the public and private sectors has assumed heightened priority. 


\section{Health financing}

The mobilization of funds is essential to ensure both access to affordable services and incentives for providers to perform at the highest standards possible in a particular context. The costs of family planning services are modest relative to other public health interventions. The cost for one couple-year of protection in developing countries is about $\$ 11.20$, which is less than the cost of one year of school or the cost of providing skilled attendance at birth (Moreland, Smith, and Sharma 2010). As we discussed in Chapter 1, investments in family planning provide a very high return in savings in other development sectors such as health and education. Who pays these costs and how the benefits are distributed between individuals and society are the larger questions in making the case for public financing of family planning services. Users increasingly pay a larger proportion of these service costs, but the question of subsidies remains a critical policy issue, particularly in designing services for the poor and other vulnerable populations (Singh et al. 2009).

\section{New service delivery models}

Greater public acceptance of family planning and wide acknowledgment of individuals' right to decide what method to use have led to an increased variety of delivery systems for providing modern contraception. Beyond hospitals, public clinics, and private physicians, other delivery systems include newer forms of community-based distribution, social marketing, social franchises, and reproductive health vouchers.

Beginning in the 1970s, community-based distribution systems made contraceptive pills and condoms available through trained community members. This approach introduced products to rural areas, helping to overcome both poor access and unmet need for contraception. After the introduction of community-based distribution, communities typically saw dramatic increases in contraceptive acceptance and use on the order of 15-25 percentage points. These services, usually operated by NGOs, have few links to commercial suppliers and are usually not able to make referrals for clinical services (WHO 1995). The service mix has traditionally been varied, and efforts are being made to include injectables, emergency contraception, the standard days methods, and birthing kits and misoprostol for the prevention of postpartum hemorrhage. There is renewed interest in a modified community-based distribution model for countries with the lowest contraceptive prevalence in sub-Saharan Africa, where access is difficult, the private sector is weak, and community support is required for acceptability of family planning. 
Social marketing programs distribute to pharmacies and other medical outlets branded products that are subsidized and promoted through social communication and marketing strategies. Social marketing programs complement commercial approaches, as their educational campaigns and distribution strategies focus on areas where commercial suppliers show little interest. For example, Population Services International and DKT provide hormonal contraception (and more recently bednets for the prevention of malaria and oral rehydration for the treatment of diarrhea) to poor communities in more than 25 African countries.

Social franchises are a further development of commercial models for providing contraception. They include PROSALUD in Bolivia, Goldstar network in Kenya, and Greenstar in Pakistan, all of which are major providers of hormonal contraceptives in the markets they serve. The social franchise has become particularly popular with providers in large markets where the need for brand identity is important. Most providers offer a variety of health services, one key element of which is family planning. Particularly in areas with a less developed health network, social franchises may be the most comprehensive source of health care and a reliable means of purchasing contraceptives.

Like its commercial counterpart, social franchise systems have identifiable elements of operation (Meuter 2008). These six elements are:

1) A prototype or pilot and its replication. The pilot program helps to develop the concept before establishing a wider service delivery system in a larger geographic area.

2) A manual defining the concept and routine processes. The manual contains all relevant information developed by the franchisor and enables franchisees to provide the services as intended in a variety of sites.

3) A brand name for the program. The brand identity reflects the services and values of the franchise and helps to improve the reputation of the individual outlets.

4) A contract governing the relationship and distribution of responsibilities. Because brand identity and the exchange of information are critical to social franchise outlets, a legal contract defines the rights and duties of the franchisor and franchisees, as well as the consequences of non-compliance.

5) Standardized training for franchisees. Initial and ongoing training is essential for ensuring quality and sustainability of social franchise systems.

6) Systematic methods of evaluation and quality control measures. Because inappropriate activities by one franchisee can negatively affect the entire net- 
work, the franchisor must evaluate the performance of all franchisees to ensure sufficient quality. In addition to traditional supervision, the franchisor often provides internet platforms to exchange best practices or facilitate the evaluation of franchisee performance.

The desired result of these six elements is to sustain a network of qualified providers in rural and peri-urban areas, build local capacity to improve the quality of care provided, and offer services at a cost that is more affordable to poorer clients than those provided in commercial and fully private markets. To increase access to these important services, many programs now include mobile services in which qualified providers make periodic visits to more isolated communities with vans equipped for clinical care. While the costs of mobile services are sometimes difficult to sustain, the rapid increase in coverage achieved by this approach is remarkable.

The emergence of these new service models, particularly social franchising and voucher schemes, has led to new partnerships with producers, procurers, and providers of hormonal contraception. For example, as part of a publicprivate partnership with USAID during the next five years, Bayer Pharma will deliver up to 50 million cycles per year of combined oral contraceptives for public markets and up to 60 million cycles per year for social marketing programs in more than 50 programs globally (Bayer 2009).

Vouchers for reproductive health services have been proposed as a means for better targeting marginalized populations. Specifically, demand-side financing strategies such as vouchers for family planning services have been adopted by KfW, the Bill and Melinda Gates Foundation, and others as a way of giving more decisionmaking ability to poor clients. These alternative financing schemes offer clients vouchers for specific reproductive products and services at a subsidized price. The vouchers can be exchanged for services at qualified outlets.

In middle-income countries, work-based health provision, whether through on-site services or commercial and social health insurance, covers increasing proportions of populations for family planning and other maternal and child services. But these systems require investments by employers, either within their local communities or within larger social security schemes, which are expensive even when costs are shared by the state, employers, and employees. With individual employers, the coverage of these services is low. And politically and financially, investments in social security schemes along with new infrastructure and staff present substantial obstacles for poorer countries. 
The innovation with vouchers lies in the focus on clients' choice and financial decisionmaking as a way of stimulating improved services in qualified service outlets, rather than financing these services through health systems. Voucher systems are being used in Bangladesh, Cambodia, Kenya, Uganda, and elsewhere to provide prenatal care, skilled attendance at birth, and contraceptive services. The use of an accreditation system and cost analysis ensures that providers meet the required standards related to infrastructure and quality of care and are willing to provide the service at the established price. As an example, Kenya's National Coordinating Agency for Population and Development (NCAPD) operates a voucher program in the rural districts of Kisumu, Kitui, and Kiambu as well as in the Nairobi informal settlements of Viwandani and Korogocho, representing a population of approximately 3 million. The NCAPD manages three services: the safe delivery program, a voucher for longterm family planning methods, and a gender-based violence recovery service. PriceWaterhouseCoopers runs the claims processing center, and the contracted facilities have been accredited by the National Hospital Insurance Fund.

A recent assessment of reproductive health voucher schemes concluded that all formal evaluations reported some positive findings, indicating that voucher programs increased the use of reproductive health services, improved quality of care, and improved population health outcomes (Bellows, Bellows, and Warren 2011). While the potential for reproductive health voucher programs appears promising, stronger evidence on cost-effectiveness and population health improvements is required to attract greater public-sector investments in this area.

These models of care-community-based distribution, social marketing, social franchising, and reproductive health vouchers—are not without their critics, particularly in countries with weak public-sector stewardship of health care. For example, Ravindran (2010) maintains that emerging forms of privatization in Pakistan provide a limited number of fragmented reproductive services, at less than desired quality, to only a small proportion of the population, with poor returns on the investment in terms health and survival, particularly for women. Nevertheless, the proposed solution is to continue to strengthen health systems, with particular attention to health equity and accountability to civil society. Each of these models of care is a partial answer to the requirement for greater responsiveness to the needs of the most vulnerable populations. The keys to their eventual success include ensuring large-scale operations and meeting individual needs through programs designed for a highly diverse clientele (Simmons, Fajans, and Ghiron 2007). 


\section{Understanding clients' contraceptive decisionmaking}

Two issues have remained prominent since the early days of family planning programs. The first is that the decisions of individuals, particularly women, to limit or space births are subject to social influence from partners, families, friends, and communities (Cleland 2001). Information-sharing within social networks about the notion of contraception, what particular method is preferred, and how to deal with side effects is largely socially determined. While programs place great emphasis on counseling and on clients making an informed choice, the decision is actually made within a much larger context than the clinic, pharmacy, or health post. For family planning programs to have an influence in this process, they need the support of key opinion leaders and social networks, including satisfied users, to ensure that potential clients feel secure in their behavior. Although investments in formal communication have waned in recent years, the use of more commercially viable television and radio programs and other social media like the internet have become much more important vehicles for sharing perspectives on use. Communication in the future must continue to use these and other strategies as contraception becomes more of a lifestyle choice in both public and private markets.

The second issue is that of method discontinuation, even in the face of the desire to avoid pregnancy. In an analysis of 18 DHS surveys, a UN report (2006) estimated the median one-year discontinuation probability at 34 percent for oral contraceptives and 46 percent for injectables, in contrast to only 12 percent for long-acting IUDs. The majority of these discontinuations were for health concerns and side effects. In addition, about 10 percent of users became pregnant and 46 percent switched to another modern method within three months of discontinuation. Rates of discontinuation are highest among the young, the less well-educated, and women with unsupportive partners. Family planning programs should focus additional efforts on women below age 25 and their families and peers, particularly to decrease high rates of method failure and discontinuation. The availability of alternative methods and support in switching methods may make a substantial difference for rural and poorly educated users. It also seems likely that increases in spousal discussion about fertility intentions and contraception would lead to decreases in discontinuation and the use of more effective methods. Again, while counseling may make a difference in method choice, it is the characteristics of the method (e.g., expected side effects) and the social context that largely determine users' behavior. 


\section{Ensuring access, quality, and low cost}

An affordable price and proximity of a source for acquiring contraception are key determinants of access and use. Policymakers have expressed growing interest in the use of generic products and second-tier pricing strategies to ensure that hormonal contraception is available to users at the lowest prices. Once new products are off patent, generic producers seek to develop market share with the provision of lower-priced products in national and emerging regional markets. With the demand for hormonal contraceptives rising in many markets by up to 5 percent per year, low-priced products earn sufficient profits to keep generic producers in this market. A clear obstacle to sustaining a market niche for hormonal contraceptives, however, is the fact that nearly half the world's population (and nearly two-thirds of the population in sub-Saharan Africa) lives on less than $\$ 2$ per day (PRB 2009).

For nearly two decades, WHO, donors, and manufacturers in both developed and developing countries have been seeking to improve quality assurance in the production of hormonal contraception (see, e.g., WHO 1995). With the demand for additional inexpensive methods, including for procurement by international donors, we see increased focus on understanding the segmentation of markets and procuring products through a wider variety of arrangements and sources. WHO is seeking to improve the quality of manufacturing of medicinal products, including contraceptives, so that procurement agencies and country recipients can be certain that products and manufacturing processes meet the appropriate international standards.

Members of the Reproductive Health Supplies Coalition collaborate with donors, procurement agencies, manufacturers, and other organizations to develop sustainable contraceptive markets, increase the use of Good Manufacturing Practice, improve procurement capacity, and strengthen logistic management systems. In addition, the coalition hosts a website to disseminate information about the sources, shipment, and costs of contraceptive products. The RHInterchange provides up-to-date, standardized data on shipments of contraceptive supplies to more than 140 countries (see www.rhsupplies.org).

The most difficult challenge ahead is to reduce inequities in access and use according to wealth, sex, ethnic group, age, marital status, and religious affiliation. Contraceptive services for sexually active adolescents, whether married or not, face barriers related to access, quality, and cost. Moreover, many of these inequities overlap to create extremely disadvantaged groups-for example, poor girls from a minority ethnicity or religion. The social benefits of family planning 
in terms of reducing maternal deaths can only be realized if the poorest individuals and those with unmet need are reached on a wide scale. The integration of services is a fundamental aspect of health system strengthening and achieving efficiencies of care, but the challenges of implementing integrated systems are formidable (DfID 2009).

Nevertheless, the integration of family planning services with other health and reproductive health services, especially antenatal and postnatal care and immunization, is an increasingly important strategy, both in terms of national policy and, where feasible, in the local organization of care. Disease-focused programs, whether concentrating on prevention or treatment, have been reluctant to integrate with family planning services for several reasons, including a lack of capacity and interest among staff. Furthermore, entrenched procurement systems often operate independent supply chains, despite serving many of the same service delivery points, providers, and clients. As an example of the severe negative consequences of segregated services, the Director of Health Services for Haiti lamented in 2004 that the country had sophisticated laboratory services for monitoring viral loads of HIV-positive clients, but could not ensure reliable provision of supplies for testing anemia in women about to give birth.

\section{Conclusions}

Reproductive health care for women and men and the need for services have evolved in response to trends in contraceptive use, demographic changes, health transitions, and changing perspectives on feasible and appropriate health care. Widely accepted rationales for investments in reproductive health include individual rights and unmet needs, as well as beneficial effects on maternal and child health. But countries can no longer implement family planning programs as stand-alone services or luxuries for only the wealthiest segments of the population; such programs must become an integral part of health systems that respond to the full range of human needs. Health systems now function within a larger market for care in which links between services, resources, and needs require clearer articulation and greater financial and management support. Explicit strategies for developing health systems, including health financing, are especially critical for those populations upon whom the burdens of poor health fall most heavily. 


\section{CHAPTER 4}

FAMILY PLANNING COMMUNICATION PROGRAMS

$\mathrm{n}$ this final chapter we focus on what family planning communication programs seek to achieve, how they have evolved in the past 50 years, how specialists approach the design of such programs, and how effective they have been in changing contraceptive behavior.

Behavior change communication (BCC) programs are the most widely used means of disseminating family planning messages in developing countries. While such programs take different forms depending on societal norms regarding number of children and acceptance of contraceptive use in a given country, they often have several characteristics in common. First, they often appeal to aspirations: encouraging the audience to look to a better future and promoting family planning as one means to that end. One such message is that having fewer children ensures a better quality of life for parents and children. Second, BCC programs may provide factual information that facilitates contraceptive adoption, including types of methods, safety, sources of supply, and management of side effects. Third, communication programs may seek to dispel myths and misconceptions, in an effort to overcome barriers to use. Finally, BCC programs aim to motivate the intended audience to action: to discuss family planning with their spouse or partner, visit a clinic or community worker, initiate use of a contraceptive method, and manage side effects should they occur, rather than discontinue use.

Population experts have increasingly recognized the role of ideational change in the inclination and motivation of populations to reduce their fertility (Freedman 1997; Kincaid 2000; Cleland et al. 2006). BCC programs are an integral part of this process, often accelerating long-term trends in the spread of information and changes in social norms that might eventually have taken place in their absence.

\section{Components of a BCC program}

For many, the term family planning communication evokes the image of a campaign designed to reach women of reproductive age to encourage them to use 
contraception. In fact, communication programs operate in different domains to reach different audiences.

Advocacy is one type of communication, aimed at influencing the opinions and decisions of policymakers regarding laws, regulations, and other structural factors that affect contraceptive use. Communication aimed at service providers is a second domain; such programs may increase levels of knowledge and encourage providers to improve the quality of services offered. The third and fourth domains include communities and individuals. Communication programs can have a powerful influence on community norms, helping to shape perceptions about new behaviors and their acceptance by community members. "Individuals" in the case of family planning are women of reproductive age, as well as people with a significant influence on women's contraceptive behavior (e.g., husbands, partners, mothers-in-law). In this chapter we focus largely on communities and individuals, although many of the principles of strategic communication are also applicable to communication for policymakers and service providers.

BCC comprises four main channels of communication: mass media, community-level events (often grouped under the heading of community mobilization), interpersonal communication/counseling, and electronic media (Salem et al. 2008; Bertrand, Merritt, and Saffitz 2011). Although a given country, program, or organization may rely more heavily on one of these channels, the most comprehensive and potentially effective BCC programs use most or all of them in a complementary manner. Interventions with a strong mass media component are also referred to as "campaigns." Most systematic evaluations of family planning communication programs have examined large-scale programs, usually with a mass media component, sometimes supplemented with other types of communication. For this reason the "evidence" related to such programs is much more abundant for mass media than other types of communication. This does not mean that community-level events or interpersonal communication/ counseling are less effective; rather, they are less frequently the focus of evaluation and publication in peer-reviewed journals.

Mass media includes television/radio in multiple formats such as public-service announcements, soap operas, dramas, songs, call-in talk shows, billboards, and posters. BCC programs also use "small media" with more limited reach, such as videos, audio cassettes, pamphlets/flyers, and family planning paraphernalia (e.g., t-shirts, key chains, hats, calendars, and mugs). Community-level events involve many activities, with a common characteristic of meeting the population face-to-face in their social environment. Interpersonal communication/counseling often occurs in an institutional setting, such as a clinic, school, 
or workplace. Counseling may also occur in outreach settings (e.g., adolescent peer-education programs) and among friends and families as a natural extension of a media campaign (Storey et al. 1999; Valente and Saba 2001). Hotlines, another influential type of interpersonal communication/counseling, have the advantages of individualized messages and anonymity. Electronic media include text messaging, internet counseling, social networking, and related modes of communication via cell phones or the internet.

Snyder et al. (2003) described the elements of 39 family planning programs designed with technical assistance from the Center for Communication Programs (Johns Hopkins University) between 1986 and 2001. On average, individual campaigns used about five communication channels. The most common were radio $(76 \%)$, print materials $(72 \%)$, television $(62 \%)$, and outreach workers $(52 \%)$. Many campaigns also communicated through meetings or conferences $(48 \%)$, health centers $(38 \%)$, and centralized meeting places (35\%). Some used schools (17\%), door-to-door outreach (10\%), and the workplace (10\%). Many campaigns featured a training workshop for health professionals (59\%). Promotions included give-aways or novelty items (45\%), contests (41\%), and awards $(24 \%)$. The most popular media formats were radio spots (62\%), followed by TV spots (41\%), educational programs on radio (45\%), and educational programs on TV (21\%). Formats and events based on an education-entertainment approach were also common, including fairs, festivals, concerts, and other events (52\%), theater performances (48\%), radio soaps (35\%), and TV soaps (28\%). A number of campaigns used donated time for their radio or TV messages. Media presentations often used elements that help make a campaign memorable: more than half of the campaigns had a pictorial logo, while others used a slogan (38\%), a celebrity spokesperson (35\%), and a song or jingle (31\%). Celebrities included movie stars, musicians, well-known athletes, radio personalities, and disc jockeys.

Effective communication programs draw heavily on evidence-based research and evaluation. Specifically, program planners use different types of research and evaluation in the initial design, as well to make mid-course corrections. Formative research includes the use of existing data (e.g., from the DHS or studies conducted on the subject, especially in the same country), complemented by new data collection to identify current levels of knowledge, media habits and preferences, barriers to contraceptive use, and other relevant information. Pretesting of materials permits testing for ease of comprehension, cultural acceptability, identification with the materials, and related factors, before final production or dissemination. Evaluation of reach and effectiveness allows program 
managers to use strategies and channels that reach large numbers of individuals and are most likely to produce favorable outcomes.

Many observers have asked whether "selling" family planning is like selling soap or toothpaste. In fact, many of the techniques used in marketing commercial products are also used in promoting family planning (especially social marketing programs that promote contraceptives). However, as numerous researchers (e.g., Rogers 2003; Storey, Saffitz, and Rimon 2008) have pointed out, complex behaviors are more difficult to change. Indeed, contraceptive use has numerous social, cultural, economic, and political dimensions that make "selling" family planning much more difficult than selling most commercial products.

\section{Evolution of BCC programs in family planning}

From the earliest days of family planning programs, individuals and organizations responsible for promoting contraceptive use acknowledged the important role of communication in this process. In the 1950s, India, which established some of the first family planning programs in the developing world, used the red triangle to identify and spread awareness of programs (Ledbetter 1984). Through the 1960s and 1970s, the common term for this approach was information-education-communication (IEC). In time, those working in this field came to prefer the term "behavior change communication," which implies not just imparting information but achieving the desired result of behavioral change-in this case, contraceptive use. Others have further expanded the concept to "social and behavioral change communication" (SBCC) to reflect the social and population-level perspective whereby change at the individual level occurs within the concentric circles of influence of spouse/family, community, and society (AED/C-Change 2010a). BCC connotes a clearly defined objective to be achieved through a specific communication program. SBCC often implies additional goals of empowering communities, where these goals are considered as important as or more important than attaining the specific behavior of contraceptive use (Figueroa et al. 2002).

In the early stage of a family planning program, modern contraceptionboth the idea of fertility regulation and the methods themselves-provoked considerable moral and social resistance and deep-seated health concerns. Thus, simply increasing access to contraceptives would have been ineffective. Several scholars (e.g., Cleland 2001; Kincaid et al. 2007) have identified the importance of ideational change as a precursor to behavior change. Ideation refers to knowledge, beliefs, and values that can evolve within a society to accelerate the 
pace of fertility decline, in contrast to the material conditions that were previously believed to explain levels of fertility (Cleland 2001). It is also important to recognize the political dimension of family planning programs, especially in Asia in the early years of such programs, where national political figures publicly endorsed family planning to achieve developmental goals, and programs used mass mobilization strategies to influence leaders throughout the country (e.g., teachers, village heads, local religious leaders) to support this movement.

We can trace family planning communication programs through different "eras." In the 1960s, the predominant model was the "clinic era," characterized by a doctor and nurse lecturing to patients on contraceptive use in a clinical facility. The 1970s brought the "field era," where service delivery extended beyond clinics. Community-based distribution and home visits were popular ways to encourage women to use contraception. During the "social marketing era" in the 1980s, programs used marketing techniques to promote family planning among targeted populations (usually urban and/or middle class or above) who were attracted by the clever advertising and the convenience of purchasing contraceptives outside of clinics. By the 1990s, the era of "strategic communication" brought greater attention to evidence-based programs and evaluation, and programs made greater use of multiple, reinforcing channels and participatory approaches (Piotrow et al. 1997; Rogers 2003).

Communication programs have evolved substantially over the past 50 years. In the early years, it was not uncommon for program planners to design materials in the capital city with little attention to the interests, needs, and fears of rural populations. Many countries adopted the slogan "a small family is a happy family," without tailoring the message to the local context. Because the media industry in many developing countries was still in its infancy, early family planning programs could often place their spots or programs on the national media with little competition from other outlets. Some of the early communication was highly creative and innovative (Mechai's program in Thailand in the 1970s used various gimmicks, such as condom-blowing contests, to give a light-hearted tone to a sensitive topic). However, as the media industry has advanced in developing countries, so has the sophistication in communication strategy and evidence-based approaches, resulting in higher-quality family planning programs. Successful campaigns have generally used the widest possible variety of channels that their budgets can afford and that local cultural norms can tolerate.

Entertainment-education (EE) — a novelty in health communication programs until around 25 years ago- has become integral to BCC programs in 
family planning and other areas of public health (Coleman 1986; Singhal and Rogers 1999; Piotrow and de Fossard 2004). It uses emotion and drama to draw the attention of audiences and engage them in a given topic, so that they want to find out what happens, who triumphs, and who succumbs. In the process of telling an engaging story, EE programs provide vital information on the topic and offer examples of desirable behaviors. Soap operas often include a "good" figure, a "bad" figure, and a transitional figure who starts down the wrong path but eventually sees the light and is rewarded for doing so. Songs and music videos are particularly effective in reaching younger audiences. In 1988, Tatiana and Johnny topped the pop music charts in Mexico and then in other Latin countries with "Détente," a song that advised adolescents to "wait" before having sex (Coleman and Meyer 1990). Other forms of EE include variety shows, quiz shows, puppet shows, drama contests, and community rallies.

Since the late 1960s, when the US government began to promote family planning in developing countries worldwide, communication has played a vital role in the international family planning movement. Whereas in much of the developing world today, family planning is seen as one of many public health services, in the 1960s and 1970s it was a politically controversial topic for politicians and was socially divergent from the pronatalist cultural norms of most developing countries. Given the lack of precedent for conducting family planning communication, international donors gave key recipients of such funding (e.g., the Johns Hopkins Center for Communication Programs, which directed the Population Communication Services Project from 1982 to 2001) ample financial support, technical latitude, and continuous encouragement to develop novel methods of communication. Moreover, such technical assistance organizations, by working in many countries simultaneously, frequently applied the lessons learned in one country to other countries and other continents (Piotrow et al. 2003). Since 2001, however, no project funded by a major donor has had an exclusive focus on international family planning communication at the global level.

Scholars and activists have long recognized the importance of participation and two-way communication in behavior change programs. Often community-based, this type of grassroots communication engenders a greater sense of personal involvement, in addition to building local capacity. Much of the community mobilization operates on the principle that empowering communities to take ownership of their health needs is essential to effective and sustainable programs. Social networking further strengthens commitment to change, especially as new practices become integrated into social norms. Under this ap- 
proach, communities are directly responsible for the planning, implementation, and evaluation of programs designed to bring about change.

However, the decreases during the past decade in donor funding for international family planning have severely limited new advances in state-of-the-art BCC. A few notable exceptions exist: the Mabrouk! ("Congratulations") Initiative in the Menya governorate of Egypt promoted family planning among newly married couples as one of several health-related behaviors over the lifecycle. The program was launched with a televised mass wedding ceremony hosted by a local television celebrity. The launch was followed by an integrated campaign for young families, promoted through the media, the service delivery system (including hospital delivery units and a national network of private pharmacies), and in hard-to-reach communities. Within the first year, the program reached nearly 90 percent of married women in the catchment area (El-Zanaty and Way 2006).

\section{Contemporary family planning communication programs}

In the 1980s and 1990s in developing countries with strong political support for family planning, one could see and hear TV and radio ads, observe billboards, and recognize a distinctive national-level communication campaign, branded with a logo and slogan. Many countries also had soap operas related to family planning that aired nationally (Piotrow and de Fossard 2004). Today, by contrast, national campaigns with an exclusive focus on family planning are increasingly rare, reflecting the shift toward integration of family planning into maternal and child health, HIV, or primary health care services. There are exceptions; for example, in Albania a national family planning communication program focused on young people aged 18-35. Phase one promoted the safety and reliability of contraception, while phase two used "A Happy Life" theme to encourage use (AED/C-Change 2010b). However, far more prevalent are communications on family planning that are integrated with broader health messages (such as the Mabrouk! campaign, cited above) or with messages about HIV prevention.

There are several reasons for the demise of large-scale national family planning communication programs. First, following the Cairo Conference in 1994, many countries adopted a more comprehensive approach to reproductive health. Second, other concerns_-notably HIV/AIDS_captured the attention and funding of the international donor community, which tended to diminish the resources and staff available for family planning (Wilcher, Cates, and Greg- 
son 2009). Third, until the availability of antiretroviral drugs to treat AIDS, the high levels of HIV prevalence and AIDS deaths in many sub-Saharan African countries threatened to reduce population growth rates, making the promotion of family planning potentially offensive in such locations. Fourth, some countries have reached such low levels of fertility and such high levels of contraceptive use that continuous BCC messages are no longer needed to sustain contraceptive use. In such cases donors (such as USAID) have ceased to provide population funding (Crommer et al. 2004).

After a decade or more of stagnant levels of funding for family planning in general and BCC in particular, we have seen recent increases in government and private foundation funding for family planning, especially in those countries with the greatest unmet need for contraception. In view of this prospect, it is imperative to ask what international population and public health specialists and their in-country partners have learned from five decades of family planning communication programs that can be used to design, implement, and evaluate a new generation of BCC programs.

\section{Designing BCC programs for family planning}

The state of the art for designing family planning communication programs is firmly established. Most technical assistance agencies working in BCC subscribe to a systematic approach that covers the various steps in the design, implementation, and evaluation of programs. One of the best known is the P-Process (Piotrow et al. 1997), a schematic diagram that illustrates the steps for designing and evaluating a communication program. Introduced in the 1980s and still in widespread use, the P-Process outlines the following five steps: analysis; strategic design; development and testing; implementation and monitoring; and evaluation and revision. These steps, elaborated in the guide titled "Tools for Behavior Change Communication" (Salem, Bernstein, and Sullivan 2008), are described in Box 1.

Strategic communication is the basis for effective behavior change programs. Elements of strategic communication include the following (Piotrow et al. 1997):

Systematic approach guided by research. Practitioners use the P-process or a similar schematic model to guide them step-by-step through the process. They use research to guide the design; process evaluation to ensure the program is carried out according to plan; and evaluation to measure the extent to which the program objectives are achieved. 


\section{BOX 4.1}

P-Process: Five steps for designing behavior change communication programs

\section{Step 1: Analysis}

- Understand the dynamics of the health issue (severity and causes of the problem, facilitators and barriers to behavior change, aspects that can be addressed through communication).

- Identify the primary audience (those at risk for the problem) as well as those who influence their health behaviors; determine current levels of knowledge, attitudes, behaviors, and media access/habits.

- Conduct participant analysis and identify the potentially most effective means of reaching this audience.

\section{Step 2: Strategic design}

- Define the objectives of the program-the desired changes in knowledge, attitudes, social norms, and behaviors.

- Develop a conceptual framework to indicate how program activities are expected to achieve these objectives.

- Use this framework to select monitoring and evaluation indicators.

- Prioritize communication channels to be used.

- Develop a creative brief to share with those who will develop the messages. The brief should characterize the intended audience, identify the behavioral change objectives, describe the benefits to the audience, and outline key messages.

- Draw up an implementation plan, including activities, partners' roles and responsibilities, timeline, budget, and management plan.

- Develop a monitoring and evaluation plan.

\section{Step 3: Development and pretesting}

- Develop messages and materials, based on formative research and the strategic plan outlined above.

- Tailor messages to the audience's stage of behavior change.

- Choose the type of appeal (empowering, entertaining) and tone (humorous, authoritative).

- Pretest the messages and materials with members of the intended audience.

- Revise messages and materials on the basis of the pretest results.

\section{Step 4: Implementation and monitoring}

- Develop and implement a dissemination plan.

- Manage all aspects of the process: activities, staffing, budget, and responses from the audience and other stakeholders.

- Monitor the program and make midcourse adjustments.

\section{Step 5: Evaluation}

- Measure outcomes and, if the study design permits, impact.

- Disseminate results to partners, key stakeholders, the news media, and funding agencies.

- Record lessons learned and archive research findings for use in future programs.

- Revise and redesign the new program after evaluating all findings. 
Results-oriented. The purpose of BCC programs is to change behavior, not simply to inform or educate. Effective programs have clearly stated, measurable objectives. Whereas current contraceptive use is the most common "desired result," other changes such as increased spousal communication or more supportive attitudes toward family planning can lead to other desired results in the future.

Based on theory. A number of behavioral health theories guide the planning and evaluation of communication programs, including the extended parallel process model (Witte 1994), social learning theory (Bandura 1986), and diffusion of innovation (Rogers 2003). Theories identify motives for action, message strategies, and target audiences (Storey, Saffitz, and Rimon 2008).

Audience segmentation. Well-designed programs target specific segments of the audience according to sex, age, socioeconomic status, geographic residence, ethnicity, and other relevant traits. Segmentation allows program planners to tailor the messages to be most relevant and compelling for a particular population, thus increasing their effectiveness while limiting expenditure on those outside the target population.

Strategic positioning. Family planning has multiple benefits: economic advantages, women's health, marital harmony, and reproductive rights, among others. Yet some potential benefits are more persuasive than others, depending on the cultural setting. Formative research can be critical in identifying the most persuasive argument for promoting family planning in a given population.

Multiple reinforcing channels. Combining mass media, interpersonal, and community channels helps to enhance the effect of BCC programs (Salem, Bernstein, and Sullivan 2008). This practice reinforces key messages, creates "buzz" that triggers informal communication, and gives momentum to the ideas of the campaign. Audiences respond favorably to recognizing a slogan or logo through multiple channels.

Quality programming. Given the proliferation of media channels in most developing countries, audiences can choose between countless radio stations, multiple TV stations (including cable), the internet, newspapers, magazines, comics, and other sources of information and entertainment. Family planning messages must be of sufficient quality to compete with commercial publicity and break through the "media clutter."

Client-centered. Again following the lead of commercial marketers, highquality BCC programs identify the needs, interests, and concerns of potential 
clients and seek to address them in the presentation of the product or service and in the program that promotes them. It reflects the dictum, "put yourself in the client's shoes."

Benefit-oriented. BCC programs are more likely to achieve their objectives if they advise clients of the benefits of the desired behavior change, consistent with the findings from formative research on what the intended audience values most highly. For example, it is essential to state explicitly the benefits that can result from contraceptive use to prevent unwanted pregnancy and reduce family size.

Service-linked. Because the initiation of contraceptive use and the management of side effects often require some contact with a clinic or pharmacy, BCC programs should identify service delivery locations, hours, and costs. Identifying the link between communication and service delivery can be particularly effective in publicizing quality improvements for local populations (Storey et al. 1999).

Participatory. Communication is more effective when the audience is actively involved. Community-level events and interpersonal communication and counseling foster participation. Mass media can do so as well, through call-in radio programs, game shows, and contests. As we noted above, programs in the past decade have emphasized local participation and capacity building.

Cost-effective. Most programs strive to achieve change "at scale," that is, to reach a substantial part of the target population and effect change among some portion of that audience. The advantage of using mass media is that even if the percentage change is small, the base to which it is applied can be in the hundreds of thousands, if not millions, making the cost per person reached and the cost per unit of change relatively low (Kincaid and Do 2006).

\section{What is the evidence that BCC programs change behavior?}

Family planning is one of two health topics (the other being HIV/AIDS) with the greatest body of evidence from developing countries with which to test the effects of communication programs on a behavior or outcome. Family planning programs have been subject to extensive external scrutiny, and the high levels of funding directed to BCC programs have led to recurrent calls to demonstrate the return on this investment. Because national family planning programs tend to include multiple cycles, it is logical for practitioners to learn as much as possible from one cycle before beginning the next. Much of the evaluation of fam- 
ily planning communication has focused on programs with a strong mass media component, or mass media mixed with interpersonal channels. There is notably less evaluation of programs that rely entirely on interpersonal communication at the community level.

A number of researchers have sought to assess the effects of family planning communication programs on fertility outcomes. This question poses major methodological challenges, because it is not possible to evaluate family planning communication programs using experimental designs or case-control methods. The most comprehensive campaigns include mass media that potentially reach all segments of the target population; one cannot randomly assign individuals or even communities to a "treatment group." Because of this limitation, the vast majority of evaluations use non-experimental or quasi-experimental designs. Evaluators have turned increasingly to the quasi-experimental one-group/ posttest-only design that applies statistical controls to reduce the potential bias of confounding variables, allowing one to make claims of plausible attribution. This approach involves techniques that Babalola and Kincaid (2009) have termed multivariate causal analysis (MCA).

Singhal and Rogers (1999) report the results of some early evaluations of family planning communication programs, especially those using the entertainment-education format. These evaluations generally fall in the category of nonexperimental designs that establish a link between exposure to programs and a desired result. Examples include the first soap opera in Mexico to promote family planning (broadcast in 1977-78) in 180 half-hour episodes. The program, Acompaname ("Come Along with Me"), promoted family planning, equal status of women, and the importance of spousal communication. Government clinics reported a 33 percent increase in family planning adoption, and phone calls to the family planning program increased from 0 to 500, many citing the soap opera as their reason for calling. Poindexter (2004) reported similarly positive responses to the programs Tushauriane ("Let's Discuss," 60 episodes) and Ushikwapo Sbikamana ("When Assisted, Assist Yourself," 200 episodes), both of which premiered in Kenya in 1987. Evaluations showed that by the end of the two series, contraceptive use in Kenya had increased by 58 percent. In addition, women reported a decrease in desired family size from 6.3 to 4.4 children. Some critics question the extent to which one can attribute these changes to communication programs, but there is plausible evidence of their contribution to the observed effects.

One of the most widely cited evaluations based on a quasi-experimental design involved Twende na Wakati ("Let's Go with the Times"), a radio soap opera 
in Tanzania that promoted family planning and HIV/AIDS prevention. The placement and timing of the program permitted a natural experiment in which all areas of the country except one (Dodoma) received the program from 1993 to 1995 , followed by a two-year period in which the program reached all areas of Tanzania. Using Dodoma as a control (comparison area) allowed researchers to measure the effect of the program. Evidence from five independent data sources all supported the conclusion that Twende na Wakati had measurable effects on contraceptive-method adoption and increased confidence that exposure to the soap opera played an important role in the early stage of the fertility transition in Tanzania (Rogers et al. 1999: 205). Critics of this study have cited the possible influence of another soap opera playing at that time, as well as preintervention differences in the treatment and comparison areas.

As part of a review for the US National Academy of Sciences, Hornik and McAnany (2001) analyzed the effects of media on fertility change. They evaluated major studies of campaign effects published from 1970 to 1999, presenting the key findings and methodological critiques of each study. They also outlined the pathways by which various media might have an effect on use of family planning services or on fertility outcomes. They found evidence of effects in the following areas:

1) Campaigns have measurable short-term effects on increasing demand for services at clinics, although the effect appears to dissipate after the program ends.

2) Access to media (exposure to ordinary content, not specific family planning messages) may have societal-level effects. For instance, they write, "if the spread of mass media has effects on fertility, it reflects a complex social process: ...multiple channels, providing reinforcing messages, over time, producing inter-personal discussion and a slow change in values, and working at a level of social aggregation higher than the individual” (p. 234).

3) Self-reported attention to messages delivered through IEC programs correlates strongly with fertility behaviors. For example, Westoff and Bankole (1997) provided evidence that self-reported attention to media messages about family planning influenced fertility-related behavior (controlling for likely co-variates) in a multi-country analysis of DHS data from sub-Saharan Africa (Burkina Faso, Ghana, Kenya, Madagascar, Namibia, and Zambia). One cannot separate IEC or mass media messages from the other activities of family planning programs, but they operate over the long term and with constant reinforcement of messages. 
However, in terms of the type of effect that family planning communication programs aim to achieve-namely, change in behavior at the population level-Hornik and McAnany found mixed evidence, owing in part to the methodological limitations in evaluating communication programs cited above. The evaluation showed substantial association, but not necessarily causation.

The strongest evidence for the population-level effects of family planning communication programs comes from the work of Snyder and colleagues, based on meta analysis of a number of health topics, including family planning (Snyder and Hamilton 2002; Snyder et al. 2003; Snyder 2001, 2007a). Snyder (2001) has argued that rather than ask simply whether campaigns are effective, it is more useful to determine the magnitude of campaign effects. These meta analyses have served several useful purposes: to estimate the average effect size* of family planning programs in developing countries; to compare the effectiveness of such programs to campaigns related to other topics; and to identify variables related to effect size, such as "reach" (or exposure).

In 2003 Snyder and colleagues conducted a meta analysis of 38 campaigns that received US government funding between 1986 and 2001, with technical assistance from the Johns Hopkins Bloomberg School of Public Health/Center for Communication Programs. The results indicated that on average the greatest campaign effect for men and women was on knowledge of modern family planning methods $(r=.15)$. Positive effects were also found for partner communication about family planning $(\mathrm{r}=.10)$, approval of family planning $(\mathrm{r}=.09)$, behavioral intentions $(\mathrm{r}=.07)$, and use of modern contraceptive methods ( $\mathrm{r}$ $=.07$ ). The authors noted that these effect sizes were similar to those found in US-based public health campaigns.

In 2007 Snyder published a meta analysis comparing effect size across different health topics, including the 58 family planning communication programs from developing countries. As illustrated in Figure 4.1, family planning communication programs fall mid-range among other public health topics in terms of effect size when considering campaigns from both developing countries and the United States. Campaign effects were greatest for seat belt use $(r=.15)$, dental care $(\mathrm{r}=.13)$, and adult alcohol reduction $(\mathrm{r}=.11)$, while they were weakest for youth drug and marijuana campaigns ( $\mathrm{r}=.01-.02)$ (Snyder 2007a).

\footnotetext{
* Effect size is a statistical formulation of an estimate of program effect that expresses its magnitude in a standardized form that is comparable across outcome measures using different units or scales (Rossi, Lipsey, and Freeman 2004).
} 


\section{FIGURE 4.1}

Average effect of public health campaigns on behavior

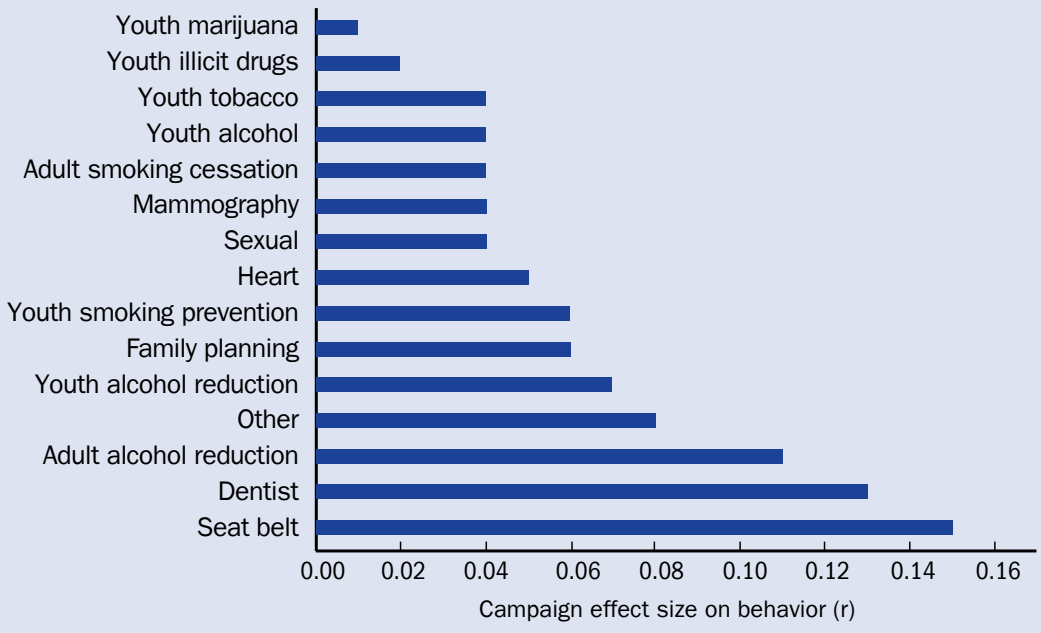

SOURCE: Snyder (2007b).

In addition to effectiveness as measured by behavior change, Snyder has also analyzed the concept of "reach" across different studies. Reach refers to the proportion of the audience that recalls seeing, hearing, or coming into contact in some other way (e.g., attending a group meeting) with the communication program. It differs from coverage in that it does not measure the proportion of the population that has experienced the desired behavior or outcome (such as vaccination). According to Snyder (2007a), exposure to family planning campaigns in developing countries (which averaged 71 percent of the intended audience) was higher than exposure to US-based campaigns (about 40 percent), although the figure for the US is based on a small number of studies. One reason for this difference may be that family planning campaigns in developing countries tended to use many channels of communication; also, in the early years of these campaigns, communication programs may not have had to compete with as much "media clutter" as they would have more recently.

Other recent evaluations of family planning communication programs have included the use of propensity score matching to clarify the effects of campaigns on contraceptive use. Propensity score matching allows the researcher to "create" an unexposed, matched control group that is statistically equivalent 
to those exposed to the campaign on all relevant dimensions and to compare outcomes (Babalola and Kincaid 2009). Using this method to evaluate a family planning communication program in Burkina Faso, Babalola and Vondrasek (2005) found that, compared with no exposure, high campaign exposure was associated with an adjusted increase of 22 percentage points in the proportion of women currently using modern contraceptive methods. Similarly, low exposure was associated with a 7-percentage-point increase compared with no exposure. The campaign was also associated with increased knowledge about contraceptives and more favorable attitudes toward family planning. Do and Kincaid (2006) applied propensity score matching along with structural equation modeling to evaluate an entertainment-education television drama on health knowledge and behavior in Bangladesh. They found modern contraceptive use to be 57 percent among women exposed to the program, compared to 46 percent in the unexposed matched control.

A review by the Center for Communication Programs (2010) summarizes current knowledge on the effectiveness of family planning communication on contraceptive use: "Due to methodological and practical constraints, it is hard to make any rigid claims about causality. However, replication is one measure of proof. The fact that all the reviewed reports and published literature establish clear and in many cases significant positive links between exposure to communication interventions and family planning use vouches for the veracity of this relationship."

\section{New directions for family planning communication programs}

Three major changes in the past decade will affect future directions for family planning communication programs.

\section{Integration of family planning and HIV programs}

After years of separate approaches, family planning and HIV prevention staff have developed synergies in their programs, which is particularly appropriate in countries with high HIV prevalence. These synergies include integrating family planning into HIV counseling and testing, integrating family planning in the prevention of mother-to-child transmission (PMTCT) services, and offering family planning to HIV-positive women (Wilchera, Cates, and Gregson 2009). Similarly, strong synergies now exist between family planning and adolescent reproductive health programs, which, because of the requirements 
imposed by PEPFAR funding, have tended to stress HIV and STI prevention over contraceptive use. Among unmarried adolescents and young adults-especially those in non-stable relationships-condom use is in fact the "method of choice" for avoiding both pregnancy and HIV/STIs, at least in countries with high HIV prevalence and substantial investments in programs promoting condom use.

\section{Innovations in communication technology}

The past decade has brought a number of new communication technologies that are being used in public health programs. For example, cell phones have become nearly ubiquitous in countries worldwide. Based on recent trends, almost all world regions are expected to achieve full mobile coverage, even in rural areas, by 2015. Even Africa (the exception) may reach 90 percent coverage in rural areas by that date (International Telecommunication Union 2010). Cell phones have been used to send reminders to HIV-positive patients to improve adherence to antiretroviral therapy (Lester et al. 2009) and to send data from health facilities to regional data collection points. As cell phones and related devices become more sophisticated, we can anticipate new applications for communicating vital information to potential or current clients.

The internet also offers new possibilities for communication related to family planning. Especially among adolescents and young adults, this medium offers a means of providing information on contraceptives in a highly targeted form through "virtual counselors," such as Trixy in Peru. Adolescents can access such websites conveniently, anonymously, and without embarrassment. In a number of countries in sub-Saharan Africa, teens are using the internet to obtain information on sexual and reproductive health (Borzekowski, Fobil, and Asante 2006; Nwagwu 2007).

\section{Emergence of new contraceptive methods}

Future family planning communication programs will need to introduce prospective and current users to new methods as they become available. In some cases they will need to address any dissatisfaction or negative perceptions related to the methods they are replacing (for example, Sinoplant in place of Norplant). In other cases they will need to educate and motivate clients to accept new modes of use or delivery, such as Uniject for Depo Provera, which in the near future may allow community workers (or even clients themselves) to administer the injection (Lakha, Henderson, and Glasier 2005; Prabhakaran 2008). 


\section{Conclusion}

International family planning programs have been one of the most effective public health interventions of the past 50 years. Birth rates in the developing world have dropped from an average of 6 children per woman to below 3 . Family planning - highly controversial in the early years- has become a routine part of public health service delivery in many countries with little (in fact, too little) fanfare. Although we are unable to determine how much of that change is attributable to behavior change communication programs, communication has been the "leading edge" in the vast majority of countries. Entire populations have moved along the stages of behavior change from knowing little and disapproving greatly, to becoming informed, persuaded, and motivated to act. Practitioners of communication programs have learned to obtain the benefits of the mass media (reach and cost-effectiveness) along with the advantages inherent in more participatory approaches with strong community-level involvement.

The strategies for designing and implementing family planning communication programs are well tested, yet the resources to execute them have been lacking in recent years. New generations of women and men are entering their reproductive years with the same (or, some might argue, even greater) need for timely, accurate, and culturally appropriate information about family planning. As the international donor community and host-country governments renew their commitment to family planning communication, they should build on what has worked in the past while taking advantage of the new information technologies that will allow them to achieve even more with each coming generation. 


\section{CONCLUSIONS}

he impetus for this report is the marked decline of international interest in, and funding of, family planning programs in poor countries. After outlining the reasons for this neglect, we addressed three central issues: the rationale for a revival of the family planning agenda; the effectiveness of investment in contraceptive promotion and services; and the design and operational features of family planning programs. We summarize our key conclusions in this final chapter.

\section{Rationale}

Family planning is unique among development initiatives in its range of potential benefits, encompassing economic development, maternal and child health, educational advances, empowerment of women, and environmental protection. Some of these benefits are uncontested. For instance, the contributions of contraceptive use to reductions in maternal mortality, mainly through avoidance of unintended pregnancies, and to reductions in infant and child mortality, largely through longer spacing between births, are well established. Similarly, achievement of the Millennium Development Goals related to schooling is obviously more likely when pressures from an ever-increasing school-age population are lessened as a result of fertility decline. And clearly, the advent of reproductive choice marks a large and welcome step in the empowerment of women.

Documenting the benefits of family planning and fertility decline for the reduction of poverty has been a more controversial task. Yet, nearly all the recent evidence supports the view that high fertility and associated high youth dependency ratios act as a brake on improvements in standards of living. Declines in both fertility and dependency ratios are conducive to savings and investment and enhance human capital by increasing access to education and training. These economic considerations apply with particular force to the poorest countries of sub-Saharan Africa, where the combination of continued rapid population growth, stagnant agricultural productivity, widespread food insecurity and under-nutrition, climate change, and pressure on fragile environments pose severe challenges. The solution will be multi-sectoral, with agriculture well to the 
forefront, but continued failure to address rapid population growth as an urgent priority will make success much harder, and perhaps impossible, to achieve. Recent demographic trends in Africa are not encouraging. Instead of proceeding steadily as assumed in United Nations population projections, fertility declines have slowed in the past decade. Still, as we have demonstrated, demographic trends are clearly responsive to policy and program initiatives.

\section{Effectiveness}

Critics skeptical of the effectiveness of family planning programs have argued that higher incomes, higher education of women, and lower child mortality are the essential forces that reduce fertility, while promotion of the means to achieve smaller family sizes, namely effective contraception, plays a minor role. If the motive to control childbearing is sufficiently strong, they argue, the means will be found without the need for public investment. Although improvements in child survival are an essential precondition for fertility transition, survival chances in most African countries have already exceeded the level at which steep fertility declines began in many countries of other regions. It is also true that reproductive change is relatively easy to achieve among well-educated adult populations whose incomes are rising.

Nevertheless, the experience of the past 50 years shows beyond doubt that state-sponsored family planning programs and efforts to legitimize the concept of smaller families have played a key role in reducing fertility, even in some of the poorest and most traditional countries, such as Bangladesh. The effectiveness of such programs stems from the considerable costs associated with the use of modern contraceptive methods. These costs include lack of information and access, fears about health effects, and social disapproval. Evidence of the negative impact of such costs comes from the gap between freely expressed reproductive wishes and non-use of contraception (the so-called unmet need), from high levels of unintended childbearing, and from widespread resort to illegal and often unsafe abortion. Well-designed programs can reduce these costs and produce very rapid increases in contraceptive use, which in turn tend to foster a downward adjustment of desired family size.

Acceptance of the means to attain one's desired family size increases the motivation to do so. In poor, largely illiterate countries, the record suggests that government programs are essential engines of change. No such country has experienced deep and sustained reductions in fertility rates in the absence of a strong and committed government family planning program. The experience 
of Kenya in the 1980s and of Rwanda in recent years demonstrates that strong government-led efforts can be as effective in Africa as they were in Asia and elsewhere three decades ago.

\section{Design and operational features}

Family planning has been one of the most successful development interventions of the past 50 years, but priorities change as programs evolve. In those African countries where contraceptive use is very low and attitudes are ambivalent or even hostile, strong political commitment is essential for rapid gains in contraceptive prevalence, and efforts to gain the endorsement of elites (religious and local leaders, medical doctors, teachers, the army, and so on) are also key. Substantial investments in public information and behavior change communication programs to catalyze latent demand are a top priority. Such activities are needed to address the diverse obstacles to contraceptive use mentioned above, and their essential aim is to convert what is initially seen as a disruptive, often frightening new behavior into a routine part of everyday life. Countries have used many imaginative communication strategies, and the evidence of their effectiveness is strikingly positive.

Family planning delivery systems need to be designed as an integral part of the overall health system, which is broadly defined to include public and private medical sectors, social marketing, and outreach components. The fragility and uneven coverage of health services in many poor African countries represent considerable constraints. In towns and cities and more densely populated areas with adequate coverage of retail outlets, social marketing is an invaluable complement to clinic-based provision of services. In most African countries, pills and injectables are the most commonly used contraceptive methods by married couples while condoms are the primary contraceptive method among sexually active single people. All three methods may be reliably sold over the counter.

In remote, sparsely populated rural areas, community-based distribution programs are the only feasible option, at least in the short term. Historically, they have been operated mainly by NGOs and have taken numerous forms (salaried, paid on commission, volunteers; women, men, or both sexes; multipurpose or family planning only). While such programs have proved highly effective in diverse settings, integration within the wider health system has been difficult. Harnessing the potential of community-based distribution in countries where family planning provision to rural populations is a priority is essential, but will require careful program design and pilot testing. 
We have pointed to signs that donors and governments are renewing their interest in family planning programs following at least a decade of neglect. The long struggle to incorporate family planning in the list of Millennium Development Goal targets has been successful, albeit within the broader context of "universal access to reproductive health." The task ahead is to convert this shift into effective national programs in those countries where high fertility and rapid population growth continue to jeopardize social and economic development. 


\section{REFERENCES}

AED/C-Change (Academy for Educational Development). 2010a. "What is social and behavioral change communication (SBCC)?" "http://www.c-changeprogram.org/sites/default/files/ SBCC\%20Framework_5.10.pdf». Accessed 2 October 2010.

. 2010b. «http://www.c-changeprogram.org/where-we-work/albania». Accessed 2 October 2010 .

AFD (Agence Française de Développement). 2009. (Delarue, J, Naudet, JD, Sauvat, V.). Les évaluations sont-elles utiles_Revue de littérature sur "connaissance et decisions," Série Note Méthodologiques $\mathrm{N}^{\circ} 3$.

Ali, Mohamed M and John Cleland. 2010. "Contraceptive switching after method-related discontinuation: Levels and differentials," Studies in Family Planning 41(2): 129-133.

Askew, Ian, Alex Ezeh, John Bongaarts, and John Townsend. 2009. Kenya's Fertility Transition: Trends, Determinants and Implications for Policy and Programmes. Nairobi: Population Council.

Asturias de Barrios, Linda et al. 1998. Unmet Need for Family Planning in a Peri-Urban Community of Guatemala City. Washington, DC: International Center for Research on Women.

Babalola, S. and C. Vondrasek. 2005. "Communication, ideation and contraceptive use in Burkina Faso: An application of the propensity score matching method," Journal of Family Planning and Reproductive Health Care 31(3): 207-212.

Babalola, Stella and D. Lawrence Kincaid. 2009. "New methods for estimating the impact of health communication programs," Communication Methods and Measures 3(1): 61-83.

Bandura, A. 1986. Social Foundation of Thought and Action: A Social Cognitive Theory. Upper Saddle River, NJ: Prentice Hall.

Bankole, A., G. Rodriguez, and C.F. Westoff. 1996. "Mass media messages and reproductive behavior in Nigeria," Journal of Biosocial Science 28(2): 227-239.

Barro, Robert J. 1997. "Determinants of economic growth: A cross-country empirical study," Development Discussion Paper No. 579, Harvard Institute for International Development.

Bayer. 2009. Annual Report. Bayer AG. «www.bayer.com».

Becker, Gary. S. 1960. An economic analysis of fertility," in Demographic and Economic Change in Developed Countries. Princeton, NJ: Princeton University Press, pp. 209-231.

1981 (2nd ed. 1991). A Treatise on the Family. Cambridge, MA: Harvard University Press.

Bellows, Nicole M., Ben W. Bellows, and Charlotte Warren. 2011. "The use of vouchers for reproductive health services in developing countries: Systematic review," Tropical Medicine and International Health 16(1): 84-96. 
Bernstein, Stan. 2005. "The changing discourse on population and development: Toward a new political demography," Studies in Family Planning 36(2): 127-132.

Bertrand, Jane T., Alice Payne Merritt, and Gary Saffitz. 2011. "Health communication: A catalyst to behavior change," in Richard Parker and Marni Sommer (eds.), Handbook on Global Public Health. Oxford: Routledge.

Birdsall, Nancy. 1994. "Another look at population and global warming," in Proceedings of the UN Expert Group Meeting on Population, Environment and Development. New York: United Nations, pp. 39-54.

Blanc, Ann K. and Amy O. Tsui. 2005. "The dilemma of past success: Insiders' views on the future of the international family planning movement," Studies in Family Planning 36(4): 263-276.

Bloom, David E., David Canning, and Pia N. Malaney. 2000. "Demographic dynamics and economic growth in Asia," Population and Development Review 26(Supp.): 257-290.

Bogue, Donald J. and Amy O. Tsui. 1979. "Zero population growth?," National Affairs 55: 99_ 113.

Bongaarts, John. 1994. "The impact of population policies: Comment [on Lant H. Pritchett]," Population and Development Review 20(3): 616-620.

1997a. The role of family planning programmes in contemporary fertility transitions," in Gavin W. Jones, John C. Caldwell, Robert M. Douglas, and Rennie M. D’Souza (eds.), The Continuing Demographic Transition. Oxford: Oxford University Press.

1997b. "Trends in unwanted childbearing in the developing world," Studies in Family Planning 28(4): 267-277.

2008. "Fertility transitions in developing countries: Progress or stagnation?," Studies in Family Planning 39(2): 105-110.

2011. "Can family planning programs affect high desired family size in sub-Saharan Africa?," International Perspectives on Sexual and Reproductive Health 37(4): 209-216.

Bongaarts, John and Judith Bruce. 1995. "The causes of unmet need for contraception and the social content of services," Studies in Family Planning 26(2): 57-75.

Bongaarts, John and Susan Cotts Watkins. 1996. "Social interactions and contemporary fertility transitions," Population and Development Review 22(4): 639-682.

Borzekowski, Dina L., Julius Fobil, and Kofi Asante. 2006. "Online access by adolescents in Accra: Ghanaian teens' use of the internet for health information," Developmental Psychology 42(3): 450-458.

Boulay, M., J.D. Storey, and S. Sood. 2002. "Indirect exposure to a family planning mass media campaign in Nepal," Journal of Health Communication 7(5): 379-399.

Bradley, Sarah E.K., Hilary M. Schwandt, and Shane Khan. 2009. Levels, Trends, and Reasons for Contraceptive Discontinuation. DHS Analytical Studies No. 20. Calverton, MD: ICF Macro.

Bryant, John. 2007. "Theories of fertility decline and the evidence from development indicators," Population and Development Review 33(1): 101-127.

Bryceson, Deborah F. 2009. "Sub-Saharan Africa's vanishing peasantries and the spectre of a global food crisis,” Monthly Review, July-August. 
Caldwell, John C. and Pat Caldwell. 1988. "Is the Asian family planning program model suited to Africa?," Studies in Family Planning 19(1): 19-28

Canadian Network for International Surgery (CNIS). 2010. «www.cnis.ca». Accessed November 2010.

Casterline, John. 2001a. "Diffusion processes and fertility transition: Introduction," in John Casterline (ed.), Diffusion Processes and Fertility Transition: Selected Perspectives, Committee on Population, Division of Behavioral and Social Sciences and Education, National Research Council. Washington, D.C.: National Academy Press.

Casterline, John (ed.). 2001b. Diffusion Processes and Fertility Transition: Selected Perspectives, Committee on Population, Division of Behavioral and Social Sciences and Education, National Research Council. Washington, D.C.: National Academy Press.

Casterline, John B., Aurora E. Perez, and Ann E. Biddlecom. 1997. "Factors underlying unmet need for family planning in the Philippines," Studies in Family Planning 28(3): 173-191.

Casterline, John B. and Steven W. Sinding. 2000. "Unmet need for family planning in developing countries and implications for population policy," Population and Development Review 26(4): 691-723.

Casterline, John B., Zeba A. Sathar, and Minhaj ul Haque. 2001.”Obstacles to contraceptive use in Pakistan: A study in Punjab," Studies in Family Planning 32(2): 95-110.

Center for Communication Programs (CCP). 2010. "You can't not communicate. Summary report: Reviewing existing evidence of the contribution of communication interventions to increasing family planning use.” Baltimore: Johns Hopkins Bloomberg School of Public Health/Center for Communication Programs.

Cleland, John. 1985. "Marital fertility decline in developing countries: Theories and evidence," in John Cleland and John Hobcraft (eds.), Reproductive Change in Developing Countries. Oxford: Oxford University Press.

2001. "Potatoes and pills: An overview of innovation-diffusion contributions to explanations of fertility decline," in John B. Casterline (ed.), Diffusion Processes and Fertility Transition: Selected Perspectives. Washington, DC: National Academy Press, pp. 39-65.

Cleland, John and Christopher Wilson. 1987. "Demand theories of the fertility decline: An iconoclastic view," Population Studies 41: 5-30.

Cleland, John, James F. Phillips, Sajeda Amin, and Gholam M. Kamal. 1994. The Determinants of Reproductive Change in Bangladesh: Success in a Challenging Environment. Washington, DC: World Bank.

Cleland, John, Stan Bernstein, Alex Ezeh, Anibal Faundes, Anna Glasier, and Jolene Innis. 2006. "Family planning: The unfinished agenda," The Lancet 368(9549): 1810-1827.

Cleland, John, Robert Ndugwa, and Eliya Zulu. 2011. "Family planning in sub-Saharan Africa: Progress or stagnation?," Bulletin of the World Health Organization 89: 137-143.

Cleland, John, Agustin Conde-Agudelo, Herbert Peterson, John Ross, and Amy Tsui. In press. "Contraception and health," The Lancet.

Coale Ansley J. and Edgar M. Hoover. 1958. Population Growth and Economic Development in LowIncome Countries: A Case Study of India's Prospects. Princeton, NJ: Princeton University Press.

Coale, Ansley J. and Susan Cotts Watkins (eds.). 1986. The Decline of Fertility in Europe. Princeton: Princeton University Press. 
Coleman, Patrick L. 1986. "Music carries a message to youths," Development Communication Report (53):1-3.

Coleman, Patrick L. and Rita C. Meyer. 1990. Communication for Social Change-Proceedings from the Enter-Educate Conference. Baltimore: Johns Hopkins University, Center for Communication Programs.

Commission for Africa. 2005. Our Common Interest: Report of the Commission for Africa. London: Commission for Africa.

Conde-Agudelo A., A. Rosas-Bermudez, and A.C. Kafury-Goeta. 2006. "Birth spacing and adverse perinatal outcomes: A meta-analysis," Journal of the American Medical Association 295(15): 1809-1823.

Crommer, Charlotte, Tanvi Pandit, Joan Robertson, and Alexandria Niewijk. 2004. "The family planning graduation experience: Lessons for the future," submitted by LTG Associates and Social \& Scientific Systems to USAID.

DaVanzo, Julie, Lauren Hale, Abdur Razzaque, and Mizanur Rahman. 2008. "The effects of pregnancy spacing on infant and child mortality in Matlab, Bangladesh: How they vary by type of pregnancy outcome that began the interval," Population Studies 62 (2): 131-154.

Davis, Kingsley. 1945. "The world demographic transition," Annals of the American Academy of Political and Social Science 237(Jan): 1-11.

DfID. 2009. "Eliminating world poverty: Building our common future," White Paper (20), Department for International Development, London. «http://www.infodev.org/en/Publication. 671.html».

. 2010. Choices for Women: Planned Pregnancies, Safe Births and Healthy Newborns: The UK's Framework for Results for Improving Reproductive, Maternal and Newborn Health in the Developing World. London: Department for International Development.

Dixon-Mueller, Ruth. 1993. Population Policy and Women's Rights: Transforming Reproductive Choice. Westport: Praeger.

Do, Mai and D. Lawrence Kincaid. 2006. "Impact of an entertainment-education television drama on health knowledge and behavior in Bangladesh: An application of propensity score matching," Journal of Health Communication 11(3): 301-325.

Dyson, Tim. 2005. "On development, demography and climate change: The end of the world as we know it?," Population and Environment 27(2): 117-149.

Easterlin, Richard A. 1975. "An economic framework for fertility analysis," Studies in Family Planning 6(3): 54-63.

1978. "The economics and sociology of fertility: A synthesis," in Charles Tilly (ed.), Historical Studies of Changing Fertility. Princeton: Princeton University Press, pp. 57-113.

Easterlin, Richard A. and Eileen M. Crimmins. 1985. The Fertility Revolution: A Supply-Demand Analysis. Chicago: University of Chicago Press.

Eastwood, R. and M. Lipton. 1999. "The impact of changes in human fertility on poverty," Journal of Development Studies 36(1): 1-30.

Ehrlich, Paul. 1968. The Population Bomb. New York: Ballantine Books.

El-Zanaty, Fatma, Ann Way, Sunita Kishor, and John Casterline. 1999. Egypt In-depth Study on the Reasons for Nonuse of Family Planning. Cairo: National Population Council. 
El-Zanaty, Fatma and Ann Way. 2006. Egypt Demographic and Health Survey 2005. Cairo: Ministry of Health and Population, National Population Council, El-Zanaty and Associates, and ORC Macro.

Ezeh, Alex, Blessing Mberu, and Jacques Emina. 2009. "Stall in fertility in Eastern African countries: Regional analysis of patterns, determinants and implications," Philosophical Transactions of the Royal Society, Series B 364: 2991-3007.

Family Health International (FHI). 2010. "Mobile technology: Text messages for better reproductive health," «http://www.fhi.org/en/Research/Projects/Progress/GTL/mobile_tech. htm». Accessed 22 July 2010.

FAO (Food and Agriculture Organization). 2003. World Agriculture: Towards 2015/2030: An FAO Perspective. London: Earthscan.

2009. The State of Food Insecurity in the World. Rome: FAO.

Faria, V.E. and J.E. Potter. 1999. “Television, telenovellas and fertility change in North East Brazil," in R. Leete (ed.), Dynamics of Values in Fertility Change. Oxford: Oxford University Press.

Feyisetan, Bamikale and John B. Casterline. 2000. "Fertility preferences and contraceptive change in developing countries," International Family Planning Perspectives 26(3): 100-109.

Figueroa, Maria Elena, D. Lawrence Kincaid, Manju Rani, and Gary Lewis. 2002. "Communication for social change: An integrated model for measuring the process and its outcomes," New York, Rockefeller Foundation (Communication for Social Change Working Paper Series No. 1). «http://www.communicationforsocialchange.org/pdf/socialchange.pdf».

Foreit, Jim and Sarah Raifman. 2011. Increasing access to Family Planning (FP) and Reproductive Health (RH) services through task-sharing between Community Health Workers (CHWs) and Community MidLevel Professionals in Large-Scale Public-Sector Programs: A Literature Review to Help Guide Case Studies. Washington, DC: Population Council.

Freedman, Ronald. 1997. "Do family planning programs affect fertility preferences? A literature review," Studies in Family Planning 28(1):1-13.

Freedman, Ronald and Bernard Berelson. 1976. "The record of family planning programs," Studies in Family Planning 7(1): 1-40.

Gardner, Michelle and Lila Amaliah. 1999. "Indonesia: Analysis of conflicting crisis-related research results,” Frontiers Technical Report. Jakarta: Population Council.

Gillespie, Duff, Saifuddin Ahmed, Amy Tsui, and Scott Radloff. 2007. "Unwanted fertility among the poor: An inequity?" Bulletin of the World Health Organization 85:100-107.

Godfray, H. Charles J. et al. 2010. "Food security: The challenge of feeding 9 billion people," Science 327: 812-818.

Greene, Margaret E. and Thomas Merrick. 2005. Poverty Reduction: Does Reproductive Health Matter? HPN Discussion Paper Series. Washington DC: World Bank.

Gwatkin, Davidson R. et al. 2007. Socio-Economic Differences in Health, Nutrition and Population. Washington, DC: World Bank.

Hobcraft, J.N., J.W. McDonald, and S.O. Rutstein. 1985. "Demographic determinants of infant and child mortality: A comparative analysis," Population Studies 39(3): 363-385.

Hodgson, Dennis and Susan Cotts Watkins. 1997. "Feminists and neo-Malthusians: Past and present alliances," Population and Development Review 23(3): 469-523. 
Hogan, Margaret C. et al. 2010. "Maternal mortality for 181 countries, 1980-2008: A systematic analysis of progress towards Millennium Development Goals," The Lancet 375(9726): 1609-1623.

Hornik, Robert and Emile McAnany. 2001. "Mass media and fertility change," in John Casterline (ed.), Diffusion Processes and Fertility Transition: Selected Perspectives. Washington, D.C.: National Academy Press.

Hutchinson, Paul and Jennifer Wheeler. 2006a. "The cost-effectiveness of health communication programs: What do we know?” Journal of Health Communication 11(Supp. 2): 7-45.

2006b. "Advanced methods for evaluating the impact of family planning communication programs: Evidence from Tanzania and Nepal," Studies in Family Planning 37(3): 169-186.

ICDDR,B. 1994. Health and Demographic Surveillance System-Matlab, Volume 21, Registration of Health and Demographic Events 1992, Scientific Report No. 73-May 1994, Health and Demographic Surveillance Unit, Public Health Sciences Division, International Centre for Diarrhoeal Disease Research, Bangladesh.

2001. Health and Demographic Surveillance System-Matlab, Volume 32, Registration of Health and Demographic Events 1999, Scientific Report No. 88-Oct 2001, Health and Demographic Surveillance Unit, Public Health Sciences Division, International Centre for Diarrhoeal Disease Research, Bangladesh.

International Budget Partnership. «http://www.newtactics.org/en/blog/new-tactics/using-budgets-monitoring». Accessed May 2012.

International Telecommunication Union. 2010. World Telecommunication/ICT Development Report 2010. Geneva: ITU.

IPCC (Intergovernmental Panel on Climate Change). 2007. Climate Change 2007: Impacts, Adaptation and Vulnerability - Contribution of Working Group 2 to the Fourth Assessment Report of IPCC. Cambridge, UK: Cambridge University Press.

Jain, Anrudh K. 1989. Fertility reduction and the quality of family planning services," Studies in Family Planning 20(1): 1-16.

2011. "Measuring the effect of fertility decline on the maternal mortality ratio," Studies in Family Planning 22(4): 247-260.

Joshi, Shareen and T. Paul Schultz. 2007. "Family planning as an investment in development: Evaluation of a program's consequences in Matlab, Bangladesh," Yale University Economic Growth Center Discussion paper no. 951. New Haven: Yale University.

Kelley, Allen C. 2001. "The population debate in historical perspective: Revisionism revised," in Nancy Birdsall, Allen C. Kelley, and Steven W. Sinding (eds.), Population Matters: Demographic Change, Economic Growth, and Poverty in the Developing World. Oxford: Oxford University Press, pp. 24-54.

Kelley, Allen C. and Robert M. Schmidt. 1995. "Aggregate population and economic growth correlations: The role of the components of demographic change," Demography 32(4): 543-555.

Khuda, Barkat-e-, John Caldwell, Bruce Caldwell, Indrani Pieres, Pat Caldwell, and Shameen Amhed. 1999. "Determinants of fertility transition in Bangladesh," in R. Leete (ed.), Dynamics of Values in Fertility Change. Oxford: Oxford University Press.

Kincaid, D. Lawrence. 2000. "Social networks, ideation, and contraceptive behavior in Bangladesh: A longitudinal analysis," Social Science \& Medicine 50(2): 215-231. 
Kincaid, D. Lawrence, Alice Payne Merritt, Liza Nickerson, Sandra de Castro Buffington, Marcos Paulo P. de Castro, and Bernadete Martin de Castro. 1996. "Impact of a mass media vasectomy promotion campaign in Brazil," International Family Planning Perspectives 22(4):169-175.

Kincaid, D. Lawrence and Mai P. Do. 2006. "Multivariate causal attribution and cost-effectiveness of a national mass media campaign in the Philippines," Journal of Health Communication 11(Supp. 2): 69-90.

Kincaid, D. L., M.E. Figueroa, J.D. Storey, and C.R. Underwood. 2007. Communication, Ideation and Contraceptive Use: The Relationships Observed in Five Countries: Proceedings of the World Congress on Communication for Development. Washington, DC: World Bank.

Knodel, John and Etienne van de Walle. 1979. "Lessons from the past: Policy implications of historical fertility studies," Population and Development Review 5(2): 217-245.

Koenig, Michael A., James F. Phillips, Ruth S. Simmons, and Mehrab Ali Khan. 1987. "Trends in family size preferences and contraceptive use in Matlab, Bangladesh," Studies in Family Planning 18(3): 117-127.

Kohler, Hans-Peter. 2001. Fertility and Social Interactions: An Economic Perspective. Oxford: Oxford University Press.

2012. “Copenhagen Consensus 2012: Challenge Paper on 'Population Growth.” PSC Working Paper Series, PSC 12-03.

Lakha, Fatim, Charlotte Henderson, and Anna Glasier. 2005. "The acceptability of self-administration of subcutaneous Depo-Provera," Contraception 72(1): 14-18.

Ledbetter, Rosanna.1984. “Thirty years of family planning in India," Asian Survey 24(7): 736-758.

Lee, Ronald D. and Rodolfo A. Bulatao. 1983. "The demand for children: A critical essay," in Rodolfo A. Bulatao and Ronald D. Lee (eds.), Determinants of Fertility in Developing Countries: A Summary of Knowledge. New York: Academic Press.

Lester, Richard T. et al. 2009. "The HAART cell phone adherence trial (WelTel Kenya1): A randomized controlled trial protocol,” Trials 10: 87.

Mammen, Kristen and Christina Paxton. 2000. "Women's work and economic development," Journal of Economic Perspectives 14(4): 141-164.

Mayhew, S.M. and S. Adjei. 2004. "Sexual and reproductive health: Challenges for priority-setting in Ghana's health reforms," Health Policy and Planning 19: 50-61.

Meadows, Donella H. et al. 1972. The Limits to Growth. London: Earth Island.

Meuter, Julia. 2008. "Social franchising," Das Online-Handbuch Demografie des Berlin Institut. March. «http://www.berlin-institut.org/online-handbookdemography/social-franchising. html». Accessed 1 October 2009.

Mishra, Vinod K., Robert D. Retherford, P.S. Nair, and Griffith Feeney. 1999. "Reasons for discontinuing and not intending to use contraception in India," National Family Health Survey Subject Reports, No. 13. Mumbai, India: International Institute for Population Sciences.

Montgomery, Mark R. and John B. Casterline. 1993. "The diffusion of fertility control in Taiwan: Evidence from pooled cross-section time-series models," Population Studies 47: 457-479.

1996. "Social learning, social influence, and new models of fertility," Population and Development Review 22(Supp.): 151-175. 
Moreland, Scott, Ellen Smith, and Suneeta Sharma. 2010. World Population Prospects and the Unmet Need for Family Planning. Washington, DC: The Futures Group International.

Moreland, Scott and Sandra Talbird. 2006. Goals: The Contribution of Fulfilling the Unmet Need for Family Planning for Achieving the Millennium Development Goals. Washington, DC: USAID.

National Academy of Sciences. 1971. Rapid Population Growth: Consequences and Policy Implications. Baltimore: Johns Hopkins University Press.

National Institute of Population Research and Training Dhaka, Bangladesh and Mitra and Associates Dhaka, Bangladesh and MEASURE DHS. 2012. Bangladesh Demographic and Health Survey 2011, Preliminary Report. Calverton, MD: MEASURE DHS, ICF International.

National Institute of Population Studies Islamabad and Macro International. 2008. Pakistan: DHS, 2006-07: Final Report (English) DHS Final Reports. Calverton, MD: MEASURE DHS, ICF International.

National Institute of Statistics of Rwanda. 2012. Rwanda: DHS, 2010: Final Report. DHS Final Reports. Calverton, MD: MEASURE DHS, ICF International.

National Research Council. 1986. Population Growth and Economic Development: Policy Questions. Washington, DC.

Notestein, Frank. 1945. "Population-the long view," in Theodore W. Schultz (ed.), Food for the World. Chicago: Chicago University Press, pp. 36-57.

1953. "Economic problems of population change," in Proceedings of the Eighth International Conference of Agricultural Economists. London: Oxford University Press, pp. 13-31.

Nwagwu, Williams E. 2007. "The internet as a source of reproductive health information among adolescent girls in an urban city in Nigeria," BMC Public Health 7: 354.

O'Sullivan, G.A., J.A. Yonkler, W. Morgan, and A.P. Merritt. 2003. A Field Guide to Designing a Health Communication Strategy. Baltimore, MD: Johns Hopkins Bloomberg School of Public Health/Center for Communication Programs.

Phillips, James F., Wayne S. Stinson, Shushum Bhatia, Makhlisur Rahman, and J. Chakraborty. 1982. "The demographic impact of the Family Planning-Health Services Project in Matlab, Bangladesh," Studies in Family Planning 13(5): 131-140.

Pinstrup-Andersen, Per. 2002. "Food and agricultural policy for a globalizing world: Preparing for the future," American Journal of Agricultural Economics 84: 1201-1214.

Piotrow, Phyllis Tilson, D. Lawrence Kincaid, Jose G. Rimon, and Ward Rinehart. 1997. Health Communication: Lessons from Family Planning and Reproductive Health. Westport, CT: Praeger.

Piotrow, Phyllis Tilson, Jose G. Rimon II, Alice Payne Merritt, and Gary Saffitz. 2003. Advancing Health Communication: The PCS Experience in the Field. Center Publication 103. Baltimore: Johns Hopkins Bloomberg School of Public Health/Center for Communication Programs.

Piotrow, Phyllis Tilson and Esta de Fossard. 2004. "Entertainment-education as a public health intervention,” in A. Singhal, M. J. Cody, E. M. Rogers, and M. Sabido (eds.), EntertainmentEducation and Social Change: History, Research, and Practice. Mahwah, NJ: Lawrence Erlbaum Associates, pp. 39-60.

Poindexter, David O. 2004. "A history of entertainment-education, 1958-2000," in A. Singhal, M. J. Cody, E. M. Rogers, and M. Sabido (eds.), Entertainment-Education and Social Change: History, Research, and Practice. Mahwah, NJ: Lawrence Erlbaum Associates, pp. 21-37. 
Population Reference Bureau (PRB). 2009. "World population data sheet," Washington, DC: PRB. «http://www.prb.org/Publications/PopulationBulletins/2009/worldpopulationhighlights 2009.aspx». 2010.

Prabhakaran, Sujatha. 2008. "Self-administration of injectable contraceptives," Contraception 77(5): 315-317.

Pritchett, Lant H. 1994. "Desired fertility and the impact of population policies," Population and Development Review 20(1): 1-55.

Rafalimanana, Hantamalala and Charles F. Westoff. 2000. "Potential effects on fertility and child health and survival of birth-spacing preferences in Sub-Saharan Africa," Studies in Family Planning 31(2): 99-110.

Ravindran, T.K. Sundari. 2010. "Privitisation in reproductive health services in Pakistan: Three case studies," Reproductive Health Matters 18(36): 13-24.

Retherford, Robert and James Palmore. 1983. "Diffusion processes affecting fertility regulation," in Rodolfo A. Bulatao and Ronald D. Lee (eds.), Determinants of Fertility in Developing Countries, Volume 2. New York: Academic Press.

Richey, C. and R.M. Salem. 2008. "Elements of success in family planning programming," Population Reports, Series J, no. 57. Baltimore, INFO Project, Johns Hopkins Bloomberg School of Public Health.

Robey, Bryant, John Ross, and Indu Bhushan. 1996. "Meeting unmet need: New strategies," Population Reports, Series J, no. 43. Baltimore, MD: Johns Hopkins University.

Robinson, Warren and John Cleland. 1992. "The influence of contraceptive costs on the demand for children," in James F. Phillips and John A. Ross (eds.), Family Planning Programmes and Fertility. New York: Oxford University Press, pp. 106-122.

Robinson, Warren C. and Gary L. Lewis. 2003. "Cost-effectiveness analysis of behaviour change interventions: A proposed new approach and an application to Egypt," Journal of Biosocial Science 35(4): 499-512.

Rochat, R., D. Kramer, P. Seanayake, and C. Howell. 1980. "Induced abortion and health problems in developing countries," The Lancet 2(8192): 484.

Rogers, Everett M. 1973. Communication Strategies for Family Planning. New York: Free Press. 1983. Diffusion of Innovations. New York: Free Press.

- 2003. Diffusion of Innovations, 5th edition. New York: Free Press.

Rogers, Everett M. and D. Lawrence Kincaid. 1981. Communication Networks: Toward a New Paradigm for Research. New York: Free Press.

Rogers, Everett M., Peter W. Vaughan, Ramadhan M.A. Swalehe, Nagesh Rao, Peer Svenkerud, and Suruchi Sood. 1999. "Effects of an entertainment-education radio soap opera on family planning behavior in Tanzania," Studies in Family Planning 30(3): 193-211.

Rosenzweig, Mark R. and Kenneth I. Wolpin. 1980. "Testing the quality-quantity fertility model: The use of twins as a natural experiment," Econometrica 48(1): 227-240. 
Rosenzweig Mark and Junsen Zhang. 2009. "Do population policies induce more human capital investment? Twins, birth weight and China's 'one-child' policy," Review of Economic Studies 76(3): 1149-1174.

Rosero-Bixby, Luis and John B. Casterline. 1994. "Interaction diffusion and fertility transition in Costa Rica," Social Forces 73(2): 435-462.

Rossi, Peter H., Mark W. Lipsey, and Howard E. Freeman. 2004. Evaluation: A Systematic Approach. 7th edition. Thousand Oaks, CA: Sage Publications.

Roudi-Fahimi, F. 2002. Iran's Family Planning Program: Responding to a Nation's Needs, MENA Policy Brief. Washington, DC: Population Reference Bureau.

Rutstein, Shea. 2008. Further Evidence of the Effects of Preceding Birth Intervals on Neonatal, Infant and Under-Five-Year Mortality and Nutritional Status in Developing Countries: Evidence from the Demographic and Health Surveys. Calverton, MD: Macro International, DHS Working Paper No. 41.

Salem, Ruwaida M., Jenny Bernstein, Tara M. Sullivan, and Robert Lande. 2008. "Communication for better health,” Population Reports, Series J, no. 56. Baltimore: INFO Project, Johns Hopkins Bloomberg School of Public Health.

Salem, Ruwaida M., Jenny Bernstein, and Tara M. Sullivan. 2008. "Tools for behavior change communication,” Info Reports, No. 16. Baltimore: INFO Project, Johns Hopkins Bloomberg School of Public Health.

Schultz, T. Paul. 1976. "Determinants of fertility: A microeconomic model of choice," in Ansley J. Coale (ed.), Economic Factors in Population Growth. New York: Halstead Press.

1981. Economics of Population. Reading: Addison-Wesley.

1987. "School expenditures and enrollments, 1960-1980: The effects of income, prices and population growth," in D. Gale Johnson and Ronald D. Lee (eds.), Population Growth and Economic Development: Issues and Evidence. Madison: University of Wisconsin Press.

Sen, Gita, Adrienne Germain, and Lincoln C. Chen (eds). 1994. Population Policies Reconsidered: Health, Empowerment and Rights. Boston: Harvard University Press.

Shah, I. and E. Ahman. 2009. "Unsafe abortion: Global and regional incidence, trends, consequences, and challenges," Journal of Obstetrics and Gynaecology Canada 12: 1149-1158.

Simmons, Ruth, Laila Baquee, Michael A. Koenig, and James F. Phillips. 1988. "Beyond supply: The importance of female family planning workers in rural Bangladesh," Studies in Family Planning 19(1): 29-38.

Simmons Ruth, Peter Fajans, and Laura Ghiron (eds.). 2007. "Scaling up health service delivery: From pilot innovations to policies and programs," World Health Organization and ExpandNet.

Sinding, Steven W., John A. Ross, and Allan G. Rosenfield. 1994. "Seeking common ground: Unmet need and demographic goals," International Family Planning Perspectives 20(1): 23-27, 32.

Singh, Susheela, Jacqueline Darroch, Lori Ashford, and Michael Vlassoff. 2009. Adding It Up: The Costs and Benefits of Investing in Family Planning and Maternal and Newborn Health. New York: Guttmacher Institute and UNFPA.

Singhal, Arvind and Everett Rogers. 1999. Entertainment-Education: A Communication Strategy for Social Change. Mahwah, NJ: Lawrence Erlbaum Associates. 
Smits, L.J. and G.G. Essel. 2001. "Short interpregnancy intervals and unfavourable pregnancy outcome: Role of folate deficiency," The Lancet 358: 2074-2077.

Snyder, Leslie B. 2001. "How effective are mediated health campaigns?," in Ronald E. Rice and Charles K. Atkin (eds.), Public Information Campaigns, 3rd ed. Thousand Oaks, CA: Sage, pp. 181-190.

. 2007a. "Health communication campaigns and their impact on behavior," Journal of Nutrition Education and Behavior 39(2 Supp.): S32-S40.

- 2007b. "Meta analyses of mediated health campaigns," in Raymond W. Preiss, Barbara Mae Gayle, Nancy Burrell, Mike Allen, and Jennings Bryant (eds.), Mass Media Effects Research: Advances Through Meta-analysis. Mahwah, NJ: Lawrence Erlbaum Associates, pp. 327-345.

Snyder, Leslie and Mark Hamilton. 2002. "Meta-analysis of U.S. health campaign effects," in R. Hornik (ed.), Public Health Communication: Evidence for Behavior Change. Mahwah, NJ: Lawrence Erlbaum Associates.

Snyder, Leslie B., Louise Badiane, Svetlana Kalnova, and Nafissatou Diop-Sidibe. 2003. "Metaanalysis of family planning campaigns advised by the Center for Communication Programs at Johns Hopkins University compared to campaigns conducted and advised by other organizations" (unpublished draft paper), Johns Hopkins Bloomberg School of Public Health and US Agency for International Development.

Stash, Sharon. 1999. "Explanations of unmet need for contraception in Chitwan, Nepal," Studies in Family Planning 30(4): 267-287.

Storey, Douglas, Marc Boulay, Yagya Karki, Karen Heckert, and Dibya Man Karmacharya. 1999. "Impact of the integrated radio communication project in Nepal, 1994-1997," Journal of Health Communication 4(4): 271-294.

Storey, D., G. Saffitz, and J. Rimon. 2008. "Social marketing," in K. Glanz, B. Rimer, and K. Vishwanath (eds.), Health Behavior and Health Education: Theory, Research, and Practice, 4th ed. San Francisco: Jossey-Bass.

Tietze, Christopher. 1981. Induced Abortion: A World Review. New York: Population Council.

Townsend, J.W., R. Sitruk-Ware, K. Williams, I. Askew, and K. Brill. 2011. "New strategies for providing hormonal contraception in developing countries," Contraception 83(5): 405-409.

Trussell, James and Anne R. Pebley. 1984. "The potential impact of changes in fertility on infant, child, and maternal mortality," Studies in Family Planning 15(6): 267-280.

United Nations (UN). 1973. Determinants and Consequences of Population Trends. New York: Department of Social Affairs, Population Division, United Nations.

2004. World Population Policies 2003. New York: Department of Social Affairs, Population Division, United Nations.

2006. Levels and Trends of Contraceptive Use as Assessed in 2000. New York: Department of Social Affairs, Population Division, United Nations.

2009. World Population Prospects: The 2008 Revision. New York: Department of Social Affairs, Population Division, United Nations.

2011. World Population Prospects: The 2010 Revision. New York: Department of Social Affairs, Population Division, United Nations. 
United Nations Commission on Population and Development. 2009. Flow of Financial Resources for Assisting in the Implementation of the Programme of Action of the International Conference on Population and Development: Report of the Secretary-General. New York: Commission on Population and Development, Forty-second session, 30 March - 3 April 2009.

United Nations Population Fund. 1988. Global Population Assistance Report 1982-1985. New York: United Nations Population Fund.

USAID. 2010. «http://www.usaid.gov/our_work/global_health/pop/funding/index.html».

Valente, Thomas and Walter P. Saba. 2001. "Campaign exposure and interpersonal communication as factors in contraceptive use in Bolivia," Journal of Health Communication 6(4): 303-322.

Viswanathan, Hema, Sona Godfrey, and Nancy Yinger. 1998. Reaching Women: A Study of Unmet Need in Uttar Pradesh, India. Washington, DC: International Center for Research on Women.

Watkins, Susan Cotts. 1986. "Conclusions," in Ansley J. Coale and Susan Cotts Watkins (eds.), The Decline of Fertility in Europe. Princeton: Princeton University Press.

. 1987. "The fertility transition: Europe and the third world compared," Sociological Forum 2(4): 645-673.

Westoff, Charles F. 1999. "Mass communications and fertility," in R. Leete (ed.), Dynamics of Values in Fertility Change. Oxford: Oxford University Press.

Westoff, Charles F. and Luis Hernando Ochoa. 1991. "Unmet need and the demand for family planning," Demographic and Health Surveys Comparative Studies No. 5. Columbia: Institute for Resource Development.

Westoff, Charles F. and Akinrinola Bankole. 1995. "Unmet need: 1990-1994," Demographic and Health Surveys Comparative Studies No. 16. Calverton, MD: Macro International.

1997. "Mass media and reproductive behavior in Africa," Demographic and Health Surveys Analytical Reports No. 2. Calverton, MD: Macro International.

Westoff, Charles F. and Germán Rodriguez. 1995. "The mass media and family planning in Kenya," International Family Planning Perspectives 21: 26-31, 36.

Wilcher, Rose, Willard Cates Jr., and Simon Gregson. 2009. "Family planning and HIV: Strange bedfellows no longer," AIDS 23 (Supp. 1): S1-S6.

Willis, Robert J. 1974. Economic theory of fertility behavior," in Theodore W. Schultz (ed.), Economics of the Family: Marriage, Children and Human Capital. Chicago: University of Chicago Press, pp. 25-75.

Winikoff, Beverly and Maureen Sullivan. 1987. "Assessing the role of family planning in reducing maternal mortality," Studies in Family Planning 18(3): 128-143.

Witte, K. 1994. "Fear control and danger control: A test of the extended parallel process model," Communications Monographs 61(2): 113-134.

World Bank. 1999. World Development Report. Washington, DC: World Bank.

2008. World Development Report. Washington, DC: World Bank.

2009. Improving Effectiveness and Outcomes for the Poor in Health, Nutrition, and Population: An Evaluation of the World Bank Group Support since 1997. Washington, DC: World Bank. 
2010. “The World Bank's Reproductive Health Action Plan 2010-2015," «http://site resources.worldbank.org/INTPRH/Resources/376374-1261312056980/RHActionPlan FinalMay112010.pdf».

World Health Organization (WHO). 1995. Community-based Distribution of Contraceptives. Geneva: Human Reproduction Program.

- 2007. Quality Assurance of Pharmacenticals: Meeting a Major Public Health Challenge. Geneva, pp. 1-17.

2010. Monitoring the Building Blocks of Health Systems: A Handbook of Indicators and Their Measurement Strategies. Geneva, pp. 1-93.

Yinger, Nancy V. 1998. Unmet Need for Family Planning: Reflecting Women's Perceptions. Washington, DC: International Center for Research on Women.

Zhu, B.P. 2005. "Effect of interpregnancy interval on birth outcomes: Findings from three recent US studies," International Journal of Gynecology and Obstetrics 89: S25-S33. 


\section{AUTHORS}

JANE T. BERTRAND is Neal A. and Mary Vanselow Professor and Chair, Department of Global Health Systems and Development, Tulane University School of Public Health and Tropical Medicine.

JOHN BONGAARTS is Vice President and Distinguished Scholar, Population Council.

JOHN CLELAND is Professor of Medical Demography, London School of Hygiene and Tropical Medicine.

MONICA DAS GUPTA is Senior Demographer, The World Bank.

JOHN W. TOWNSEND is Vice President and Director, Reproductive Health Program, Population Council. 
Family planning programs are among the most successful development interventions of the past 50 years. They are unique in their range of potential benefits, encompassing economic development, maternal and child health, educational advances, and women's empowerment. Research shows that with high-quality voluntary family planning programs, governments are able to reduce fertility and produce large-scale improvements in health, wealth, human rights, and education.

This publication is a comprehensive resource for policymakers and donors, making the case for increased funding and support of voluntary family planning, and detailing how to design programs to operate both ethically and effectively. 